University of Louisville

ThinkIR: The University of Louisville's Institutional Repository

Electronic Theses and Dissertations

\title{
$5-2011$
}

\section{Principals' leadership behaviors as perceived by teachers in at- risk middle schools.}

\author{
R. Anthony Johnson 1970- \\ University of Louisville
}

Follow this and additional works at: https://ir.library.louisville.edu/etd

\section{Recommended Citation}

Johnson, R. Anthony 1970-, "Principals' leadership behaviors as perceived by teachers in at-risk middle schools." (2011). Electronic Theses and Dissertations. Paper 696.

https://doi.org/10.18297/etd/696

This Doctoral Dissertation is brought to you for free and open access by ThinkIR: The University of Louisville's Institutional Repository. It has been accepted for inclusion in Electronic Theses and Dissertations by an authorized administrator of ThinkIR: The University of Louisville's Institutional Repository. This title appears here courtesy of the author, who has retained all other copyrights. For more information, please contact thinkir@louisville.edu. 
PRINCIPALS' LEADERSHIP BEHAVIORS AS PERCEIVED BY TEACHERS

IN AT-RISK MIDDLE SCHOOLS

By

R. Anthony Johnson

A.S., Chaminade University, 1995

B.A., University of Louisville, 1999

M.A., University of Louisville, 2000

S.Ed., University of Louisville, 2008

A Dissertation

Submitted to the Faculty of the

College of Education and Human Development of the University of Louisville in Partial Fulfillment of the Requirements

for the Degree of

Doctor of Philosophy

Department of Education

University of Louisville

Louisville, Kentucky

May 2011 



\section{PRINCIPALS' LEADERSHIP BEHAVIORS AS PERCEIVED BY TEACHERS}

IN AT-RISK MIDDLE SCHOOLS

\section{By}

R. Anthony Johnson

A.S., Chaminade University, 1995

B.A., University of Louisville, 1999

M.A., University of Louisville, 2000

S.Ed., University of Louisville, 2008

A Dissertation Approved on

April 13, 2011

by the Following Dissertation Committee:

Dr. Joseph Petrosko, Dissertation Chairperson

\begin{tabular}{l}
\hline Dr. John Keedy \\
\hline Dr.'Ann Larson
\end{tabular}

Dr. Phyllis Connelly

Dr/Molly Sullivan 


\section{ACKNOWLEDGEMENTS}

To Dr. Joseph Petrosko for your flexibility in accommodating an assistant principal's working schedule, I extend my thanks. I greatly appreciated your suggestions, support, and patience during this process. Throughout this experience, I marveled at how simply you could manipulate data. I am fortunate to have had you as an advisor.

To Kelly Ising and Marji Settles I extend thanks for all your assistance in reminding me that a form was due last week or that I forgot to register for class. I value both of you greatly, and I will never forget all you have done to keep me on track.

To Don Reid I thank you for all your support and encouragement in finishing my dissertation and recognizing how valuable family time is. You have changed my family's life for the better, which will always be appreciated.

To my daughters Sierra, Trinity, and Maisah, I thank you. When I was discouraged with finishing this dissertation, I continued because I wanted you to know how important education is and to show you that you can accomplish anything if you give your best effort. I look forward to being able to spend more time with you playing sports, going to the lake, and wrestling before bedtime.

To my wife and dream girl Rebekah, I extend my love and thanks. When I was overwhelmed, your understanding, encouragement, and support helped me persevere. You took on the brunt of the parental responsibilities during this lengthy process, and I am eternally grateful for you. I realize that I am very fortunate to have you in my life, and I could not have made it through this without you. 


\begin{abstract}
PRINCIPALS' LEADERSHIP BEHAVIORS AS PERCEIVED BY TEACHERS IN AT-RISK MIDDLE SCHOOLS

R. Anthony Johnson

April 13, 2011

A need for greater understanding of teachers' $(N=530)$ perceptions of the leadership behaviors of principals in Title I middle schools $(n=13)$ is prevalent exists. The researcher used the "Audit of Principal Effectiveness" survey to collect data. The researcher also used Hierarchical Linear Modeling as the quantitative analysis. Significant teacher-level variables were teacher age, years the teacher worked for current principal, and teacher gender. Significant schoollevel variables were principal gender, principal teaching experience, and percentage of low-income students scoring proficient in mathematics. Principals should understand how teacher- and school-level variables affect the principals' perceived leadership behaviors. This study has implications for university personnel, school district personnel, school principals, and hiring committees.
\end{abstract}


TABLE OF CONTENTS

PAGE

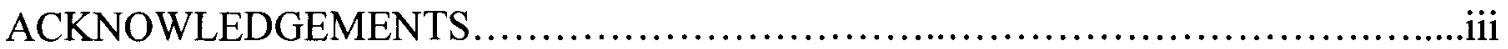

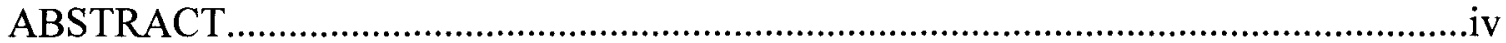

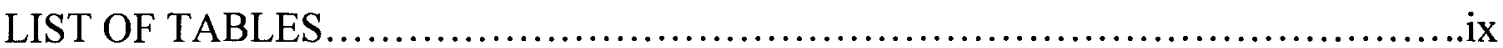

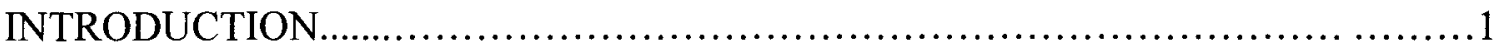

Principal Accountability ....................................................

Decentralization of Accountability..............................................

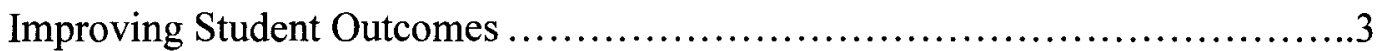

Educational Leadership ................................................... 4

Perception of the Leadership Role............................................5

Organizational Development .................................................

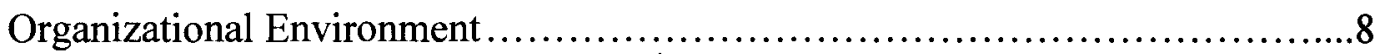

Educational Program........................................................

Effective Instructional Leadership ...............................................11

Kentucky Education Reform Act and No Child Left Behind ....................11

Jefferson County Public Schools ...........................................13

Statement of the Problem.....................................................

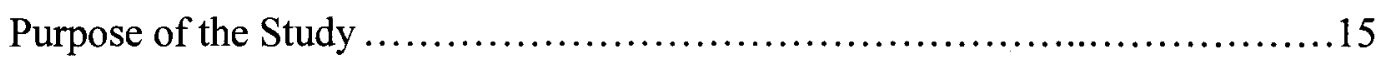

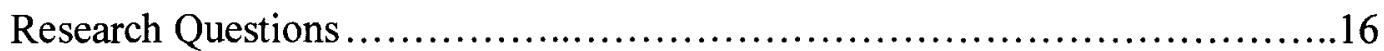

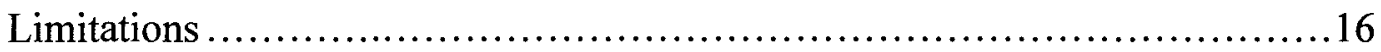


Definitions .............................................................. 17

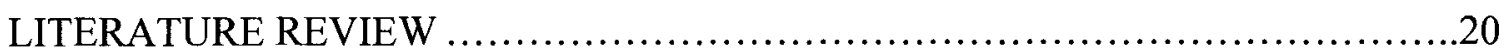

School-Effectiveness Research ..............................................21

Principal-Effectiveness Research.........................................34

Principal-Accountability Reform........................................34

Decentralization of Accountability Reform .................................58

Improving Student Outcomes Reform ....................................68

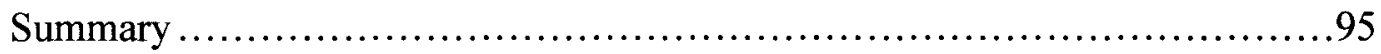

Teacher's Perception of Leadership Behavior.................................97

Development of the Audit of Principal Effectiveness........................ 101

Subsequent Research Using the Audit of Principal Effectiveness................102

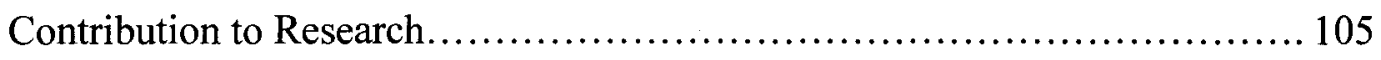

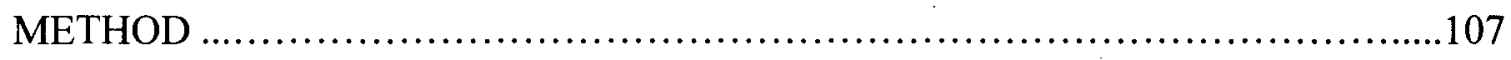

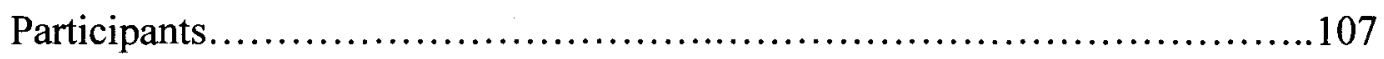

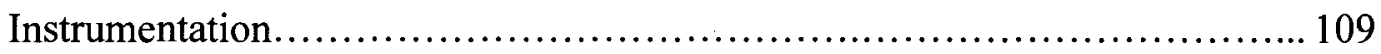

Data Collection.............................................................. 111

Variables............................................................... 111

Research Design and Data Analysis..................................... 113

Research Questions.................................................. 114

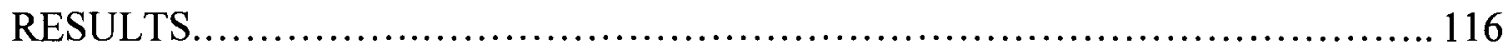

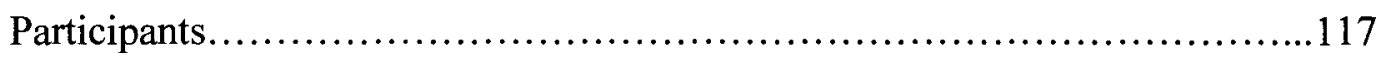

Descriptive Statistics on Demographic Variables...........................117

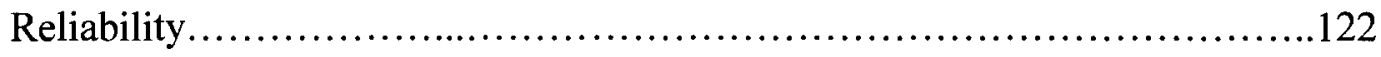




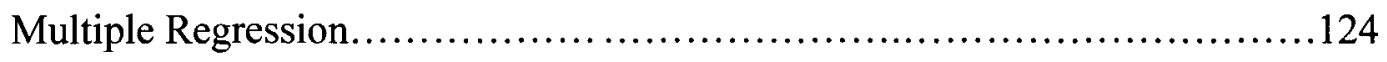

Hierarchical Linear Modeling...........................................128

One-Way ANOVA with Random Effects...................................129

Random Coefficient Model...............................................132

Intercepts-as-Outcomes Model...................................... 136

Overall Summary of Data Analysis......................................141

DISCUSSION OF FINDINGS....................................................

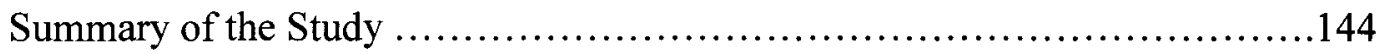

Presentation of Findings ..................................................... 145

Research Questions .................................................... 145

Teacher-Level Variables ............................................... 146

School-Level Variables............................................... 148

Implications ......................................................... 150

Recommendations for Future Research.............................. 152

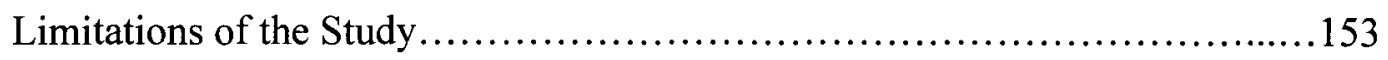

Conclusion......................................................... 153

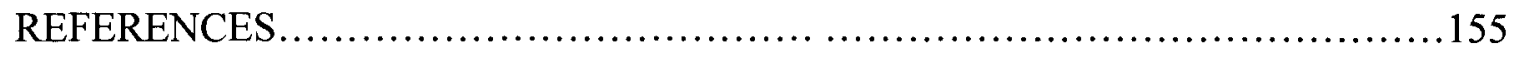

APPENDIX A: Audit of Principal-Effectiveness .....................................169

APPENDIX B: Audit of Principal Effectiveness Domain and

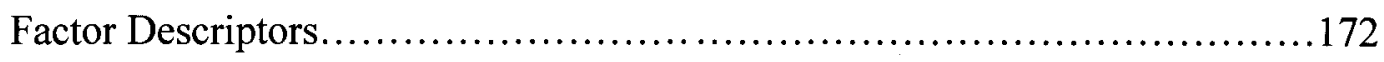

APPENDIX C: Audit of Principal-Effectiveness Domain and

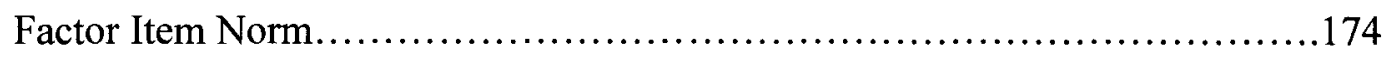

APPENDIX D: Research Permission......................................... 175 
APPENDIX E: Institutional Review Board Approval............................176

APPENDIX F: Approval to Use the Audit of Principal Effectiveness Survey..........179

CURRICULUM VITAE...................................................... 180 


\section{LIST OF TABLES}

TABLE

PAGE

1. Title I Middle Schools Represented in the Study .............................. 108

2. Reliability Coefficient Estimates for Each Domain and Factor...................110

3. Frequency Distributions for Demographic Variables of

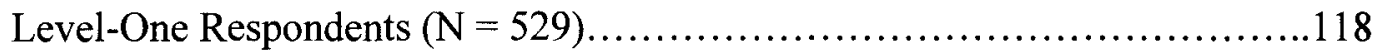

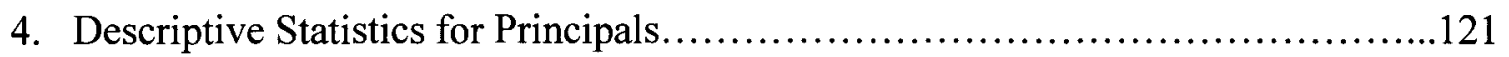

5. Factor Reliability, Mean, and Standard Deviation ............................ 123

6. Factor Correlation: Principal Leadership Factors............................ 124

7. Teacher-Level Regression: Statistics for Significant

Predictors of Dependent Variables...................................126

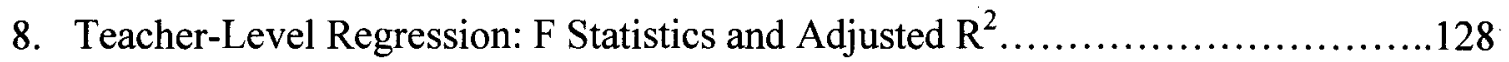

9. Random ANOVA Models Fixed Effects: Average School

Means and Standard Errors............................................ 130

10. Random ANOVA Models Random Effects: Variance

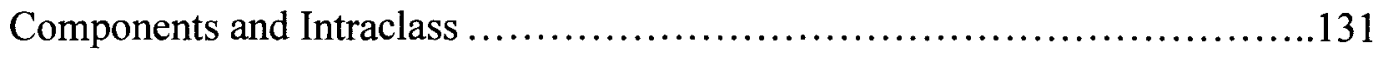

11. Random Coefficient Models Fixed Effects: Average School

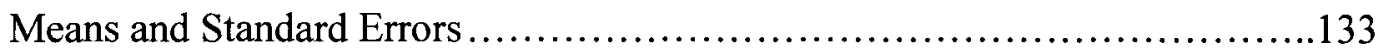

12. Random Coefficient Models Random Effects: Variance Components .............134 
13. Random Coefficient Models Random Effect: Level-One Variance Component and Proportion of Variance in Variable Accounted for

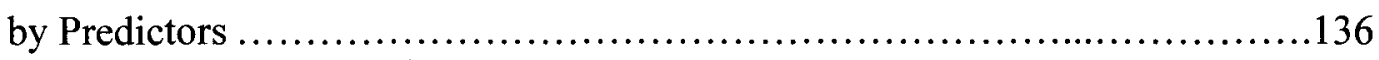

14. Fixed Effects for Intercept and Slopes-as-Outcomes Models:

Coefficients and Standard Errors for Intercepts.............................138

15. Intercept-as-Outcomes Models Random Effect: Level-One

Variable Accounted for by Predictors......................................140

16. Significant Predictors of Leadership Factors at the

Teacher and School Level...................................................141 


\section{CHAPTER I}

\section{Introduction}

The role of the principal in educating students has changed dramatically over the past thirty years. During the late 1960 s and early 1970 s, researchers studied schools that were effective in educating at-risk students and determined what characteristics made them successful. Many of these studies placed the principal as a key figure in the schooleffectiveness research. School-effectiveness research, specifically the principal's leadership effects on at-risk student achievement, is especially important due to the increased pressure placed on school leaders to close achievement gaps among demographic groups such as African-American, special-needs, and Caucasian students in public schools. The No Child Left Behind (NCLB) Act of 2002 mandated reduction in achievement gaps.

Accountability is a component of the Kentucky Education Reform Act (KERA) of 1990, which passed in accordance with the Kentucky Supreme Court opinion (Rose v. Council for Better Education, 1989) that declared Kentucky's public school system unconstitutional. The reform act included high standards for student achievement and held school leaders accountable for meeting these goals. KERA, as well as NCLB, tremendously increased school accountability by local school leaders. School reform initiatives required systemic change at the state and local levels; principals had to be the leaders at the local school level for the quality of education to improve and result in improved student achievement. The principal moved from the role of school manager to 
the role of instructional leader in the school. Without question, principals were essential to school-level reform efforts, and accountability for student outcomes began to be placed on the principal.

\section{Principal Accountability}

Principal-accountability reform occurred when "A Nation at Risk" prompted reform efforts in the 1980s. The National Commission on Excellence in Education (NCEE, 1983) presented this report to the United States Secretary of Education. The report detailed American students' test scores in comparison with students' scores from other industrialized nations, and American students' scores paled in comparison. This finding grabbed the attention of American society. The report demanded educational improvement in many ways, including holding leaders accountable for the progress of education. The report instigated many top-down initiatives by recommending that the federal government, state and local leaders, superintendents, and principals be held accountable for educational improvement (NCEE, 1983). The quest for improved student outcomes brought about an increased focus on principal accountability. Within the accountability movement, more centralized control evolved, placing power and authority in the administration at the school level. School centralization, a top-down approach, called for principals to be instructional leaders, and centralization became known as the catalysts for change in effective schools. According to Edmonds (1979), principal leadership was one of five key components needed to provide effective schools for America's urban poor. A measure of the effectiveness of schools and of their instructional leadership was student success, particularly success on standardized tests. 


\section{Decentralization of Accountability}

Decentralization of accountability occurred in the mid-1980s and early 1990s and brought change through the decentralization of schools. Decentralization meant delegating power and sharing authority with various groups of stakeholders (e.g., teachers, staff, parents, and community members). The Carnegie Forum on Education and Economy Task Force (1986) Report, A Nation Prepared: Teachers for the TwentyFirst Century and Tomorrow's Teachers: A Report of the Holmes Group, moved from criticizing education to suggesting solutions, requiring the principal to build instructional capacity within the school. As decentralization increased, so did accountability. Improving student outcomes became the ultimate objective of all reform efforts. Reform initiatives heightened the need for increased instructional capacity. States began to administer assessments to increase accountability measures and determine student outcomes.

Improving Student Outcomes

Improving student outcomes reform occurred in the late 1990s. The major policy assumption was that discretion be delegated to the states in determining the appropriate "mix" of accountability and support mechanisms to help schools succeed, with all students being held to high academic performance standards. Since the late 1990s reformers have been highly focused on the central task of improving student outcomes, a trend foreshadowed by KERA and the National Commission on Excellence in Education 1983 report: "A Nation at Risk" (1983). The state-level accountability for improved student outcomes was ratcheted up to the national level with NCLB, which mandated that all reform measures in some way must be connected to improved student outcomes, 
especially in schools historically characterized by poverty, single-parent families, and other correlates of low achievement. This press for student achievement was being driven primarily by the notion that students who were better educated translated to a more competent workforce, deemed necessary for the United States to remain globally competitive economically.

School-effectiveness research often refers to the importance of strong principal leadership. The reason for this attention on the principal in the literature is due to a strong interest on the part of educators to better understand their role in schooleffectiveness research. The educational reform movement and the search for conditions and causes on effective schools have generated a great deal of interest in the principalship. I will discuss briefly the definition of educational leadership and role perception.

\section{Educational Leadership}

Liphan (1974) implied that leadership is not all a matter of group maintenance but "the initiation of a new structure or procedure for accomplishing an organization's goals and objectives. To be the leader, one must be concerned with initiating change." According to Fuhr (1970) the administrator, on the other hand, may be identified as the individual who utilizes existing structures or procedures to achieve an organizational goal or objective. As in the case of the leader, the administrator may bring to bear the authority of his role and the influence of his personality in his relationships with other members in the organization. However, the administrator is concerned primarily with maintaining, rather than changing, established structure, procedure, or goals (Fuhr, 1970). Neagley and Evans (1964) stated that, in any size district, the principal should be 
recognized as the educational leader of his school and immediate community. The principal is responsible for the supervision of instruction as well as the execution of administrative functions.

\section{Perception of the Leadership Role}

Conceptualizing leadership in terms of the perceptions of those who experience it is the starting point for many approaches to measuring leadership. Much of what is known about school leadership practices is more accurately, knowledge about teachers' perceptions of leadership. Much of what is learned from the literature regarding principals' leadership behavior, comes from researchers' knowledge of teachers' perceptions of school leadership (Bass, 1985). Therefore, the leadership behavior of the middle school principal can best be measured by how middle school teachers perceive them. Effective middle school leadership is often measured in the literature by the following: (a) the perception of the extent to which the principal involves staff in making crucial decisions that affect instruction, (b) the degree to which the principal is perceived to involve parents and advisory groups in the school program; (c) the extent to which the principal protects faculty from undue pressures so that their main focus is on teaching; and (d) the extent to which the principal leaves teachers alone to do their work and have academic freedom (Heck, et al., 1990). Nakornsri (1977) studied the differences between teachers' perceptions of their principal's administrative performance and the relationship, if any, between teachers' perceptions of their principal's role behavior and administrative performance. Considering the teachers' educational level, there was a difference in their perceptions of the principal's role behavior and administrative performance. It was further reported that principals do not differ in their role by sex. However, they do differ 
as far as their educational leadership ability is concerned. Female principals exemplified higher levels of educational leadership ability than did male principals.

Role-perception study in recent years has been concerned with systematic descriptions of what principals actually do. Research studies using this method have measured principals' use of time and the nature of the tasks with which they are involved through observations (Gronn, 1982; Willis, 1980). These studies have revealed that principals' working days are characterized by brevity, variety, and fragmentation. Most activities engaged in by principals last for few minutes and are constantly interrupted by demands from various sources (Martin \& Willower, 1981; Willis, 1980).

The secondary principal is confronted with an overwhelming number of responsibilities, demands, pressures, and expectations (Lyons, 1981). The principal, as the educational administrator of his school, is expected to fill many roles. He or she is expected to set the tone and pace of his institution, to see that the school runs safely, smoothly, and efficiently (Kearney, 1977). Goldhammer (1969) discussed the performance of the school principal. Goldhammer perceived principals as managers who must have the ability to work effectively with people to secure their cooperation. Effective principals were aggressive in securing recognition of the needs of their schools and, as such, were enthusiastic as principals, accepting responsibilities as those of a mission rather than as those of a job. Finally, they were committed to education, and especially capable of distinguishing between long- and short-term educational goals. In a study conducted by Branscum (1983), the major findings indicated that the expectations of secondary school principals and those of board members, superintendents, and teachers were similar in several areas. Both principals and teachers 
indicated that principals should possess competencies in community relations and service, pupil personnel services, pupil control, and personnel services. The participants believed that these are areas in which principals can devote effective top-priority efforts. Similarly, neither the principals nor the role partners believed competencies in financial management or school plant operations and auxiliary services were highly important. The findings suggested that both principals and teachers view the principalship as a position in which competencies in dealing with the human component of the school (community, teachers, students, and central office personnel), and with the improvement of the educational program, are ideally important. The three domains of organizational development, organizational environment, and effective instructional leadership are three areas that have been identified by the "Audit of Principal Effectiveness" (APE) to measure the principal's leadership behaviors as perceived by teachers (Valentine, 1987).

\section{Organizational Development}

The domain of organizational development indicates the ability of the principal to work with personnel inside and outside the school to establish processes and relationships which most effectively promote positive growth and change of the organization as a whole (Valentine, 1987). Factors included in the domain of organizational development are organizational direction, organizational linkage, and organizational procedures.

The principal occupies a strategic position in school organizational development and change. Blumberg and Greenfield (1980) asserted that in many ways the school principal is the most important and influential individual in any school. He or she is responsible for all of the activities that occur in and around the school building. It is his or her leadership that sets the tone of the school; the climate for learning; the level of 
professionalism and morale of teachers; and the degree of concern for what students may or may not become. The principal is the main link between the school and the community, and the way he or she performs in that capacity largely determines the attitudes of students and parents about the school. If a school is a vibrant, innovative, child-centered place; if it has a reputation for excellence in teaching; if students are performing to the best of their ability; one can almost always point to the principal's leadership as the key to success. In an effective organization, the leader articulates its major purposes and undertakes systematic dissemination (Brandt, 1982). Clark, Lottto, and McCarthy (1982) found principals need to provide frequent articulation of the school's goals, transmitting them to parents, citizens, staff, and students.

\section{Organizational Environment}

The domain of organizational environment indicates the ability of the principal to nurture the ongoing climate of the school through development of positive interpersonal relationships among members of the organization and effective day-by-day operational procedures for the school (Valentine, 1987). The factors classified under organizational environment are teacher relations, student relations, interactive processes, and affective processes. Organizational environment is constantly changing and is determined more by prevailing forces that affect activity than by mechanical considerations.

Organizational environment refers to the internal environment of an organization that influences work behavior. The organization has its own tempo, norms, traditions, styles, and values that are determinants of behavior. If improved organizational performance is desired, it is as important to change organizational environment as it is to enhance individual performance. Individuals within an organization come and go, but the 
organizational environment and the forces generating collective feelings remain. The extent to which individuals constitute an organizational force is determined by their positions and the leadership they give to the overall direction of an organization. In a study of successful schools, researchers reported that principals were skilled in providing a structured environment in which teachers could function effectively, and where they felt appreciated and regarded for their effort (Levine \& Stark, 1982).

\section{Educational Program}

The domain of educational program provides insight into the ability of principals to serve as educational leaders of schools through active involvement in instructional leadership and curriculum development (Valentine, 1987). The factors classified under the educational improvement domain are instructional improvement and curriculum improvement. Principals have a discernible effect on a school's productivity. They appear to exert this influence primarily as instructional leaders (Bossert, Dwyer, Rowan, and Lee, 1982). Bamburg and Andrews (1991) studied both high- and low-achieving elementary schools and found that principals in higher-achieving schools placed greater emphasis on instructional activities while their faculties made an effort to be excellent instructors.

Educational improvement or instructional leadership refers to those practices and activities of a principal that are concerned with the school's central purposes: teaching, learning, and the resources that support the activities. Effective principals are often found to be characterized by strong participation in the planning, monitoring, and evaluation of the instructional program (Austin, 1979; Cotton \& Savard, 1980; Edmonds, 1979). Schools in which principals believe strongly in the importance of instruction are 
more likely to show gains in student achievement (Wellisch, MacQueen, Carriere, \& Duck, 1978). Stringfield and Teddlie $(1988,1991)$ pointed out that principals of highly effective schools see themselves as proactive and are actively involved in a complex process of achieving multiple goals. They have a realistic sense of their schools' strengths and weaknesses. They take responsibility for their schools' problems and share credit for their schools' successes; they are intimately familiar with the school curriculum and can conceptualize it from the child's perspective. They understand and redress their teachers' weaknesses and capitalize on the teachers' strengths.

Researchers have pointed out that principals believe that they should be involved in instruction and curriculum and that a greater portion of their time should be spent in the classroom (Boocock, 1972). Studies have revealed that principals spend most of their time at school on managerial tasks unrelated to curriculum and instruction (Cuban, 1984), thus pointing to a discrepancy between beliefs and practices. In a study conducted by Peterson (1978) it was concluded that principals spend less than $5 \%$ of their time in the classroom and less than $6 \%$ of their time planning and coordinating instructional programs curriculum, and materials.

Hannaway and Sproull (1979) stated that $90 \%$ of high school principals' activities were concerned with issues other than curricular and instructional issues. Martin and Willower (1981) reported a slightly higher percentage. They stated that $17 \%$ of the principals' time was devoted to their schools' academic programs. This time was described as passive or supportive rather than active or directive. Meyer and Rowan (1978) reported that only $12 \%$ of the school principals said they had any real decision power over instructional methods used by teachers, a finding that was corroborated by 
Deal and Celotti (1980). Furthermore, principals generally perform infrequent evaluations of instruction, and the evaluations are unsystematic, subjective, and replete with generalities and praises (Cohen \& Miller, 1980). Even though the principals considered instruction in their schools to be their first priority, in practice they did not appear to exercise much control over the teaching and learning processes in classrooms. Effective Instructional Leadership

Effective instructional leaders establish and implement clear goals and specific achievement objectives for the school. They plan, implement, and evaluate instructional programs, including learning objectives and instructional strategies for the school. They also provide a purposeful school environment conducive to learning, conduct an effective school program, and evaluate teachers and staff members.

This study on principals' leadership will be performed in Kentucky. Any study of school leadership in Kentucky must consider the effects of the state's school reform law. The principal's role as a leader in organizational development, organizational environment, and the educational program will be influenced by the Kentucky Education Reform Act (KERA).

\section{Kentucky Education Reform Act and No Child Left Behind}

The KERA of 1990, initiated by a lawsuit over school finance, was an exhaustive effort to reform public education (Pipho, 1990). Following the passage of House Bill 940, Governor Wallace Wilkinson established a six-member task force to create a new statewide school system (Pankratz \& Petrosko, 2000). KERA increased school accountability and included an assessment system that measured school progress. A revision of virtually every area of the education system took place, and the school reform 
law became a critical turning point in education across the Commonwealth of Kentucky. School-Based Decision Making (SBDM) was an initiative of KERA. SBDM was the venue through which schools exercised authority to plan and make policy that addressed student outcomes (Lindle, 2000). David (2000) indicated that principals faced the biggest challenge in the implementation of SBDM due to the task of leading and educating SBDM council members. SBDM was one of the most comprehensive reform initiatives in the nation. Unquestionably, increased school accountability elevated responsibility for school leaders.

In 1998 the Kentucky legislature replaced the testing system, Kentucky Instructional Results Information System (KIRIS), with the Commonwealth Accountability Testing System (CATS). Kentucky's accountability system is a highstakes system referred to as CATS. The actual test administered to students is the Kentucky Core Content Test (KCCT). The KCCT includes the California Test of Basic Skills (CTBS/5), assessed writing portfolios, open-ended response items, multiple choice questions, and also other indicators of school performance (Kentucky Department of Education, 2002). The over-riding goal of CATS is for all schools in Kentucky to reach Proficiency as defined by the Kentucky Board of Education (KBE). The accountability system provides the mechanism for measuring this goal and thus provides feedback to schools on how they are progressing toward the long-term goal set by KBE.

The No Child Left Behind (NCLB) Act was a landmark in education reform designed to improve student achievement and change the culture of America's schools (United States Department of Education, 2003, p. 3). The CATS was the benchmark the state of Kentucky used to meet the NCLB requirement that all children meet the goal of 
Proficiency as defined by each state. The assessment guidelines described the measurement process for Proficiency, which was defined as a score of 100 on a 140-point scale (Kentucky Department of Education, 2002). This goal is to be met by 2014 . Jefferson County Public Schools

This study on teachers' perceptions of the principal's leadership behaviors was conducted in Jefferson County Public Schools (JCPS) located in Jefferson County, Kentucky. JCPS has more than 98,000 students attending 150 schools, making it the 28th largest school district in the United States. JCPS is administered by an elected sevenmember Board of Education, responsible for administering an $\$ 890$ million budget.

In 1971, several civil-rights organizations filed a lawsuit in court asking that the Louisville, Jefferson County, and Anchorage school systems be merged, due to the large concentration of African Americans in the city school district and extremely low concentration in the other two. This disparity created conditions similar to that of racial segregation. In 1974, Judge James F. Gordon ordered the merger of the Louisville and Jefferson County school districts, an order followed up by the state Board of Education, which on February 28, 1975, made the merger effective on April 1 of that year. A merger and desegregation plan was created, which included mandatory busing and racial guidelines for school assignments. One of the byproducts of this plan was mandatory busing. The initial plan was for African-American students to be bused 10 of their 12 years in school and white students to be bused 2 of 12 years. The court ceased active supervision of this plan in 1978.

The racial guidelines used have seen several revisions since that time. In 1984, a plan was instituted for middle and high schools that involved a system of zones and 
satellite areas. A mandatory $15 \%$ to $50 \%$ African-American population in all schools was established in 1996. The segregation order was lifted in 2000, but JCPS maintained the $15 \%$ to $50 \%$ guideline in most schools. In 2002 , a lawsuit was filed by a parent of a school-age child, claiming denial of enrollment in a school because of race. In June 2007, the United States Supreme Court handed down a verdict that Jefferson County's student-assignment plan violated constitutional guarantees of equal protection. In 2008 and 2009 the Jefferson County Board of Education passed student assignment plans for elementary, middle, and high schools, primarily based upon the economic status of families in Jefferson County. The purpose is to maintain diversity on a number of variables, including ethnicity.

\section{Statement of the Problem}

School-effectiveness researchers have studied schools that were effective in educating at-risk students and have determined what characteristics made them successful. Many of these studies placed the principal as a key figure in the schooleffectiveness research. School-effectiveness research has identified principals as instrumental in leading effective schools. The principal's leadership effects on at-risk student achievement is especially important due to the increased pressure placed on school principals to close achievement gaps and to meet adequately yearly progress in public schools.

The quest for improved student outcomes has brought about an increased focus on principal accountability. Principals are held accountable for the performance of their students on standardized assessments. Research indicates the principal is the instructional leader in the school and is instrumental in causing change and improvement. 
The need for improvement is especially important in schools historically characterized by poverty, single-parent families, and other correlates of low achievement.

Given the current expectations for schools to demonstrate improvement in student performance on standardized tests, research studying leadership factors of the principal as perceived by teachers will be helpful to practitioners. Teachers who work within the school are a potential source of feedback for principals. In addition, teacher perceptions of the school principal are important, for how teachers perceive the principal may affect their own effectiveness. School improvement hinges on a successful working partnership between teachers and the principal. The problem addressed by this study is the need for a greater understanding of how teachers perceive the leadership behaviors of school principals. For example, comparatively little information exists on the influence of teacher demographic variables on perceptions of school principals. In addition, little information is available about how school-level variables (e.g. achievement levels) affect teacher perceptions of the principal.

Purpose of the Study

The purpose of this study is to determine the magnitude of the relationship among the following: (a) principal-leadership factors as perceived by teachers; (b) schoolprincipal demographic variables; (c) school demographic variables; and (d) schoolachievement test scores. The researcher also will determine, at the teacher level and the school level, what extent of perceived principal leadership behaviors, as measured by the Audit of Principal Effectiveness (APE) (Valentine and Bowman, 1984), are predicted by teacher and school demographic variables. If effective leadership behaviors, as perceived by teachers, can be determined, the selection of effective principals with these 
characteristics would possibly increase teachers' and students' performance. This study will increase the knowledge base of factors predicting perceptions of principal effectiveness in the areas of educational program, organizational development, and organizational environment.

Research Questions

The following research questions were examined during the completion of this study:

1. What is the magnitude of linear relationship among the following variables: (a) principal-leadership factors as perceived by teachers; (b) school-principal demographic variables; (c) school demographic variables; and (d) schoolachievement test scores?

2. At the individual teacher level, to what degree are perceived school principal leadership behaviors predicted by teacher demographic variables (e.g., age, level of experience)?

3. At the school level, to what degree are perceived school principal leadership behaviors predicted by teacher demographic variables (e.g., age, level of experience) and school-level variables: (a) school-principal demographic variables, (c) school demographic variables, and (d) school-achievement test scores?

\section{Limitations}

The following are the limitations of the study:

1. The study was limited to the Jefferson County Public School District in Louisville, Kentucky. 
2. The study was limited to Title I middle schools.

3. The findings of this study are limited to the validity and reliability of the instruments used.

\section{Definitions}

Affective Processes: The principal encourages the expression of feelings, opinions, pride, and loyalty through team management, sensitivity, humor, and personal example (Valentine \& Bowman, 1988).

Commonwealth Accountability Testing System (CATS): The assessment used to gauge success within public education in Kentucky. CATS utilizes writing portfolios, the Kentucky Core Content Test, the ACT, and other non-academic components to assess the performance of students.

Curriculum Improvement: The principal promotes an articulated, outcome-based curriculum through diagnosis of student needs and systematic program review and change (Valentine \& Bowman, 1988).

Instructional Improvement: The principal influences positively the instructional skills present in the school through clinical supervision, knowledge of effective schooling, and commitment to quality instruction (Valentine \& Bowman, 1988).

Interactive Processes: The principal organizes tasks and personnel for the effective day-by-day management of the school, including providing appropriate information to staff and students, developing appropriate rules and procedures, and setting the overall tone for discipline in the school (Valentine \& Bowman, 1988). No Child Left Behind (NCLB) Act: The latest federal legislation that enacts the theories of standards-based education reform, which is based on the belief that setting high 
standards and establishing measurable goals can improve individual outcomes in education. The Act requires states to develop assessments in basic skills be given to all students in certain grades, if those states are to receive federal funding for schools. The Act does not assert a national achievement standard; standards are set by each individual state.

Kentucky Educational Reform Act: In 1990, the Kentucky General Assembly passed the Kentucky Education Reform Act (KERA) in response to a ruling the previous year by the Kentucky Supreme Court that the commonwealth's education system was unconstitutional. The court mandated that the Legislature enact broad and sweeping reforms at a systemic level, statewide (Rose v. Council for Better Education, 1989).

Organizational Direction: The principal provides direction for the school through work with faculty to develop goals, establish expectations, and promote appropriate change (Valentine \& Bowman, 1988).

Organizational Linkage: The principal promotes positive working relationships between the school, the community the school serves, and other educators and agencies that work with the school (Valentine \& Bowman, 1988).

Organizational Procedures: The principal utilizes effective procedures for problem-solving, decision-making, and change (Valentine \& Bowman, 1988).

Student Relations: The principal develops effective working relationships with students through appropriate communication skills, encouragement, support, and high visibility (Valentine \& Bowman, 1988). 
Teacher Relations: The principal develops effective working relationships with staff through appropriate communication skills, sensitivity to needs, appropriate support, and reinforcement (Valentine \& Bowman, 1988).

Title I Schools: Schools where at least 40 percent of the children in the school attendance area are from low-income families or at least 40 percent of the student enrollment is from low-income families eligible to receive federal Title I funds. The proportion of low-income families is most frequently measured by the percent of students receiving free and reduced-price lunch. Schools with percentages of low-income students of at least 40 percent may use Title I funds, along with other federal, state, and local funds, to operate a "schoolwide program" to upgrade the instructional program for the whole school. 


\section{CHAPTER II}

\section{Literature Review}

This study addresses school-effectiveness research, specifically predictors of principals' leadership behaviors in at-risk urban schools. The school-effectiveness literature is frequently referenced by education researchers today. Even though much of the methodology is vague, the analytical approach is often not described, and the terminology is not consistent from study to study. However, effectiveness research did provide groundwork for education investigations that continued for decades and placed the principal in the foreground of research about how to improve urban schools with atrisk populations.

School-effectiveness research, specifically the principal's leadership behaviors, is especially important due to the increased pressure placed on school leaders to close achievement gaps in public schools. Once school leadership became entrusted to those at the local level, accountability measures increased to evaluate progress of the leadership at the local level. Accountability is a component of the Kentucky Education Reform Act (KERA), which passed in accordance with the Kentucky Supreme Court opinion (Rose v. Council for Better Education, 1989) that declared Kentucky's public school system unconstitutional. KERA included high standards for student achievement and held school leaders accountable for meeting these goals. KERA as well as the No Child Left Behind Act of 2002, tremendously increased the school accountability of local school leaders. 
The literature review that follows has two major sections: (a) schooleffectiveness research and (b) principal-effectiveness research. Reviewing schooleffectiveness research is important because researchers studied schools that were effective in educating at-risk students and determined what characteristics made them successful. Many of these studies placed the principal as a key figure in school effectiveness. The research reviewed includes information on landmark studies in school-effects research. In addition, the principal-effectiveness research to be reviewed includes the following subtopics: (a) principal-accountability reform, (b) decentralization of accountability reform, and (c) improving student-outcomes reform.

\section{School-Effectiveness Research}

A landmark research study on equality of educational opportunity, (Coleman et al., 1966), formed the cornerstone for school-effectiveness research. This study, known as the "Coleman Report", intended to show the extent to which school achievement related to students' ethnic and social background; the possible influence of the "school" factor on learning attainment was also examined.

In reaction to the "Coleman Report", general criticism arose on the limited interpretation of the school characteristics. Usually, only the material characteristics were referenced such as the number of books in the school library, the age of the building, the training of the teachers, their salaries, and expenditure per pupil. However, Coleman et al. included other characteristics in the survey, such as (a) the attitude of school heads toward pupils, (b) attitude of teachers toward pupils, and (c) the attitude of teachers toward integrated education, i.e. multiracial and classless teaching. The overall result of the "Coleman Report" indicated a relatively high correlation between socioeconomic and 
ethnic family characteristics and learning attainment, and a small or even negligible influence from school and instructional characteristics.

Coleman et al. wrote "Equality of Educational Opportunity Study", which summarized research on the impact of school resources on student achievement as measured by standardized tests. The federally sponsored research study, related to the 1964 Civil Rights Act, involved more than 4,000 elementary and secondary schools. The participants in the report were students $(N=645,000)$ sampled from 1,170 high schools and 3,223 elementary schools.

Coleman et al. used surveys to operationalize the independent variables: (a) facilities; (b) programs; (c) student characteristics; and (d) staff characteristics. The dependent variable for the study was student achievement on standardized tests: (a) reading; (b) writing; (c) calculating; and (d) problem solving. The researchers used a regression analysis to predict student-level achievement. The data analysis determined the effect of the independent variables. The student outcomes considered in the study were students' achievement on standardized tests in reading, writing, calculating, and problem solving. The researchers reported that $5 \%$ to $35 \%$ of the variance in individual level achievement was attributable to between-school factors, with the remaining variance attributable to within-school factors. This large range in the variation attributable to between-school factors was due to differences in the between-school effect for different ethnic groups. More between-schools variance existed in the scores of Puerto Ricans, American Indians, Mexican-Americans and African American in the southern United States; less between-schools variance existed in the scores of African 
Americans in the northern United States, Whites in either the northern or southern United States, and Asian Americans.

Coleman et al. concluded that the between-schools variation for the numerically larger groups (Whites and African Americans) was between 10-20\% of the total variation in individual student achievement. The researchers found that schools bring little influence to bear on a child's achievement that is independent of his background and general social context and that this very lack of an independent effect means that inequalities imposed on children by their home, neighborhood, and peer environment become the inequalities with which they confront adult life. The success of the school was more dependent on the students' family background than any other variable. The researchers concluded that schools did not make a difference; families did. Although this study did not focus on the principal's role in educating students, it did spark controversy and the focus on leadership in school-effectiveness research.

Weber's (1971) studies of four effective inner-city schools directly opposed the findings of Coleman et al. Weber established leadership as important and began the focus on leadership in the context of school-effectiveness research.

Weber conducted a study to determine how inner-city schools successfully educated poor children. The researcher defined poor as "schools in which high percentages of students were on free lunch and participating in Title I programs". He also defined an effective school by its ability to educate poor children as well as middleclass children. The schools investigated were non-selective public schools in the central part of a large city attended by very poor children. Educators nominated schools $(N=$ 95) that met Weber's criteria of being inner-city and successful. The researcher selected 
17 schools, which he visited for two to three days each. First, the researcher administered a nationally standardized and normed reading test. Second, the researcher observed reading programs and analyzed the schools as organizations. Weber selected four of the seventeen elementary schools in three cities for an extensive case study of inner-city schools characterized by high achievement at the third-grade level. All four of the schools earned scores above the national averages on standardized norm-referenced assessments. His research emphasized the importance of the actual processes ongoing at schools (e.g., strong leadership, high expectations, good atmosphere, and a careful evaluation of pupil progress); while the earlier study by Coleman et al. focused on only static historical school-resource characteristics.

The main data-collection methods were analysis of the reading test results and observations. Students in these four schools achieved as well as students in typical average-income schools, as indicated by (a) reading-achievement medians that equaled or exceeded the national norm, and (b) an unusually low percentage of non-readers for such schools. The researcher established evidence that inner-city students could learn at high levels if teachers taught students well.

Weber identified school characteristics that could be related to the successful achievement of all students: (a) strong leadership; (b) high expectations; (c) good atmosphere; (d) strong emphasis on reading; (e) additional reading personnel; (f) use of phonics; (g) individualization; and (h) careful evaluation of student progress. Weber found it striking that the principals in all four schools would be regarded as outstanding leaders by most people knowledgeable about public schools. The results established leadership as important, which initiated a series of research studies. 
Rayder, Abrams, and Larson (1978) assessed the principal and identified strong administrative support for instruction as improving student achievement. Rayder et al. (1978) examined the extent to which socio-contextual variables acting on the teacher and classroom are associated with student achievement. The participants in the study were 26 teachers and 441 third-grade students in 26 classrooms from 13 communities across the United States. The sample represented a diverse population with students being identified as $45 \%$ White, $41 \%$ Black, and $60 \%$ below the U.S. Government poverty line.

The research design was correlational/predictive and researchers analyzed data with multiple regression. The independent variables were the 13 socio-contextual factors. The dependent variable was student achievement. Researchers collected the data from the Environmental Forces Inventory (EFI) completed by 26 teachers. Using the EFI, teachers assessed the importance of socio-contextual variables on teaching.

The following variables were rated by teachers: (a) school principal; (b) central office administration; (c) other teachers in the school; (d) parents of the students in the class; (e) curriculum prescribed by the district; (f) testing programs; (g) board of education; (h) physical facilities of the classroom; (i) social environment of the community; (j) you, yourself; (k) program director; (l) program advisor; and (m) teaching assistant.

The teachers evaluated the 13 items in three different ways: (a) they rated each item $(0=$ no influence, $9=$ strong influence $)$, according to the strength or weakness of the particular item in influencing their teaching; (b) they assigned a total of 100 points to the 13 items, all to one or distributed across all of the items; and (c) they rated each item $(1=$ strong negative effect, $9=$ strong positive effect $)$. Reliability coefficients for the 
instrument ranged from .62 for individuals to .93 for districts. The Metropolitan Achievement Test and the Raven's Progressive Matrices provided the data collected on the 441 students. Researchers provided no reliability data for the Metropolitan which was a nationally norm-referenced test. They indicated that the Raven Progressive Matrices had a moderate correlation with student achievement.

The results of the study suggested the following: (a) socioeconomic factors of the parents accounted for a large amount of variance in test scores and achievement, and (b) socio-contextual variables, such as school administration, environmental conditions, and the teacher, were statistically significant predictors of student achievement. The results of this study suggested that when the teachers' self-perception of their influence is high, the students' achievement would improve ( $r=.44, \mathrm{p}<.05$ for word knowledge). Strong administrative support for instruction was also suggested as related to improved student achievement $(r=.27, \mathrm{p}<.05$ for math concepts). This study suggested not only a linkage between socioeconomic variables, such as parent's college education and student achievement but also a linkage between positive teacher self-perception of influence and student achievement. A linkage was also suggested between positive administrative support for instruction and student achievement. While the school cannot determine the socioeconomic background of the school, it can initiate steps to improve teacher selfperception and support from the school administration. This study suggested the importance of a positive, supporting environment as being associated with higher student achievement. Further research should look at the relationship between social environment of the community and achievement since the results of this study suggested 
that a poor community environment was linked to lower student achievement $(r=-.43, p$ $<.05$ for math problems).

The Brookover and Lezotte (1979) study duplicated the previous findings of Weber (1971) and was an example of further research into the characteristics of effective schools. Brookover and Lezotte (1979) conducted a study to build on knowledge gained from two earlier studies: (a) The Report of the 1974-1975 Michigan Cost Effectiveness Study and (b) Brookover's School Can Make a Difference Study. The researchers concluded that previous studies made no attempt to determine whether the predictor or criterion variables had recently undergone any noticeable change. The challenge was to provide additional analysis of variables that affect student learning and can be controlled by schools, while using a more methodologically sound research approach. As a result of the two Michigan studies, nearly a decade of data based on criterion-referenced as opposed to norm-referenced standardized measures of student performance in basic skills was available for all Michigan fourth- and seventh-grade students. Brookover and Lezotte analyzed changes in achievement to determine what relationships existed among the two independent variables: (a) social structure, and (b) school climate variables and the dependent variable student achievement. The study was conducted in elementary schools $(N=68)$ that represented a random sample of Michigan schools. The researchers chose six improving and two declining schools as subjects of their study. The participants in the study were classroom teachers $(n=72)$; special reading and mathematics teachers $(n=13)$; administrative staff $(n=9)$; and paraprofessionals $(n=20)$. 
The major methodological contribution of this study was the use of three parallel questionnaires: (a) teacher; (b) principal; (c) and paraprofessional, that assessed expectation levels, academic norms, sense of academic futility, and other socialpsychological factors associated with the school. The researchers conducted interviews with all staff that had responded to the questionnaires in each of the categories: classroom teachers $(n=72)$; special reading and mathematics teachers $(n=13)$; administrative staff $(n=9)$; and paraprofessionals $(n=20)$. The purpose of the interviews, observations, and questionnaires was to determine what differences existed between the improving and declining schools and which factors were most closely related to student success.

The results indicated nine differences between improving and declining schools. The improving schools (a) had greater emphasis on reading and math accomplishments by the staff; (b) had teachers who held expectations that all children would master basic skills; (c) had staff who expected all students to complete high school or college; (d) had teachers and principals who both accepted responsibility for and were committed to teaching basic math and reading skills; (e) had blocks of time on direct teaching of reading and math objectives, with minimal direct paraprofessional involvement; (f) had principals who showed assertive instructional leadership, were attentive to discipline, and took responsibility for the evaluation of the achievement of basic objectives; (g) accepted accountability and the actual development of an accountability model; (h) had no tension and dissatisfaction with existing conditions; and (i) emphasized the teaching of reading by the regular classroom teacher. 
The results showed there were considerable differences between schools that succeeded, in spite of socioeconomic or family background factors. The study indicated that school-climate factors could be powerful predictors of student achievement: when entered first in regression models, these variables accounted for $73 \%$ of the school-level variance in student achievement, and they accounted for only $4 \%$ when entered last. Student sense of academic futility explained about half of the variance in school-level reading and achievement in models in which researchers entered school-climate factors first.

While both the Brookover and Lezotte (1979) and Weber (1971) studies focused on inner-city elementary schools, a third important study by Rutter, Maughan, Mortimore, Ouston, and Smith (1979) of the same period was focused on high schools. The researchers, Rutter et al. (1979), reported that students in England spent approximately 15,000 hours in schools from age five until they left school. The study had several unique characteristics.

Rutter et al. conducted a three-year longitudinal study to determine whether characteristics of entering students were predictive of student outcomes. Researchers first looked at a general study sample of 12 nonselective inner-London secondary schools that included both large and small schools, mixed and single-sex schools, voluntary aided and maintained schools, as well as some on single and some on split sites. The student population of all 12 schools totaled 3,485. This total only included students with entrance data. These students were known as "cohort" children $(N=1,487)$. The remaining students $(N=1,998)$ were from "other boroughs." 
This study involved a cohort design that involved the matching of individual pupil data at intake and at age 16. The researchers used correlations and regression analyses in analyzing their results, but they also reported effect sizes in terms other than variance accounted for in student achievement. The rank order correlation between school inputs, as measured by a general composite process score and examination results, was .76 . On the other hand, the regression analyses indicated that less than $2 \%$ of the variance in students' examination results was due to the composite process score. Entrance data on students provided a means for the researchers to determine whether characteristics of entering students were predictive of student outcomes. After determining that entrance characteristics did not account for all differences in outcomes at the secondary schools, the researchers investigated the differences among schools through (a) interviews of staff, (b) student questionnaires, and (c) two years of observations. The researchers applied the following measures to identify successful schools: (a) attendance, (b) pupil behavior, (c) examination success, (d) pupil employment one year after leaving school, and (e) delinquency levels.

The determinations from the study were: (a) the schools students attended influenced student outcomes; (b) characteristics and processes of schools made a difference in student achievement; (c) the study had a much stronger methodological approach than earlier studies because there was no need to compensate for lack of baseline data by making assumptions and using statistical techniques to control for preexisting student differences as in the earlier investigations; (d) several non-cognitive outcomes the researchers investigated (i.e., attendance, pupil behavior, pupil employment after leaving school and delinquency levels) added to the methodological significance. 
The Rutter et al. study supported earlier school-effectiveness findings, which had focused on elementary schools in the United States. This study added powerful supplemental information to earlier research because it focused on high schools. Although Rutter et al. did not specifically mention the principal, the researchers implied principal leadership because the factors they identified as critical for school success were directly associated with the principal's role. School environment, degree of academic emphasis, and combined school processes, for example, were part of the principal's responsibility. Although high schools were the focus of this study, the findings supported characteristics that were as significant in successful elementary schools. Rutter et al. set the standard for methodologically sound research that supported earlier school-effectiveness findings establishing the principal as positively related to school success.

Edmonds' (1979) work provided an example of how researchers began to report previous findings, draw conclusions, and strengthen their own data by supporting their conclusions with earlier published work. As the school-effectiveness body of literature grew, summaries, such as the Edmonds' Educational Leadership article, began to appear. Edmonds began a search for effective schools educating poor children in Detroit, Michigan. The search started in September 1974 with the analysis of the Stanford Achievement Test and the Iowa Test of Basic Skills school data from 20 schools that comprised the Model Cities Neighborhood. To be deemed an effective school, schools earned at or above the city average grade-equivalent in mathematics and reading. An ineffective school was defined as below the city average. Of the 20 schools, researchers identified five schools as effective in teaching both mathematics and reading. Edmonds widened his study by broadening his sample to include effective schools with different 
social backgrounds. He identified 55 more schools for analysis. Edmonds took the results of his research and that of others to make a powerful case for the creation of effective schools for the urban poor. Edmonds stated he was no longer interested in just describing effective schools; he also wished to create effective schools, especially for the urban poor. The model, generated through the effective schools research, included the following factors: (a) strong instructional leadership from the principal; (b) a pervasive and broadly understood instructional focus; (c) a safe and orderly school learning environment or climate; (d) high expectations for achievement from all students; and (e) the use of student achievement test data for evaluating school success.

Edmonds described the Brookover and Lezotte (1979) study as notable, chiefly for its reinforcement of leadership, expectations, atmosphere, and instructional emphasis as essential instructional determinants of pupil performance. First, Brookover ad Lezotte recommended that achievement of minimal goals and objectives in reading and math should be non-negotiable. Second, they concluded there should be emphasis on the principal's role as the director of instruction and evaluator of the school's instructional program. The intent was a program of professional improvement for principals, which emphasized their accountability for the improvement of instruction in their building. Third, the authors recommended accountability of principals and teachers for minimum basic-skills objectives. Finally, the researchers stressed that professional development should emphasize the educator's professional responsibility for the basic instruction of all students. The generic reference to educator implied that both teachers and principals were responsible for instructional leadership at their schools. 
In summary, research reports presented during the late 1960s and early 1970 s claimed that student outcomes, that could be attributed to school inputs, was small when compared to those attributable to student background characteristics. Best known of these studies was a survey by the National Center for Education, published in 1966 "Equality of Educational Opportunity Study" (Coleman et al., 1966), which has often been cited as the study that initiated school-effectiveness research in the United States. This study concluded that schools had little effect on students' achievement that was independent of their family background and social context. James Coleman was the primary author of the report, often referred to as the Coleman Report. Weber (1971) opposed the Coleman et al. research findings by identifying eight school characteristics that could be related to the successful achievement of all students. Weber established leadership as important and began the focus on leadership in the context of schooleffectiveness research. Rayder, Abrams, and Larson (1978) assessed the school principal as a variable and found that strong administrative support was related to improved student achievement. The Brookover and Lezotte (1979) study was an example of further research into the characteristics of effective schools. The study indicated that schoolclimate factors could be powerful predictors of student achievement. Rutter et al. (1979) focused on high schools in contrast with previous research that focused on elementary schools. Edmonds' (1979) work showed how researchers began to support their own conclusions using previous research.

The Coleman Report did much to trigger school-effectiveness research. The greatest debate in this area deals with how much variance in student performance is accounted for by the student and how much by the school. Researchers began to 
investigate what criteria were present in urban schools identified as having successful student performance on standardized tests. In the urban schools, the student population was poor and members of ethnic minorities. These studies were classified as schooleffectiveness research because the researchers focused on schools that were "effective" in spite of difficult circumstances. The research findings did provide groundwork for education investigations that would continue for decades and placed the principal in the foreground of research about how to improve schools with at-risk populations.

\section{Principal-Effectiveness Research}

This section is divided into three subsections: (a) principal-accountability reform (b) decentralization of accountability reform, and (c) improving student outcomes reform. The school-effectiveness research findings called for researchers to study the role of the principal and to advance the research in this area. Principal-effectiveness research followed school-effectiveness research with a more in-depth study of the principal's role to determine the principal's influence on at-risk students. School-reform initiatives required systemic change at the state and local levels. Principals had to be the leaders at the local school level for the quality of education to improve and result in improved student achievement. The principal moved from managing the school to becoming the instructional leader in the school. Without question, principals were essential to schoollevel reform efforts, and the accountability for student outcomes began to be placed on the principal.

\section{Principal-Accountability Reform}

"A Nation at Risk" prompted the principal-accountability reform efforts in the 1980s. The National Commission on Excellence in Education (NCEE, 1983) presented 
this report to the United States Secretary of Education. The report compared test scores of American students to student test scores from other industrialized nations. American student test scores were lower than scores of other nations. The authors demanded educational improvement in many ways, including holding leaders accountable for the progress of education. The report instigated many top-down initiatives by recommending that the federal government, state and local leaders, superintendents, and principals be held accountable for educational improvement (NCEE, 1983). The quest for improved student outcomes brought about an increased focus on principal accountability. Within the accountability movement, more centralized control evolved, placing power and authority in the administration at the school level. School centralization, a top-down approach, called for principals to be instructional leaders and catalysts for change in effective schools. The following studies examined the principal's influence on student achievement during this principal-accountability reform era.

Blumberg and Greenfield (1980) determined what characteristics were common to effective principals. The participants were principals $(N=8)$ nominated by teachers, principals, and colleagues who believed they were making a difference in their schools. The researchers conducted interviews with the four elementary and four secondary principals selected for this study. The study intended to investigate both the unique approaches the principals used and what characteristics were common to them.

The research findings indicated that the principals had various styles for achieving successful leadership, and each principal solved problems and successfully led in a way that best suited him or her personally. All eight principals had visions for their schools, although these visions varied. The data further indicated that all principals were 
personally highly goal-oriented and did not find ambiguous situations to be problematic. The data revealed effective principals had high needs for warmth and affection and an inclination toward friendliness and good-natured fellowship. Including others in projects on problem solving was identified as a high need, and principals indicated they had moderate to high needs for others to include them.

Researchers then asked more in-depth, analytical questions about each of the characteristics common to the effective principals. They concluded that the principals' actions built confidence among teachers. By including others in problem solving, the principals lessened the need for reactive behaviors, embraced the ambiguity of the school situation, and fostered the attainment of shared goals. The proactive nature of the principals was revealed by characteristics they possessed: (a) vision, (b) initiative, and (c) resourcefulness. The principals were resourceful in managing time to allow them to achieve their personal objectives. The principals were initiators of action and were not afraid to challenge the system by using their influence or authority to make their schools better.

Blumberg and Greenfield (1980) concluded the effective principal provided for individual resource needs, such as teaching supplies and substitutes for teachers' personal leave. Effective principals also consistently focused discussions and professional interactions around the real issues of educating students. The principals sought to narrow the gap between what they perceived to be current practices and what they believed to be good practices. Student learning was the forefront for meeting the principal's individual needs. The principals saw teachers as those who could help them make a difference at 
the school. Data revealed that the process these principals used to lead and involve others was direct, proactive, and related to the principal's vision.

Some research on principals has focused on the process of setting standards for professional behavior in the school. For example, Keedy and Achilles (1982) studied principals and how they set the school norms. They conducted a case study to establish the importance of school norms and to determine how principals set norms. Multiple methodological steps were applied in the study. Effective schools were first identified using the Dyer model for selecting outlier schools. These were schools that were achieving at a higher level than would be expected, given the number of at-risk students in the school. This model incorporated stratification, a random selection of schools, obtaining predictor scores, and forming a pool of outlier schools $(n=13)$ from the entire sample $(N=98)$. The criteria used to select six elementary schools for case studies were: (a) willingness to participate; (b) the nomination technique; and (c) length of principal tenure. Data-collection methods included direct observation, open-ended questions, a norm checklist, and a questionnaire.

The researchers developed the norm checklist from a literature review summary and validated it by having 35 teachers and principals check the norms they perceived to be present in their schools. They developed six norm groups from a total of 35 norms on the checklist. These groups were norms-defining: (a) principal's obligations to teachers; (b) teacher behavior as a professional educator; (c) school's high expectations for students; (d) how principals affect teachers who affect students; (e) a principal's authority of position; and (f) school climate. The researchers used commonality of agreement between teachers and their respective principals to determine within-school, among- 
school, and between-group analysis. The researchers collected the data from categories (e.g., within-school was within each of the six schools; among-school combined the six within-school analyses; and between-groups compared principal perceptions with teacher perceptions). Three categories specifically mentioned interaction with teachers (i.e., gobetween, decision-making/input, and peer pressure). Other categories included authority of position, human relations, modeling, and resource provider.

The data indicated principals did use norms to manage their schools. As a management tool, norm-setting was related to three principal behaviors. First, the principals used norm-setting to establish standards of performance for teachers. Second, principals worked with teachers to set high learning expectations for students. Finally, the principals used norms as a management tool in the coordinating and sequencing of schoolwide goals and objectives. They achieved schoolwide goals and objectives when the two other conditions existed (i.e., teachers were successful and students achieved at high levels).

With isolated incidents where principals used other approaches to norm-setting, principals most commonly used four behavioral approaches to set norms: (a) resource provider, (b) modeling, (c) authority of position, and (d) human relations. Data indicated that effective principals in all six schools were observed in the resource-provider role more than any other activity. Actions ranged from providing teaching materials and organizational maintenance to responding to personal requests such as sick leave. Principals met both professional and personal teacher needs in various ways, including money for materials and equipment and assistance with instructional programs. 
Keedy and Achilles (1982) reported that the resource-provider function of principals transcended barriers between the administrative sphere and the teacher sphere. Through the bargaining with teachers, the principals had direct influence on the classroom (i.e., influence on curriculum choices, establishing norms for good teaching, impacting teacher autonomy, and developing effective principal-teacher interaction norms). There was a fundamental difference in how teachers responded to principals, which was directly correlated to the teacher's perception of the principal as a resource provider. Principals increased their effectiveness by enabling teachers. Keedy and Achilles sought to understand the principal and teacher relationship better by asking questions of teachers. They determined that principal success with student-achievement goals was directly related to the way principals interacted with teachers. These researchers supported the need to continue to study the indirect effect principals had on teacher behavior.

Leithwood and Montgomery (1982) studied the principal's role as collaborator and relationship builder. They conducted a study to assess the status of knowledge about effective and ineffective principal behaviors. The researchers searched for ways that principals improved the effectiveness of their schools. The researchers used the following questions: (a) What cognitive frameworks do principals use in thinking about their role? (b) What language do principals use to describe their own professional activities and problems? and (c) How can principal behavior be classified so that subsequent descriptions will be meaningful to principals as well as focused on critical aspects of their behavior? 
The study design was qualitative, because the researchers used content analysis to analyze data from previously reported research on educational change. Leithwood and Montgomery (1982) used various sources of information to locate studies, including library indexes, library card catalogs, journal tiles, dissertation abstracts, and the ERIC system. For inclusion, a study had to meet the following criteria: (a) the study had to have empirical data relating to one or more of the research questions; and (b) the methodology had to be clearly stated. The researchers also reviewed the following categories of studies: (a) the role of the principal, (b) school change, and (c) school effectiveness.

To determine how to summarize and classify the studies for selection, the researchers conducted an initial study. The researchers conducted 23 principal interviews using audiotapes to record the data. The researchers transcribed interviews onto file cards and sorted them into clusters. Using a grounded theory approach, the following major categories emerged and were used for reporting results: (a) goals of the effective principal, (b) factors affecting student classroom and school-wide experiences, and (c) categories of strategies used by principals.

Thirty-nine empirical studies (i.e., 17 surveys, 15 case studies, 2 combined survey and case study designs, 2 ethnographies, 2 pre-experiments, and 1 conference paper) met the authors' criteria for inclusion. Using the dimensions found in the original study (i.e., goals, factors, and strategies), effective principal behavior was described. Findings pertinent to this review were that principals distinguished the establishment of interpersonal relationships as an important strategy for influencing classroom and school factors. Although one principal goal was to be task-oriented, that goal did not take the 
place of relating collaboratively to teachers. Data suggested that the effective principal worked toward balanced attention to instructional leadership, routine administration, and human relations.

In another study summarizing past research, Purkey and Smith (1983) conducted an extensive review of more than 100 school-effectiveness studies. They limited their review to studies that determined or examined school-level factors associated with school effectiveness. The review differed from other reviews of the school-effectiveness literature in the following ways: (a) their orientation was skeptical; (b) evidencegathering was extended to include schools performing at levels higher than expected; and (c) research included case studies, surveys, and evaluations as well as studies of program implementation and organizational theories. The researchers determined that an academically effective school was distinguished by a structure, process, and climate of values and norms that emphasize successful teaching and learning.

The organizational-structure variables identified in academically effective schools included (a) instructional leadership, (b) school-site management, (c) staff stability, (d) curriculum articulation, (e) organization, (f) schoolwide staff development, (g) parental involvement and support, (h) school-wide recognition of academic success, (i) maximized learning time, and (j) district support. These organizational factors did not ensure that a school would be an academically effective school; however, if these factors are in place it is more likely that a school will be effective in educating all students, regardless of family background or socioeconomic status.

The process variables that defined the school culture and climate were the following: (a) collaborative planning and collegial relationships, (b) sense of community, 
(c) clear goals and commonly shared high expectations, and (d) order and discipline. These factors alone did not ensure a culture and climate that yielded a productive school, but a school's culture, or more specifically its climate, seemed to be the determining factor in its success or failure as a place of learning. Purkey's and Smith's review (1983), as well as the other studies discussed (Weber, 1971; Brookover and Lezotte, 1977;

Edmonds, 1979), provided significant evidence that instructional leadership impacted the technical core of schools. The influence that an instructional leader had on the teaching and learning was extensive.

How can the principal best interact with teachers to improve achievement? Glasman (1984) evaluated the principal's role in leading student achievement. His work established that student test scores could be impacted if principals led the analysis and sharing of results with staff. The researcher hypothesized that with effective principals: (a) achievement data would be shared with the staff; (b) the data would have a positive influence on student achievement; and (c) student achievement data would not be used as a basis for evaluation of teachers. The survey developed by the researcher had a 7-point Likert scale $(1=$ low, $7=$ high $)$ for each item and was pilot tested prior to distribution. Reliability or validity measures were not included in the study. In California, a random selection of elementary school districts $(N=95)$ was made with 88 agreeing to participate in the study. After district superintendents identified the "most" $(n=85)$ and "least" effective principals ( $n=117)$ in their districts, questionnaires were sent with a return rate of $83 \%$. The independent variable was effectiveness of the principals, and the dependent variables were: (a) the use of achievement data; (b) the data's influence on student achievement; and (c) student achievement data used in conjunction with teacher 
evaluations. Between $66 \%$ and $76 \%$ of the principals in Glasman's (1984) research used student-achievement data for teacher evaluations. Most principals (between $74 \%$ and $81 \%)$ believed the data could be used to adjust teachers' instructional practices, leading to professional growth. Data could then be used to investigate professional-development needs of the staff. Sixty percent of the principals believed the data could be wielded in teacher evaluations to regulate classroom practices. Each year as principals evaluated staff, they could ascertain whether changes had been made since the previous year, based on student-achievement data. The low percentage of effective principals using these data during teacher evaluations shows that principals understand that student-achievement data represents a threat to teachers.

Glasman (1984) noted that $42 \%$ of the effective and $52 \%$ of the least effective group agreed that using student-achievement data during teacher evaluations could restrict variation of classroom practices. If teachers became so focused on student achievement, then risk-taking and creativity would likely diminish as teachers try to imitate a successful set of instructional sequences to ensure the same "admirable" result each time. A question-by-question analysis revealed no significant differences between the effective and ineffective principal groups on the individual survey items. Glasman found principals used student-achievement data for teacher evaluations primarily to adjust teachers' instructional practices and regulate classroom protocol.

Blumberg and Greenfield (1986) continued their earlier study of principal behavior by using seven of the eight principals who had previously been interviewed. Follow-up interviews focused on the proactive nature of these principals and their desires to make differences in their schools. Blumberg and Greenfield concluded that their 
research extended beyond the principal to validate the importance of teachers. Without dialogue with teachers, principals did not recognize success with student learning. Many unanswered questions remained, even after nearly a decade of study into the principalship. While these researchers had identified the behaviors and characteristics of effective principals, they recognized an additional need to determine what effective principals do to influence the school setting and other individuals at the school.

Blasé (1987) continued research on the indirect affect of the principal. Blase conducted a two and one-half year case study of principal leadership and effectiveness after recognizing evidence from the research literature of the principal's indirect effect and noting the need for thick descriptions of the complexities principals encountered in schools. The study determined what factors were responsible for teacher perspective on effective school leadership. The research was conducted at one urban, multiracial high school with approximately 1,500 students. Teachers $(N=80)$ initially participated in the study, which combined interviews (both structured and unstructured), observations and questionnaires, and investigated teacher perceptions of principal effectiveness associated with all principals they worked with since beginning to teach. Blasé moved to openended questioning with a final sample of teachers $(N=40)$, and each individual participated in three interviews to probe more deeply into principal effectiveness because of the patterns that emerged between effective and ineffective principal leadership behaviors.

The researcher collected and analyzed data in a grounded-research approach, using the themes that emerged from the literature as organizers. Blasé (1987) identified the following themes: (a) task-related behavior and (b) consideration behaviors. Task- 
related behaviors included planning, defining, organizing, and evaluating. Consideration behaviors involved recognizing people in ways that enhanced their satisfaction with their work. Further analysis indicated the task-behavior factors: (a) consistency, (b) accessibility, (c) knowledge/expertise, (d) clear and reasonable expectations, (e) decisiveness, (f) goals/direction, (g) follow-through, (h) time management, and (i) problem-solving orientation. Consideration-behavior factors included the following: (a) support in confrontation/conflict, (b) participation/consultation, (c) fairness/equability, (d) recognition (praise and reward), and (e) willingness to delegate authority.

Teachers described every effective principal as exhibiting all of the task and consideration factors. A finding that was particularly relevant for this study was that teachers observed and reported that effective principals analyzed the school situation and then developed what teachers perceived to be realistic policies, rules, goals, and standards based on that analysis. Teachers judged what they needed to achieve by perceiving the principals' expectations and by identifying what behaviors were rewarded. The problemsolving approach of effective principals affected entire schools. Reducing barriers to teacher performance resulted in solidarity and cohesiveness among teachers. Principals involved teachers in meaningful ways and, without exception, encouraged teacher participation by developing open relationships with them.

Blasé (1987) concluded that working with people was more important to principal effectiveness than technical, managerial duties of the administrator. Associative school cultures that were characterized by cohesiveness emerged where effective principals practiced. Blasé characterized interactions among teachers and principals in these cultures as cooperative, empathetic, supportive, respectful, equitable, and productive. 
Blasé also confirmed the importance of the principal's influence on teacher behaviors and supported findings about the principals' indirect effect on school success.

Achilles (1987) moved the investigation from general school effectiveness to specifically principal effectiveness by defining first- and second-generation approaches to school effectiveness. The researcher illustrated how this evolution took place in the context of Project SHAL (from the first letter of each name of the original four schools that were not further identified). SHAL was the implementation of a large-scale change innovation in one non-specified Midwestern city's mandatory, court-ordered desegregation project. As one element of the project, researchers established descriptors for what the principal of an effective school (i.e., pupil scores on standardized tests positively correlated with degree or amount of project implementation) would do. This was one of the first attempts to define the "what" and "how" of instructional leadership.

The lessons learned from SHAL were as follows. The effective principal accepted responsibility for what happened at the school. A collegial atmosphere existed which was directly related to the principal who organized the shared effort to identify goals (both academic and social) and create a shared focus on goal implementation. The effective principal emphasized and coordinated the school instructional program around student achievement and used all resources to that end. Effective principals, for example, provided teachers with resources that allowed the teachers to be more efficient. The principal carefully managed time. Principals devoted teacher in-service training to content-area knowledge and classroom management in order to help teachers with the delivery of instruction. Principals established clear standards of performance for 
teachers, students, and themselves. They monitored and evaluated the instructional program to ensure that implementation of the best practices was taking place.

Achilles (1987) recognized the criticisms of the prior school-effectiveness research and at the same time endorsed those research efforts as rallying points for school improvement. Achilles' reasoning is particularly interesting for this study because of his focus on how the prior research conclusions could be used for principal effectiveness. He believed the effective schools' work has brought to principals some important assistance at a time when schools are harshly under fire and that it gives principals direction in terms of school functions and activities. Achilles referenced research studies that were beginning to attempt to answer the "how" questions of principal effectiveness. He then suggested educators provide the public with much-needed answers about effective principals. By looking into answers to the "how" questions about principal leadership, educators could respond to the public alarm caused by the numerous national reports at that time such as "A Nation at Risk" and "A Time for Results." The natural evolution from school-effectiveness research to investigations into principal effectiveness was reflected in Achilles' observation:

At a time when numerous national studies and commission reports have been decrying education's faults and foibles, the effective schools ideas provide rays of optimism and hope and offer promise for school improvement....Answers to the what question have specified variables amenable to further study. Answers to the what question provide descriptive data and lead logically to the how question. (1987, p. 32) 
One of the "how" answers described in the literature was for the principal to provide leadership toward a vision. Vision for better schools became the topic of much research. A summary of one such study follows.

Greenfield (1987) conducted research to understand leadership toward vision by looking at the history of leadership in the existing literature. He defined vision as "values in action" and included moral imagination and interpersonal competence as precursors for effective leadership. He then sought to determine what personal characteristics could be related to the development of vision. The researcher determined there were three important factors related to vision. The effective principal first forms a picture or vision of what he or she wants to achieve. This vision then serves as a "general guide" for the principal in all activities related to managing and leading his/her school. Finally, the focus of the principal's work is always upon matters related to instruction and classroom performance of teachers. Vision, as defined by Greenfield, was the guiding force principals used to provide leadership in the school. Given this description, the researcher sought to explain how vision was developed but reserved his own definition of leadership until after he had analyzed existing literature. He concluded from the literature that values impacted the decisions made at the school. Vision was described as evolving through a process of the person's "moral imagination," or the interpretation of present reality and what it would take to improve the existing situation.

Greenfield (1987) further determined the principal was the most important individual in directing the instructional program. He then investigated the values and vision of principals. Greenfield identified the "theme" of leadership literature as how the principal is the critical actor on the school scene, and the effectiveness of instruction and 
achievements by children can be tied directly to efforts by the school principal to lead, manage, and supervise teachers and school programs. Greenfield clarified, however, that while his discussion centered around leadership by the principal, the discussion was also relevant to leadership by teachers, department heads, and others committed to school effectiveness. Leadership was not the sole work of the principal, though it had often been perceived as the principal's lone responsibility.

In addition, Greenfield (1987) defined leadership broadly as actions undertaken to develop a productive and satisfying work environment for teachers and desirable learning conditions and outcomes for children. His intent was to call attention to the importance of personal qualities of principals as leaders and to establish that the qualities could be identified and intervention could shape the development of each quality. He outlined two important aspects of principal action. The principal's decision-making practices in the context of often competing and conflicting school norms was one critical element of leadership.

Interpersonal interactions, such as verbal exchanges and face-to-face interactions, were the second very large part of the principal's leadership responsibility. Greenfield (1987) specified that principals must conceptually understand the work of teachers in order to have credibility when they sought to influence teachers. Greenfield was a forerunner in documenting the importance of principal and teacher dialogue in developing teacher-leadership skills. Greenfield offered a final insight about the principal's "authority of position." He concluded that the position alone provided an "institutionalized base for influence... [but] is not a sufficient basis for leading" (p. 70). 
The principal's position provided an element of authority but was only a base for which influence could be extended.

How does leadership relate to student outcomes? To address this question, Andrews and Soder (1987) conducted a two-year study of the relationship between principal leadership and student academic-achievement gain scores in reading and mathematics. The participants in the study were all district instructional staff in elementary schools $(N=33)$. Andrews and Soder measured the instructional staff's perceptions of principal leadership with a questionnaire designed to measure 18 strategic interactions between principals and teachers in terms of the principal as: (a) resource provider, (b) instructional resource, (c) communicator, and (d) visible presence. The independent variable was leader group, which had three levels: (1) strong-leader ( $n=$ $11)$, and (2) average-leader $(n=11)$, and (3) weak-leader $(n=11)$. The researchers divided the schools into the three groups based on staff perceptions of the principal as an instructional leader. The researchers classified the 11 highest scoring principals as strong leaders, the middle 11 as average leaders, and the lowest scoring 11 as weak leaders. The dependent variables were total reading average gain scores and total mathematics average gain scores in individual student normal curve equivalent scores on the California Achievement Test as a measure of improved academic performance. Year-end 1982 test data used a baseline with individual gains computed on the basis of year-end 1984 test scores. The researchers used analysis of variance for the statistical analysis. The findings indicated the normal equivalent gain scores of students in strong-leader schools were significantly greater in both total reading and total mathematics than those of students in schools rated as having average or weak leaders. The directions of gain 
scores were consistently highest for strong-leader schools. The order of gain scores for African-American and free-lunch students was consistent across groups, from highest for strong-leader schools to lowest for weak-leader schools. Free-lunch students' gains in total reading ranged from 5.9 points over the two years in strong-leader schools to 1.1 points in weak-leader schools. African-American students' gains in total mathematics ranged from 4.4 points in strong-leader schools, but students in weak-leader schools lost an average of 2.3 points over the same period. The findings suggested that teacher perceptions of the principal as an instructional leader were critical to the reading and mathematics achievement of students, particularly among low-achieving students.

Pollard (1989) identified the alterable variables associated with academic achievement in poor African-American and Hispanic middle and high school students. The researcher used a hypothesis proposed by Fordham Ogbu (1986): that academic achievement requires crossing cultural boundaries and taking on some of the behaviors of the dominant culture.

Parameters were set to define the minority, urban underclass from which the sample was drawn: (a) minority status, either African-American or Hispanic; (b) low socioeconomic status, eligible for both free or reduced-price lunch; and (c) average ability, defined as a stanine of four or five on the Iowa Test of Basic Skills reading section. A random sample $(n=361)$ was drawn from students, in five middle and five high schools in a large Midwestern city, who fell within the established parameters. The total population of schools and students was not reported. The instrument was a survey questionnaire composed of several scales that measured a variety of psychological variables, including interpersonal support and personal factors. The instrument was 
developed by the researcher and completed anonymously by the participating students. In this study, no Cronbach's alpha was given regarding the reliability of the instrument.

Research design was multivariate factorial. The researcher analyzed data by factor analysis to reduce the large number of variables $(n=26)$ contained within the survey instrument to a more usable number of seven. Those factors were (a) social attitudes; (b) self-perceptions of ability; (c) general social support; (d) teacher support; (e) parental influences; (f) school involvement; and (g) active problem-solving. A MANOVA was then used to test for differences by achievement group and gender (the independent variables) in the social psychological variables (the independent variables).

Results of the study include the following: (a) main effects from the MANOVA shown for both achievement levels and gender; (b) significant differences in achievement levels for self-perceptions of ability, general social support, teacher support, parental influences, and active problem-solving; and (c) girls tended to be better problem solvers than the boys and this factor accounted for most of the differences between males and females. Results from this research indicated that academic achievement was associated with several alterable social-psychological variables. The hypothesis was supported because those students who were successful were more likely: (a) to be involved in school activities; (b) to view themselves as having a higher ability; and (c) to make strong efforts to do academic work. These are values reflected by the dominant culture. The minority students crossed the cultural boundary to be successful.

Implications from this study were the following: (a) teachers and other staff members must provide support and encouragement for the students; (b) achievement is enhanced when students are involved in active problem solving; (c) achievement is 
enhanced when help is available from other students; and (d) parental involvement is a positive influence on academic achievement. These implications provide support for the use of instructional practices such as active student involvement, teachers' high expectations, and collaborative group activities. The school principal's support for these instructional practices would likely increase their presence in schools.

Heck, Larsen, and Marcoulides (1990) tested a theoretical causal model concerning how elementary and secondary school principals can influence student achievement through the frequency of implementation of certain instructional leadership behaviors. The sample consisted of schools $(N=56)$, California public elementary and high schools, with scores above or below the California Assessment Program (CAP) at both Grades 3 and 6 and also Grade 12 in reading and math for three consecutive years. The sample consisted of teachers $(N=332)$ and principals $(N=56)$.

The researchers hypothesized that three latent, dependent variables related to instructional leadership: (1) school governance, (2) instructional organization, and (3) school climate. These variables were hypothesized to affect the dependent variable, student achievement. The study design was causal comparative. A questionnaire comprised of variables measuring the implementation of 34 instructional leadership behaviors of the principal was used for data collection. Researchers mailed the questionnaires to principals with instructions to give the questionnaire to a random sample of six teachers. The coefficients of determination for the measurement model were .88 at the individual level and .91 for the school level. This indicated that the observed variables served as instruments for measuring the latent variables. 
The researchers concluded that school climate and school instructional organization were important indicators of principal instructional leadership. The principal's role in creating strong climate and instructional organization was the area that predicted school achievement in this model. Principals were able to affect student outcomes through the climate and organization of instruction, which indicated an indirect effect of principals. The effect was not obtained through direct principal and student relationship or interaction, but indirectly through other leadership behaviors. Heck, Larsen, and Marcoulides (1990) found that principals in high-achieving schools were very different from those in low-achieving schools. Principals in high-achieving schools relied on teacher input, particularly in instructional decisions, while principals in lowachieving schools tended to leave teachers alone to teach.

Leithwood and Jantzi (1990) found strategies that principals use to influence the culture of their schools and to increase collaboration. Leithwood and Jantzi conducted a study to investigate how collaborative school cultures developed during reform efforts and how principals facilitated that process. The researchers examined principal practices in elementary and secondary schools $(N=12)$ with a collaborative culture that developed throughout a three-year school-improvement initiative. The researchers selected six of these schools from a larger project on school improvement sponsored by Ontario's Ministry of Education and selected six schools involved in improvement efforts but not related to the Ministry project. The researchers sent six questionnaires regarding change to the elementary schools $(N=7)$ and seven to the secondary schools $(N=5)$. The following research questions guided the study: (a) to what extent did schools achieve collaborative teacher cultures? (b) How did the pursuit of larger goals result in 
developing more collaborative teacher cultures? and (c) What strategies were used by school administrators to develop more collaborative school cultures? The study design was exploratory and qualitative in nature. The questionnaire return rate was $94 \%$. The sample consisted of nine elementary and three secondary schools, all from southern Ontario.

The researchers conducted a total of 133 interviews with principals during a twoday visit to each school. Two interviewers collected data using two versions of a semistructured instrument intended to distinguish key elements in the change process. Little's (1982) indicators of collaboration were used to assess the extent to which collaboration had been achieved: (a) teacher talk about teaching practices; (b) teacher observations; (c) teacher planning, designing, and evaluating teaching materials together; and (d) teachers teaching each other the practice of teaching. Teams analyzed data from two schools, which included 23 interview results. Researchers constructed individual matrices for each respondent and used these to create school matrices. To ensure reliability, the researchers met with the teams twice weekly to ensure consistency. An average of approximately $70 \%$ of teachers stated that a collaborative relationship existed with the principal.

The results indicated that principals used the following strategies to influence the culture of their schools and to increase collaboration: (a) strengthening the culture, increased opportunities for teacher collaboration (i.e., teachers observing in another's classroom, providing opportunities for professional development, having staff retreats, and providing for common planning time); (b) using bureaucratic mechanisms, included principal management of financial support, scheduling, and evaluation; (c) fostering staff 
development, provided opportunities for teachers to increase skills and knowledge, and (d) having frequent and direct communication. The latter proved to be an important strategy for principals. Principals used words such as informing, persuading, directing, writing, negotiating, counseling, visiting, and discussing to indicate the prevalence of this strategy. Sharing power and responsibility was described as principals' delegating, if not giving away, sources of power traditionally vested in their positions. Using rituals and symbols to express cultural values resulted in a more collaborative culture.

The principal role had evolved to a leader who employed strategies (i.e., strengthening the culture, staff development, bureaucratic mechanisms, communication, shared power, and peer review) to increase instructional capacity to improve student outcomes. School improvement and collaborative efforts were seen as a venue for problem solving. Understanding the larger context within a collaborative culture created an understanding of the role of the principal.

A summary of principal accountability reform research shows a variety of approaches. Bloomberg and Greenfield (1980) indicated the principals saw teachers as those who could help them to make a difference in student achievement. Data revealed that the process these principals used to lead and involve teachers was direct, proactive, and related to the principals' vision. Keedy and Achilles (1982) determined that principal success with student-achievement goals was directly related to the way principals interacted with teachers. Leithwood and Montgomery (1982) determined that principals distinguished the establishment of interpersonal relationships as an important strategy for influencing classroom and school factors. The effective principal worked toward balanced attention to instructional leadership, routine administration, and human 
relations. Purkey's and Smith's (1983) review, as well as the other studies discussed (Edmonds, 1979; Brookover and Lezotte, 1977; Weber, 1971), provided significant evidence that instructional leadership impacted the technical core of schools. The influence that an instructional leader had on the teaching and learning was extensive. Glasman (1984) found principals used student achievement data for teacher evaluations primarily to adjust teachers' instructional practices and regulate classroom protocol. Blumberg and Greenfield (1986) discovered that without dialogue with teachers, principals did not recognize success with student learning. While these researchers had identified the behaviors and characteristics of effective principals, they recognized an additional need to determine what effective principals do to influence the school setting and other individuals at the school. Blasé (1987) concluded that working with people was more important to principal effectiveness than technical managerial duties of the administrator. Interactions among teachers and principals were cooperative, empathetic, supportive, respectful, equitable, and productive. Achilles' (1987) reasoning was particularly interesting for this study because of his focus on how the prior research conclusions could be used for principal effectiveness. He believed the effective-schools research brought to principals some important assistance at a time when schools were harshly under fire and gave principals direction in terms of school functions and activities. Greenfield (1987) specified that principals must conceptually understand the work of teachers in order to have credibility when they sought to influence teachers and was a forerunner in documenting the importance of principal and teacher dialogue in developing teacher leadership skills. Andrews and Soder (1987) suggested that teacher perceptions of the principal as an instructional leader were critical to the reading and 
mathematics achievement of students, particularly among low-achieving students. Pollard (1989) indicated that academic achievement was associated with several alterable social-psychological variables. Heck, Larsen, and Marcoulides (1990) concluded that school climate and school instructional organization were important indicators of principal instructional leadership. The principal's role in creating strong climate and instructional organization was the area that predicted school achievement. Leithwood and Jantzi (1990) indicated that the principal role had evolved to a leader who employed strategies (i.e., strengthening the culture, staff development, bureaucratic mechanisms, communication, shared power, and peer review) to increase instructional capacity to improve student outcomes.

\section{Decentralization of Accountability Reform}

It became evident that principals could not meet this challenge alone. The mid1980s called for principals to lead school improvement initiatives and share instructional decision-making with teachers. The following section, "Decentralization of Accountability Reform," occurred in the mid-1980s and early 1990s and brought change through the decentralization of schools. Decentralization was delegating power and sharing authority with various groups of stakeholders (e.g., teachers, staff, parents, and community members) and was the opposite of centralization. The Carnegie Forum on Education and Economy Task Force (1986) Report, “A Nation Prepared: Teachers for the Twenty-First Century and Tomorrow's Teachers: A Report of the Holmes Group" moved from criticizing the field of education to suggesting solutions. A key suggestion was to require the principal to build instructional capacity within the school. As decentralization increased, so did accountability. Improving student outcomes was the 
ultimate objective of all reform efforts. Reform initiatives heightened the need for increased instructional capacity as never before. States began to administer assessments to increase accountability measures and determine student outcomes. The Kentucky Education Reform Act of 1990 (KERA) increased school accountability and an assessment system that measured school progress. A revision of virtually every area of the education system occurred, and KERA became a critical turning point in education across the Commonwealth of Kentucky. KERA became one of the most comprehensive reform initiatives in the nation. Unquestionably, increased school accountability elevated responsibility for school leaders.

Heck (1992) conducted a study to determine the effects that principals' instructional leadership had on school achievement. The researcher used the Leadership Effectiveness and Adaptability Description questionnaire data from the principal and four teachers from elementary schools $(N=23)$ and high schools $(N=17)$ in California. Heck found that the mean frequency of instructional leadership activity in both higherand lower-performing schools was lower in the high school group. The mean effect size for the overall influence of the principal or designee was 1.1 (large) in elementary schools compared to .42 in high schools. This suggested that strong oversight of teaching and the curriculum by school leaders had more impact in elementary than in high schools. Clearly, this was an area in which further research, using identical indicators across both higher- and lower-performing primary and secondary schools, was needed. The need for principals to increase instructional capacity was evident due to the reform emphasis on accountability. 
In another study of instructional leadership, Cheng (1994) found that principal behavior and roles were indirectly related to student outcomes. Cheng conducted a study to examine principal leadership in terms of the structural leadership, human leadership, political leadership, symbolic leadership, and educational leadership related to school performance. The latter was measured using organizational-level indicators, teacherlevel indictors, and student-level indicators. The sample was taken from the research project, Education Quality in Hong Kong Primary Schools, which included primary schools supported by the Hong Kong government. The average number of students in each of the schools was 825 . The average number of teachers in each school was 27 , with an average of 15 years of teaching experience.

The study design was a correlational research design. Two models were integrated, those of Sergiovanni (1984) and Bolman and Deal (1997). Sergiovanni outlined the following leadership forces: (a) technical leadership, (b) human leadership, (c) educational leadership, (d) symbolic leadership, and (e) cultural leadership, which “...can be thought of as the means available to administrators, supervisors, and teachers to bring about or preserve change needed to improve schooling" (Sergiovanni, p. 6). This five-leadership forces model explained how principal leadership connected to student outcomes. Bolman and Deal hypothesized that four leadership characteristics exist: (1) structural leadership, (2) human resource leadership, (3) political leadership, and (4) symbolic leadership. The two models described principal leadership by five dimensions: (1) structural leadership, (2) human leadership, (3) political leadership, (4) symbolic leadership, and (5) educational leadership. 
Pearson correlations showed a relationship between principal leadership and some of the measures of student performance. The dimensions of principal leadership positively correlated with student attitude toward their school. The stronger the dimensions of leadership (i.e., human, structural, political, symbolic, and education), the higher the levels of student commitment.

The researcher concluded the students in the strong-leadership schools displayed positive attitudes toward teachers, peers, learning, and positive self-concept. In contrast, students in the weak-leadership schools were lower on those outcomes. The student-level indicators included (a) student self-concept; (b) attitudes toward peers, teachers, the school, and learning; (c) perception of homework overload; and (d) dropout intention. Strong principal leadership correlated to positive performances in these areas.

Further substantiating the indirect effect of the principal on student outcomes were findings from a study conducted by Bulach and Lunenberg (1995). The researchers conducted a study to examine the influence of principal leadership style on climate and student achievement. They hypothesized that there would be no significant relationship between leadership style and school climate scores. They further hypothesized that there would be no significant difference in leadership style and student-achievement scores. The study design was causal-comparative. The sample consisted of elementary students $(N=2,834)$, teachers $(N=506)$, and principals $(N=506)$ in Kentucky elementary schools $(N=20)$. The school sample was non-random but was distributed among urban, suburban, and rural areas and included a variety of socioeconomic levels. School populations ranged from 93 to more than 700 students. The sample of educators was 
diverse in age, race, gender, experience, and education level. The student sample was diverse in age, ethnicity, gender, and socioeconomic level.

The researchers used measurement instruments from previous research studies and defined leadership style and school climate. The Leadership Behavioral Matrix (LBM) defined leadership style. In addition, the Tennessee School Climate Inventory (TSCI) and the Group Openness and Trust Scale (GOTS) operationally defined school climate. The operational definition for student achievement was the Normal Curve Equivalent (NCE) scores for a school building on the California Test of Basic Skills (CTBS). School achievement scores were obtained from the CTBS results. The researchers used the LBM to measure the leadership style of principals. The 26-item, Likert-type scale measured behavior patterns representing four quadrants: promoter, supporter, controller, and analyzer. The overall test-retest reliability for the LBM was .86. Validity of the LBM was supported by individual scores correlated with behavioral ratings made by colleagues. Researchers used the TSCI and the GOTS to measure school climate. The TSCI contained 49 Likert-type scale items assigned to the following subtests delineated by factor-analytic methods: (a) order; (b) leadership; (c) environment; (d) involvement; (e) instruction; (f) expectations; and (g) collaboration. Internal consistency of the TSCI was estimated by Cronbach's alpha, with an average correlation of $.80(p<.01)$. The GOTS consisted of 25 Likert-type scale items that measured the following factors: (a) trust, and (b) openness. The reliability of GOTS was reported as alpha coefficients of .91 for the total scale.

Bulach and Lunenberg (1995) concluded there were no statistically significant differences found in school climate as a result of the four principal leadership styles. 
This supported the null hypothesis. Analyses of variance were computed with the nine subscales from the TSCI and GOTS as dependent variables and four levels of leadership style as the independent variable. The only subscale that had a significant $F$ ratio ( $\mathrm{p}<$ $.05)$ was the involvement subscale. The definition of involvement was "the extent to which parents and community members were involved in the school."

Pounder, Ogawa, and Adams (1995) conducted a study to analyze the associations among organizational leadership; functions of effective organizations (i.e., goal achievement, consensus, adaptation, and cultural norms); and measures of school effectiveness (i.e., student achievement, school effectiveness, student absenteeism, and faculty turnover). Researchers selected the participants using a stratified random sample from diverse roles within a large suburban school district in the intermountain West Region of the United States. The researchers chose 25 individuals from each of the 60 schools ( 25 randomly selected middle and high schools and 35 randomly selected elementary schools). The researchers chose 1 administrator, 1 guidance counselor, 20 teachers, 2 secretaries, and 1 custodian from each school. Of the 60 schools surveyed, 57 returned enough questionnaires for validity purposes (school return rate $=95 \%$ ). Participant responses $(n=1,061)$ had a return rate of $71 \%$. The independent variable was school leadership, and the dependent variables were (a) functions of effective organizations and (b) measures of school effectiveness. The Organizational Control Questionnaire/Graph $(\alpha=.48)$; Index of Perceived Organizational Effectiveness $(\alpha=.76)$; Overall Job Satisfaction Questionnaire $(\alpha=.84)$; and Loyalty Questionnaire $(\alpha=.79)$ measured the dependent variables dealing with functions of effective organization. To gauge school effectiveness, the Stanford Achievement Test, student 
absenteeism, and staff turnover were measured. Researchers used path analysis to test the relationships among variables. Pounder et al. (1995) found cultural norms significantly related to effectiveness. Student achievement had significant positive links to goal achievement and community. Therefore, as principals involve all stakeholders in forming and focusing on goals, student achievement could be affected.

Hallinger and Heck (1996) reviewed 40 studies on the principal's role in school effectiveness throughout a 15-year period from 1980 to 1995 . The purpose of the review was to study the role and impact of the principal. Three criteria guided the selection of studies: (1) principal leadership must have been one of the independent variables, indicating that researchers designed the study to examine principal leadership behavior; (2) the dependent variable had to include a measure of school performance, indicating principal effect on student outcomes; and (3) researchers made an effort to review studies that were conducted outside of the United States. Only 11 of the 40 selected studies were conducted in countries other than the United States.

The researchers chose both qualitative and quantitative studies, although most were quantitative. Other methodological approaches were cross-sectional studies, correlation designs, and surveys or interviews. The researchers used the Pitner (1988) model for categorizing the principal-leadership studies. The categories included: (a) direct effects; (b) antecedent-effects; (c) mediated-effects; (d) reciprocal-effects; and (e) moderated-effects models.

For the purpose of this review, studies will be highlighted in which researchers discussed studies involving mediated effects with antecedent variables. These studies investigated the principal's role in school effectiveness, noting the principal's interactions 
with others within the school organization. Data indicated a statistically significant effect of principal leadership on school processes and, at least, indirectly on school achievement.

Hallinger and Heck (1996) concluded that the effects of principal leadership would occur indirectly through the principal's efforts to influence those who come into more frequent direct contact with students. The principal's ability to articulate school goals and share information directly affected teachers who had direct interaction with students. This finding supported data from the previous studies in this subsection that the principal effect on student outcomes was indirect. This indirect effect was the essence of leadership.

Reavis, Vinson, and Fox (1999) conducted a case study to investigate the role of the principal in the school culture. The school was a low-performing school with 257 students ( $80 \%$ non-Caucasian ethnicity) and a new principal recently in place. The researchers collected data through (a) open-ended teacher questionnaires; (b) school document analysis; (c) observations of student and teacher advisory group meetings; (d) shadowing of the principal; and (e) principal, assistant principal, and superintendent interviews. Researchers analyzed data through constant comparative analysis.

Reavis, Vinson, and Fox (1999) reported findings as these themes that emerged: (a) heroes and heroines, (b) rites and rituals, (c) stories, (d) governance and leadership, and (e) symbols. The findings revealed that the principal was democratic in interactions with teachers and students. Researchers held several meetings with teachers and students, and these meetings began with the principal's asking for suggestions. Decisionmaking and accepting leadership for those decisions became a regular and expected role 
of teachers as well as the principal. Teachers led the professional development activities and learned how to troubleshoot computer problems and assisted colleagues in computer applications.

At the end of the principal's first year, $87 \%$ of the sophomores passed the achievement test mandated by the state, in contrast to $38 \%$ the previous year. By the end of the second year, $93 \%$ of the sophomores passed the state-mandated test. The results of quantitative student outcomes indicated positive change within the school. The results established the principal as a collaborator between teacher and students. An environment in which each person's opinion was valued and open communication was present contributed to improved student outcomes at this school.

Van de Grift and Houtveen (1999) conducted a study to determine teacher perceptions of educational leadership of principals. Researchers attempted to determine if educational leadership in primary education changed between 1989 and 1993 and 1993 and 1998. Researchers also wanted to know if there were a relationship between educational leadership and the output of primary schools. The researchers collected data in three different projects carried out in 1989,1993 , and 1998, with the same instrument about the educational leadership of principals in primary education. The researchers collected data in 1989 from a select sample of primary schools $(N=500)$. The teachers working with children in Grade 5 or 7 and completed a questionnaire on the educational leadership of their principal. About 73 schools measured eighth-grade students with an achievement test on language, arithmetic, and information-processing. The researchers collected data in 1993 from a select sample of primary schools $(\mathrm{N}=386)$. In 383 schools, the teachers from Grade 7 prepared to complete a questionnaire about their 
principal's educational leadership. The results of the study indicated that in 1989 no significant relationship was found, the results of 1993 showed a significant relationship between educational leadership and average pupil achievement over three successive years, corrected for school environment.

Several studies were examined that in some way illustrated decentralization of accountability reform. Heck (1992) indicated the need for principals to increase instructional capacity due to the reform emphasis on accountability. Clift (1992) found that shared decision-making had to be intentional or otherwise it was unsuccessful. Unless planned, the decision-making reverted to a dysfunctional, top-down structure with little or no collaboration or communication among stakeholders. Cheng (1994) concluded that students in the strong-leadership schools displayed positive performances such as attitudes toward teachers, peers, learning, and self-concept. In contrast, students in the weak-leadership schools had negative performances. Researchers found a correlation between leadership and student performance. Bulach and Lunenberg (1995) concluded there were no statistically significant differences found in school climate as a result of principal-leadership styles. Pounder, Ogana, and Adams (1995) found cultural norms, significantly related to student achievement, had significant positive links to goal achievement and community influence. Therefore, as principals involve all stakeholders in forming and focusing on goals, student achievement could be affected. Hallinger and Heck (1996) concluded that the effects of principal leadership would occur indirectly through the principal's efforts to influence those who come into more frequent direct contact with students. Reavis, Vinson, and Fox (1999) established the principal as a collaborator between teacher and students. An environment in which each person's 
opinion was valued and open communication was present contributed to improved student outcomes. Van de Grift and Houtveen (1999) discovered there was a significant relationship between educational leadership and average pupil achievement over three successive years. The decentralization of accountability reform led to improving studentoutcomes reform.

\section{Improving Student Outcomes Reform}

The following subsection, "Improving Student Outcomes Reform," occurred in the late 1990 s. Its major policy assumption was that discretion be delegated to the states in determining the appropriate "mix" of accountability and support mechanisms in helping schools succeed, with all students being held to high academic performance standards. Since the late 1990 s, reformers have been strongly focused on the central task of improving student outcomes, a trend foreshadowed by the Kentucky Education Reform Act of 1990 and the National Commission on Excellence in Education 1983 report, “A Nation at Risk" (1983). The state-level accountability for improved student outcomes was ratcheted up to the national level with the No Child Left Behind Act of 2002, which mandated that all reform measures in some way must be connected to improved student outcomes, especially in schools historically characterized by poverty, single-parent families, and other correlates of low achievement. This press for student achievement was being driven primarily by the assumption that students who were better educated translated to a more-competent workforce, deemed necessary for the United States to remain economically competitive.

Okpala, Smith, and Ellis (2000) addressed areas where principals have the ability to impact class size and teacher experience. Okpala et al. (2000) examined the impact of 
selected educational resources and family/student demographics on student achievement. The participants in the study were fourth-grade students $(n=4256)$ from 42 public elementary schools in a North Carolina county. The study was conducted during the 1995-96 school year, and the participants were purposefully selected. The following questions guided the research: (a) Was there a significant relationship between selected school characteristics and reading and mathematics achievement; (b) was there a significant relationship between selected teacher characteristics and reading and mathematic achievement; and (c) was there a significant relationship between selected student and family demographics?

The research design was correlational. Researchers collected data by mining documents from state and county education offices. The following were independent variables: (a) class size and school size; (b) teachers' education and experience levels; (c) percentage of students on free or reduced-price lunch and percentage of students with parents who had post-secondary education; and (d) number of parental volunteer hours. The dependent variables were student-achievement levels on reading and mathematics achievement tests.

The results of the study were that (a) class and school size had statistically significant relationship with changes in reading scores, but not in mathematics scores; (b) the percentage of teachers with masters' degrees were significant in explaining mathematics-achievement changes, but not in reading score changes; (c) the percentage of teachers with ten or more years of experience had statistically significant positive relationship with reading and mathematics results; (d) the percentage of students on free or reduced-price lunch (inverse relationship) and those whose parents had post-secondary 
education (positive relationship) were statistically significant in explaining reading and mathematics score changes; and (e) the number of parental volunteers was not significant in explaining student achievement.

Implications of the study included the following: (a) the results continued to support the connections among school, student, and family demographic variables and student achievement; and (b) the results provided empirical support for policy decisions that provide students with experienced teachers. Further research was needed to include other variables such as teachers' certification levels and parental involvement in student education. More studies were needed to show the impact of a variety of educational resources in the classroom.

An example where research studies were used to identify characteristics of effective schools was conducted by Johnson, Livingston, Schwartz, and Slate (2000). They reviewed research studies and identified characteristics of effective schools. Researchers conducted an extensive search in textbooks, ERIC documents, and journal articles to select the studies.

Researchers examined the opinions and perceptions of teachers, parents, and administrators regarding effective schools. Pertinent to this review was the examination of the role of the principal. Johnson, Livingston, Schwartz, and Slate (2000) reported that Hallinger and Heck (1996) examined research conducted from 1980 through 1995 on the relationship between the principal and school effectiveness. They found that the most empirically robust models confirmed that principal leadership could be related to improved student outcomes through principal influence on student outcomes. In addition, when principals shared leadership with teachers, principals had an indirect 
effect on student achievement. Johnson et al., (2000) found evidence from research studies to support the theory that effective schools had effective leaders. The effects were indirect through internal school processes. This indirect effect was in agreement with the findings from Cheng (1994) and Heck, Larsen, and Marcoulides (1990). The next study by Williams (2000) provided more information about the principal role.

Williams (2000) conducted a study to compare teachers' perceptions of principal effectiveness in secondary schools nominated for the National Secondary School Recognition Program and a randomly selected sample of schools not nominated for the National Secondary School Recognition Program in Tennessee (TNSSRP). The central question was this: Did teachers in schools nominated for the National Secondary School Recognition Program in Tennessee have similar or different perceptions of principal effectiveness, compared to teacher perceptions in schools not nominated for the program? The population $(N=51)$ was comprised of secondary schools with Grades 9 to 12 , an enrollment of 1,000 or more students, and not nominated for the TNSSRP. Researchers used the TNSSRP record to identify schools $(N=22)$ with an enrollment of 1,000 or more in Grades 9 through 12.

The sample included randomly selected secondary schools $(N=20)$ not chosen for TNSSRP and randomly selected secondary schools $(N=20)$ that were chosen for the TNSSRP. Listing the schools in alphabetical order and then assigning each school a number identified the sample. Numbers were drawn from a table of random numbers that resulted in the school selection. The sample included TNSSRP-nominated secondary schools $(N=14)$ and schools not nominated for the TNSSRP $(N=12)$. The teacher 
population for the schools not chosen for TNSSRP was 1,288; likewise, the teacher population for TNSSRP nominated schools was 1,221.

This study was a causal-comparative design with organizational development, organizational environment, and educational program as independent variables and teacher perspectives of effective principals as the dependent variable. Data analysis included the distribution of the questionnaire, "Audit of Principal Effectiveness" (APE), which described teacher perceptions of principal effectiveness. The 80-item questionnaire focused on the role of the principal and included a Likert-type scale $(1=$ not effective, $9=$ very effective $)$. The three domains that evolved from the 80 items (i.e., organizational development, organizational environment, and educational programs) had a coefficient alpha reliability rate of $.92, .94$, and .97 , respectively. To test for group differences, the researchers used the $t$-test for independent samples. A high score implied a positive view of principal effectiveness.

The findings revealed that principals in secondary schools chosen for the TNSSRP scored significantly higher in organizational development, organizational directions, and organizational procedure than principals of randomly selected secondary schools not chosen in the area of organizational development. Scores of principals in TNSSRP-nominated secondary schools were significantly higher in student relationships, affective processes, and educational programs than the scores of principals from randomly selected schools. Instructional-improvement and curriculum-improvement scores of principals chosen for the TNSSRP were significantly higher than scores of principals of randomly selected secondary schools. 
Williams (2000) reported that the goal of the Secondary School Recognition Program was to recognize exemplary schools. It was not surprising that principals of TNSSRP-nominated schools were perceived as setting lofty goals and holding high expectations. Principals scoring higher in organizational development displayed abilities to work with teachers and to establish relationships that promoted growth. The findings from the next study added support to the principal role as collaborator and relationship builder. The next study also provided support for the positive effects of the principal working as a collaborator.

McLaughlin and Hyle (2001) conducted a study to investigate the role of the principal when implementing a particular change. The central research question was this: "How did the principal successfully facilitate the change process among faculty members?" The study design was a single-site case study. The site was an elementary school located in an upper middle class, urban school district. Researchers gathered data from (a) interviews with the principal, faculty, and staff; (b) observation of the principal at faculty and grade-level meetings; and (c) a review of documents (i.e., teacher memoranda, faculty agendas, and school handbook). Researchers cross-checked the data with data collected from a second interview of faculty and staff.

After processing and coding the data, two main categories emerged. The first category included summaries of successful change efforts. The second category included individual and principal roles along with factors that contributed to successful change. In the final analysis, the following findings were reported: (a) the principal was the key change agent in the change process; (b) the principal created a context for change; (c) no curricular change was identified, and the principal did not acknowledge varying levels of 
individual teacher concern; and (d) the characteristics of principal reflection were less evident than the practice of interacting with teachers.

McLaughlin and Hyle (2001) noted that teachers and staff concurred that the environment was that of encouragement and shared decision-making. The principal must model his/her expectations through frequent and open communication and informationsharing, while frequently conveying expectations of mutual respect and collaboration for all involved. They recommended that further studies could investigate how principals managed change through reflective practice since the structure of the school day did not encourage collaborative efforts. These findings established that the role of the principal has changed from a managerial role to a more relational role, one that can increase capacity through communication and respect.

In a study by Fullan (2002), it was noted that the principal is more than an instructional leader. The principal is also a developer of teacher skills and leadership capabilities. Fullan reviewed the role of the principal and identified instructional leadership as a quality that could improve student outcomes. To move students into more rigorous and challenging curricula, he stated that teachers must be motivated, inspired, and exposed to professional-development opportunities. The working conditions and the morale of teachers must be improved.

According to Fullan (2002), leaders must possess five essential components: (1) moral purpose, (2) an understanding of the change process, (3) the ability to improve relationships, (4) the capacity to create knowledge and share it, and (5) coherence. Moral understanding was defined as "the obligation to care about other schools and students as well as one's own." The researcher described an understanding of the change process as 
providing opportunities for teachers to seek out new instructional strategies and implement them within the school year. The most important component was that of improving relationships. Fullan stated: "If relationships improve, schools get better. If relationships remain the same or get worse, ground is lost" (p. 18). Fullan meant sustained improvement for several years, not just improvement for one year. He advocated that even teachers with fragmented relationships should be encouraged to make contributions to the learning community and be reconnected to colleagues.

Creating and sharing knowledge was the ability to lead action research and study groups, impart new knowledge, and encourage the discovery of innovative instructional strategies. The focus was on sustained change and not settling for a short-term solution. Fullan (2002) emphasized the importance of developing leaders at various levels (e.g., teachers) to create sustained growth. An organization cannot flourish, at least not for long, on the actions of the top leader alone. The qualities of leadership must extend to more than just the principal. The principal as instructional leader was once a limited role and now has broadened to one that creates change. The researcher renamed the role of the principal most appropriately to "change leader." The "change leader" valued teacher leaders and fostered the conditions necessary for increased capacity and sustained change.

In contrast with qualitative studies and articles dealing with suggestions to school principals, some large-scale quantitative studies have focused on the link between principal behavior and student achievement. For example, Witziers, Bosker, and Kruger (2003) conducted a meta-analytic study to determine the impact of the principal's leadership on student achievement. The study provided an international perspective on 
the status of the direct-effects model between 1986 and 1996. The studies selected for the meta-analysis met two criteria: (1) the study had to be designed to examine educational leadership, and (2) the study had to include explicit and valid measures of student achievement. A total of 37 studies were selected.

Witziers et al. (2003) used a multi-level quantitative meta-analysis to estimate the effect size of educational leadership on student achievement among multi-national research reports conducted between 1986 and 1996. Researchers estimated effect sizes regarding the following leadership behaviors: (a) defining and communicating mission, (b) supervising and evaluating the curriculum, (c) monitoring student progress, (d) coordinating and managing curriculum, (e) visibility, (f) promoting school improvement and professional development, and (g) achievement orientation. The results of the study indicated that, in general, the effect sizes were small. The correlations between leadership and student achievement were below .10, which indicated a minimal effect size, defined by Cohen's $d$ of .20. No more than $1 \%$ of the variation in student achievement is associated with differences in educational leadership. The leadership behavior "defining and communicating mission" had the largest effect size ranging from .30 to .38 . It should be noted, however, that previous research cited in this review established that principal effects on students are indirect rather than direct. The effects of principals are mediated by the effects of teachers.

Additional research on principal behaviors involved family variables. Leithwood and Jantzi (2000) conducted a study to replicate an earlier inquiry about the relative effects on students' engagement with school of principal and teacher sources of leadership, the organizational conditions mediating such leadership, and the effects on 
student engagement of family educational culture. The participants in the study were teachers $(N=1,818)$ with a $75 \%$ response rate and students $(N=6,490)$ with a $90 \%$ response rate.

Researchers used two survey instruments to collect data. Researchers used the Organizational Conditions and School Leadership Survey to collect data from teachers on school and classroom conditions and on sources of school leadership. This survey contained 228 items measuring five sets of school conditions, two sets of classroom conditions, and the extent to which leadership was believed to be provided from people in different roles. They were rated on a five-point Likert scale $(I=$ strongly disagree, $5=$ strongly agree). Researchers used the Student Engagement and Family Culture Survey containing 61 items to measure student participation in school activities (34 items); student identification with school (17 items); and students' perceptions of their family educational culture (10 items). Students responded to each item on the same five-point scale used by teachers.

Researchers aggregated individual responses by school and then calculated descriptive statistics and reliability coefficients using Cronbach's alpha. Researchers used factor analysis to analyze the seven school and classroom conditions. The factor analysis indicated the seven organizational conditions loaded on two factors: (1) school conditions and (2) classroom conditions. The following are the five school conditions: (1) information collection $(\alpha=.88)$; (2) culture $(\alpha=.89)$; (3) purposes and goals $(\alpha=$ $.95)$; (4) planning $(\alpha=.92)$; and (5) structure and organization $(\alpha=.89)$. The following are the two classroom conditions: (1) instructional services $(\alpha=.88)$ and (2) policy and 
procedures $(\alpha=.79)$. Researchers used structural-equation modeling to assess the direct and indirect effects of principal and teacher leadership on student engagement.

The correlation coefficients among all variables indicated school conditions were significantly related to all the other variables in the model, except family educational culture. Although the two leadership roles had significant relationships with classroom conditions $(\mathrm{r}=0.23)$, principal leadership had a stronger relationship with school conditions than did teacher leadership $(r=0.73$ vs. $r=0.48)$. Principal leadership had a significant relationship with identification $(r=0.25)$ and teacher leadership did not. The path model had an acceptable fit with the data and, as a whole, explained $70 \%$ of the variation in student participation and $56 \%$ of the variation in student identification.

A comparison of the results of the two studies by Leithwood and Jantzi (2000) indicated that in both studies (a) family educational culture explained a large proportion of variation in student engagement with school, somewhat more in the present than the original study; (b) increases in student identification with school (the affective dimension of engagement) were strongly associated with increases in students' participation in school (the behavioral dimension); and (c) there were significant direct effects of organizational conditions on student identification. The study suggested that the responsibility for those effects rested with school rather than classroom conditions. There were greater total effects on student identification by principal leadership compared with teacher leadership. Principal leadership had weak but significant effects on engagement in both studies. Principal and teacher leadership had significant influences on school conditions but not classroom conditions. 
A study examining school leadership styles and the role of leadership was conducted by DeMoss (2002). The researcher conducted a case study to examine school leadership styles and the role leadership played during the course of a decade in framing how schools would respond to the high-stakes testing environment. The case studies included Chicago schools $(N=8)$ among the lowest-performing schools in the system. Four of them would become high-performing schools. This sample aimed to provide a set of schools that afforded high comparability in student populations while maximizing differences in schools' achievement levels. Researchers selected the eight schools as matched pairs serving children from four neighborhoods. All schools served AfricanAmerican students and had $90 \%$ or higher free or reduced-price lunch rates. In each neighborhood pair, one school posted positive reading-gain score trends over eight years as measured on the Iowa Tests of Basic Skills. This placed the school among the city's top quartile of improvement. The other school in the pair ranked in the lowest quartile on gain scores. Researchers observed instruction in 56 kindergarten classrooms through sixth-grade classrooms across the eight sites, visiting each class during the fall and spring and interviewing teachers about their practices and about the school's instructional and improvement approaches after each visit, including how they had addressed test-score improvement. Data strongly suggested that the ways principals framed how their schools would respond to the testing environment was responsible for schools' test performance. The researchers provided contrasting cases of the relationship between leadership and testing in each of the four pairs of neighborhood schools, showcasing first the improved school and then the school with stagnant scores. 
Two high-achieving schools, Prospect and Morris, were successful in framing how their schools would respond to standardized testing by offering several viable policy approaches for systemic school improvement. First, the principals were committed to teachers' meaningful participation in instructional decisions. Second, principals led their schools, using a philosophy based on professionalism and empowerment. Third, curriculum improvements rather than test scores were the primary target for teachers' efforts, with the tests serving as a source of information by which teachers could gauge their instructional efforts.

The case studies provided four possible target areas for district policy to support principal development for effective leadership: (1) districts should provide materials for and guidance on test-preparation approaches; (2) where schools opt for scripted directinstruction (DI) approaches to provide foundational skills for students, districts should support the adoption of other more comprehensive additions to those curricula;

(3) districts should actively and vocally support principals' continued efforts to pursue holistic, complex improvement efforts, focused on instruction, even in the face of highstakes testing; and (4) districts should provide targeted, sustained professional development for acting school principals.

Researchers conducted a study to examine the potential of the principal's active collaboration around instructional matters to enhance the quality of teaching and student performance. The sample comprised nationally selected schools $(N=24)$, which included elementary schools $(n=8)$, middle schools $(n=8)$, and high schools $(n=8)$. Marks and Printy (2003) used pedagogical quality, assessment task, and academic achievement as dependent variables. Pedagogical quality was the sum of teachers' scores 
on two components of pedagogy: classroom instruction and assessment tasks.

Classroom instruction scores were the summed ratings for observed instruction on four dimensions of high-quality instruction: (1) teacher encouragement of higher-order thinking; (2) teacher encouragement of substantive conversation; (3) teacher use of depth-of-knowledge questioning strategies; and (4) teacher connections to the world beyond the classroom. Assessment-task scores were the sum ratings on seven indicators of authentic assessment: (1) organization of information, (2) consideration of alternatives, (3) disciplinary content, (4) disciplinary process, (5) elaborated written communication, (6) problem connected to the real world, and (7) audience beyond school. Academic achievement was a measure of authentic student performance, specifically, the sum of averaged student scores in mathematics and social studies on three indicators of intellectual quality: (1) analysis, (2) disciplinary concepts, and (3) elaborated written communication.

The researchers used measures of leadership, school demographic variables and control variables as the independent variables. The independent variable leadership consisted of two separate measures, transformational and instructional. The measurement of transformational leadership contained five items. These measured the principal's collaborative engagement in reform efforts (e.g., support for teachers and for new ideas). The measurement of instructional leadership contained nine component items that came from the coding. These measured things like the degree of instructional leadership coming from the principal and from teachers. The school demographic variables included number of students in elementary, middle, and high schools; percentage of free/reduced-price lunch, percentage of African-American, percentage of Hispanic 
students; and achievement on the National Assessment of Educational Progress (NAEP).

The control variables included classroom compositional measures: percentage female, percentage African-American, percentage Hispanic, average SES, and average NAEP achievement when the dependent variable was pedagogical quality. The control variables accounted for student background characteristics when the dependent variable was student achievement.

The researchers used one-way analysis of variance (ANOVA) to compare means for the schools on their demographic, organizational, and performance characteristics according to the categorical measure of school leadership. Given that the data were a nested structure (e.g., teachers in schools, classrooms in schools, and students in classrooms in schools), the researchers used two-level and three-level Hierarchical Linear Modeling (HLM) to investigate the effect of school leadership on the two dependent variables-pedagogical quality and student achievement. The primary interest for the researchers was the effect of leadership as a school-level predictor in accounting for variance in dependent variables, while controlling at the individual level for teacher or student characteristics that could affect the outcome independently of the contribution of leadership. The study demonstrated the effectiveness of integrated leadership-both transformational and instructional-in eliciting the instructional leadership of teachers for improving school performance. The higher the school leadership variables, the higher were the scores on the dependent-variables pedagogical quality-assessment task and academic achievement. When the principal elicited high levels of commitment and professionalism from teachers and worked interactively with teachers in a shared 
instructional leadership capacity, schools had the benefit of integrated leadership; they were organizations that learned and performed at high levels.

Researchers conducted a study to identify significant relationships between principals' instructional leadership behaviors and student achievement. The participants in the study were middle-level educators $(N=325)$, including principals $(n=75)$ and eighth-grade English and mathematics teachers $(n=250)$. O'Donnell and White (2005) used principal and teacher responses to the Principal Instructional Management Rating Scale (PIMRS). The instrument assessed three dimensions of a principal's instructional leadership role: (1) defining the school mission, (2) managing the instructional program, and (3) promoting the school learning climate. Researchers used the PIMRS to measure faculty and principal perceptions regarding the frequency of instructional leadership behaviors exhibited by principals. The PIMRS was a behavior-anchored rating scale that required respondents to identify the frequency with which the principal performed 50 specific instructional leadership behaviors. The PIMRS provided information related to the frequency of performance of instructional leadership behaviors, but the instrument did not assess the quality performance of the behaviors. The dependent variable for the study was student achievement derived from the eighth-grade reading and mathematics components of the 2000-2001 Pennsylvania System of School Assessment (PSSA).

Researchers analyzed the results from principal-completed PIMRS surveys separately from the teacher-completed surveys. Although multivariate regression analyses identified that neither principal nor teacher ratings produced significant findings with regard to student achievement, researchers calculated zero-order Pearson correlation coefficients to investigate both principal and teacher ratings with regard to student 
achievement. The teacher ratings of principals identified each of the three leadership dimensions as having significant positive relationships with both mathematics and reading achievement. Promoting the school learning climate was the variable with the strongest relationship to both types of assessment scores $(p<.01)$. The findings indicated that higher teacher perceptions of principal instructional-leadership behaviors related to higher student achievement.

The researchers also investigated the relationship between teacher-perceived ratings of principals' behaviors and principals' self-ratings with regard to predicting student achievement. Researchers identified teacher ratings of the leadership dimensionpromoting the school learning climate-as a significant predictor of both PSSA mathematics and reading scores $(p<.05)$. Teacher perceptions of principals' efforts to promote the school learning climate had the largest explanatory power for predicting mathematics and reading scores. When using a similar analysis of principals' selfratings, the researchers did not find significant effects.

The authors investigated interaction effects. They found that for high-SES schools with $0 \%$ to $33 \%$ of students receiving free or reduced-price meals, the link between the variable defining the mission and reading achievement was positive. However, middle- and low-SES schools did not have positive relationships between defining the mission and student-achievement scores. This study included a very low number of respondent schools with low-SES percentages. Due to this limitation, this study's researchers recommended a more in-depth investigation of low-SES schools.

Researchers investigated the significant relationship that existed between principal quality and student achievement. The participants in the study were principals 
in high schools $(n=44)$, primary schools $(n=5)$, elementary schools $(n=61)$, and middle schools $(n=50)$. Principals were randomly selected from Virginia's public schools. Kaplan, Owings, and Nunnery (2005) used the state achievement-test data for each principal's school to measure the dependent variable of student achievement. The test was the Virginia Standards of Learning (SOL) test used as the assessment of student progress required by the No Child Left Behind Act in Grades 3, 5, 8, and high school end-of-course exams. The independent variable was principal quality as rated by the superintendent. Interrater reliability estimates were obtained for each item for the 62 high schools for which ratings were available, from both direct supervisors and a second district-level administrator. Researchers averaged these two scores. A factor analysis of individual item scores was performed to generate a composite principal-quality score for each school, which accounted for $77 \%$ of the variance in the rubric scores. Kaplan et al. grouped principals into four quartiles based on this composite score (the $1^{\text {st }}$ quartile being highest and the $4^{\text {th }}$ quartile being lowest). Researchers generated a single school-level achievement score for each year by combining the percentage of students passing SOL tests in each subject area. The composite school-level achievement score accounted for between $89.9 \%$ and $94.3 \%$ of the variance in school-level achievement across SOL tests in different subject areas. The single variable used to represent school-level achievement was expressed in terms of $z$-scores. Researchers expressed differences between groups in standard deviation units.

A one-way analysis of variance (ANOVA) compared the mean percentage of students eligible for free or reduced-price meals across levels of principal quality. Researchers performed repeated-measures analyses to examine the relationship between 
principal quality and school-level achievement, controlling for the percentage of students eligible for free or reduced-price meals. For Grades 3, 5, and 8, principal quality quartiles were used as the independent variables. For end-of-course (high school), the researchers compared the upper two quartiles to the lower two quartiles because a small number of schools reported end-of-course test results in all subject areas and few schools offered courses in every subject area tested.

The ANOVA revealed a significant relationship between principal quality and school poverty $(\mathrm{p}<.001)$. Post-hoc tests using Scheffe's procedure indicated that the mean percentage of children eligible for free or reduced-price meals was significantly higher in schools served by principals in $4^{\text {th }}$ quartile of principal quality (lowest) than in schools served by principals in the $3^{\text {rd }}, 2^{\text {nd }}$, or $1^{\text {st }}$ quartiles. The simple correlation between principal quality-factor scores and the percentage of students eligible for free or reduced-price meals was -.57 , indicating that approximately $33 \%$ of the variance in principal quality was attributable to the poverty level of the school, with higher poverty schools tending to have principals with lower principal-quality ratings.

Researchers also used repeated-measures ANOVA. For third grade, there was a significant main effect for principal quality quartile on student achievement, and a significant interaction between principal quality and school-level achievement. Schools with principals in the upper three quartiles on the quality indicator had higher mean school-level achievement than those with principals in the lower quartile, while the interaction effect was attributable to above-trend increases in the two upper quartiles and a below-trend decrease in the bottom quartile. At fifth grade, there was a significant main effect for principal-quality quartile. Researchers observed no interaction effects. 
Follow-up tests indicated that after controlling for percentage of students eligible for free or reduced-price lunch and 1998 school-level achievement, schools with principals rated in the $4^{\text {th }}$ quartile had significantly lower achievement in 2002 than schools with principals in the $1^{\text {st }}, 2^{\text {nd }}$, or $3^{\text {rd }}$ quartiles. At eighth grade, the main effect for quality was not significant, and no interaction effects were observed. Similarly, researchers observed no main or interaction effects for principal quality on the end-of-course composite achievement scores.

Results found that principals who rated higher on school-leadership standards had schools with higher student achievement than comparable schools headed by lower-rated principals. Principal quality linked statistically and practically to student achievement. Interstate School Leaders' Licensure Consortium (ISLLC) standards, translated into a rubric of actual workplace behaviors, described how effective principals worked. Principals used the data to improve their own performance as instructional leaders as they attempted to increase their schools' teaching quality and raise their students' achievement.

The following study examined the relationship between the principal's role in the implementation of effective reading programs and the reading achievement of first-grade students. Nettles and Petscher (2007) studied the direct effects of school principals on achievement in Florida schools receiving federal Reading First grants. Data used in this study to address the research questions and hypotheses consisted of the following: (a) 388 Reading First principal responses to the Principal Implementation Questionnaire (PIQ), a validated instrument used to measure the levels of reading-program implementation in Reading First schools; and (b) the student reading achievement of more than 34,000 first- 
grade students as measured by the four quarterly Dynamic Indicators of Basic Early Literacy Skills Oral Reading Fluency (ORF) assessments of the 2004-2005 academic year. In this study, researchers used a three-level Hierarchical Linear Modeling (HLM) growth-curve model to determine the amount of student-level variance in achievement that could be explained by the five dimensions measured by the PIQ. The instrument included five dimensions that assessed the quality of principal implementation of effective reading programs. Researchers retained four dimensions for analysis (Professional Development, Leadership, Assessment, and Intervention). Level-one of this model tested the growth of ORF scores over time for each of the four assessments at the individual level. Level-two of this model selected student-level variables, including gender; socioeconomic status--as determined by free and reduced-price lunch eligibility-ethnicity; whether students had limited English proficiency, and disability status. Level Three modeled variables associated with the principal. Specifically, researchers used principals' responses on the dimensions of the PIQ to define and categorize principal behavior in relation to the implementation of effective reading programs.

At the conclusion of this study, Nettles and Petscher (2007) identified some significant relationships between the implementation practices of Florida Reading First principals and student reading achievement. Specifically, increased principal implementation of effective reading-intervention practices resulted in the overall population of students gaining five additional words per minute on the dynamic Indicators of Basic Early Literacy Skills ORF subtest. Increased principal implementation of effective assessment practices showed an increase of the ORF scores for the overall population of an additional three words per minute over the school year 
and accounted for students' acquiring fluency at an accelerated rate. Researchers found other significant relationships among student subgroups, including students with disabilities and students with limited English proficiency. Because these results were cumulative, the combination of increased principal implementation across several areas showed significant practical importance for the students of this sample.

Researchers conducted a qualitative study to investigate what students perceive principals do to influence their academic achievement. The participants were eighthgrade students $(N=30)$ who attended three different middle schools in three different districts. Gentilucci and Muto (2007) used a form of stratified sampling to select one school from each district, based on its similarities with its host district. The researchers chose purposeful sampling to ensure the findings represented the perspectives of key demographic subpopulations in the respective districts. Researchers used lists of students attending each school and used a table of random numbers to randomly select the participants.

Researchers used an ethnographic data-collection methodology known as respondent-driven interviewing to gather information about students' perceptions of principal behavior and its influence on students' academic achievement. Researchers interviewed students in randomly selected pairs at their respective school sites. Each interview was audio-taped for later transcription. Researchers used an open-coding methodology to fracture the data into vignettes about principal behavior. Gentilucci and Muto (2007) used axial coding to reassemble data into a set of interrelated themes and conceptual categories to provide a more detailed explanation of how students perceived the relationship between school principals and student learning. Researchers coded 
transcripts independently and then cross-checked each other's codes, themes, and conceptual categories to ensure the reliability and consistency of the analytical process. According to the researchers, the students' perceptions of their current and former principals' instructional-leadership behavior gave important details to the researchers. Despite the fact that the districts, schools, and student populations varied, based on ethnicity, socioeconomic status, and student achievement, student comments were very similar. Researchers indicated that if principals engaged in certain student and instructionally focused behaviors, students believed effective principals can directly influence academic achievement. Students indicated that less effective principal behaviors focused on issues such as: (a) enforcing the dress code, (b) making routine announcements, (c) talking with teachers, and (d) conducting a large number of meetings. According to the authors, the participants identified direct and highly influential instructional leadership behaviors as: (a) principal approachability, (b) interactive classroom observation and/or visitation, and (c) instructional leadership behaviors that firmly established administrators as the "principal teachers" in their respective schools.

Researchers investigated how various accountability contexts, including states, local boards, districts, school-site councils, parent associations, and teachers affected the ability of principals to influence instructional and supervisory decisions in their schools. States varied in the control they exerted on school leaders in the areas of instruction and supervision (Council of Chief State School Officers, 2003). Therefore, the researchers examined the differences across states that exercised low, moderate, and high levels of control of instruction and supervision. A low-control state gave the principal more freedom to make leadership decisions in instruction and supervision. Marks and Nance 
(2007) collected data for analysis from the 1999 to 2000 Schools and Staffing Survey responses of elementary, middle, and high school principals $(N=8524)$ in low-, moderate-, and high-control states.

The dependent variables in the study were principals' perceptions of their influence on curriculum/instruction and supervision. The researchers used a five-point Likert-type scale to answer the question: How much actual influence did you think each group or person had on decisions concerning instruction and supervision? The independent variables were the following groups whose influence principals had to rate: (a) state department of education, (b) local school board, (c) school district staff, (d) principal, (e) teachers, (f) school-site council, and (g) parent associations. The curriculum and instruction factor contained three component measures: (1) setting student-performance standards for students of this school; (2) establishing curriculum at this school; and (3) determining the content of in-service, professional development for teachers in this school. The supervisory factor included four component measures: (1) evaluating teachers in this school; (2) hiring new full-time teachers at this school; (3) setting discipline policy at this school; and (4) deciding how your school budget will be spent. Principals rated their perceptions of the various other policy actors' actual influence on school curriculum and instruction decisions on a five-point Likert-type scale for each of those three component measures $(1=$ no influence to $5=$ great deal of influence). Cronbach's alpha was the following: (a) state agencies, .61; local school boards, .75; school district staffs, .72; local school councils, .74; parent associations, .72; and teachers, .85 . 
The researchers examined variation in principal influence within and between states; the study used hierarchical linear modeling as its primary analytic technique. The results indicated that the various accountability contexts differentially affected principals' influence, which also varied by domain, extent of state control, and region. Principals' influence in both the supervisory and instructional domains was strongly related to that of teachers' active participation in decision making, suggesting the benefits of mutuality in school leadership.

Zigarelli (1996) conducted a study to examine the effects of six effective school variables on student achievement with data from the National Education Longitudinal Study of 1988 (NELS 88). The Department of Education developed a survey in conjunction with the National Opinion Research Center and the Educational Testing Service, administered to a panel of eighth-grade students $(N=24,599)$ during the base year in 1988, with follow-up surveys to the same students in 1990 and 1992 during the students' tenth- and twelfth-grade years, respectively. However, there was only information available for all three years of the study for 16,842 students. This study included public and private schools $(N=1,296)$. The National Opinion Research Center conducted most of the hour-long surveys in school, soliciting information on student background, language use, home environment, perceptions of self, plans for the future, jobs and household chores, school activities, work, and social activities.

The regressor variables used in multiple regression analysis were the following: (a) school culture, (b) principal influence, (c) school relations, (d) teacher influence, (e) teacher satisfaction, and (f) parent involvement. The Department of Education used questionnaires for parents, principals, and teachers as part of the NELS 88 to measure the 
regressor variables. The dependent variable was student achievement, measured by the student's score on the twelfth-grade battery of examinations. Students completed achievement tests that measured reading comprehension, mathematics, science, and history/geography. The researcher established six constructs and correlated each of them independently with student achievement. The linear regression analysis $\left(R^{2}=0.74\right)$ of the data indicated three characteristics that were most important to effective schools: (1) an achievement-oriented school culture; (2) the ability of the principal to hire and fire teachers; and (3) high teacher morale.

Researchers explored the nature and extent of the school principal's effects on reading achievement. The study included purposefully selected elementary schools $(N=$ 87) in the state of Tennessee. Consistent with Hallinger's, Bickman's, and Davis's (1996) conceptualization of the principal's role in school effectiveness, they used teacher and principal questionnaires and a criterion-referenced reading test to collect data on (a) context factors, (b) personal characteristics of the principal, (c) measures of principal leadership, (d) in-school organizational variables, and (e) student achievement.

School administrators in all schools completed a School Information Form. This instrument enabled the researchers to collect contextual and demographic information on each school and included several SES measures. Parent involvement was measured using a 13-item scale derived from the Connecticut School Effectiveness Questionnaire (CSEQ). The scale assessed the nature and extent of parent involvement in the school. In the first and third years of the study, principals and teachers completed questionnaires. Areas of inquiry included the following: (a) factors associated with effective schools; 
(b) organizational variables hypothesized to be related to student performance; (c) faculty attitudes toward their own ability to improve student performance; (d) the valence of various incentives to school personnel; and (e) selected contextual variables potentially affecting faculty effectiveness. The CSEQ served as the source for 72 of the approximately 275 items on the questionnaire. The measures of instructional climate were (a) schools' mission statement, (b) time on task, and (c) parental involvement, derived from the CSEQ. The expectations scale was drawn from the School Structure and Climate Study as well as from the CSEQ. Researchers measured instructional organization with a dichotomous item $(0=$ did not group within grade by achievement, $1=$ did use such grouping). The achievement measure used in the study was a criterionreferenced reading test designed by the Tennessee State Department of Education in cooperation with project staff. Schools administered these tests to third- and sixth-grade students in both the fall and spring of the 1984-85 academic year. Researchers used the fall scores as a pre-test; spring scores served as a post-test. Researchers tested the operationalized model using a structural modeling program. Estimation proceeded in several steps consistent with the researchers' interest in examining several possible models of principal effects.

The results supported the belief that a principal could have an indirect effect on school effectiveness through actions that shaped the school's learning climate. The researchers also found that principal leadership itself was influenced by both personal and contextual variables. The study confirmed the appropriateness of viewing the principal's role in school effectiveness through a conceptual framework that placed the principal's 
leadership behavior in the context of the school organization and its environment, and that assesses leadership effects on student achievement through mediating variables.

\section{Summary}

This study has reviewed a number of research projects that have dealt with the improvement of student outcomes. In many studies, school-principal behavior or schoolleadership factors were predictor variables. Okpala, Smith, and Ellis (2000) suggested that class, school size, percentage of teachers with a master's degree, percentage of teachers with ten or more years experience, the percentage of students on free or reducedprice lunch, and the percentage of students with parents who had post-secondary education were statistically significant in influencing student achievement. Johnson, Livingston, Schwartz, and Slate (2000) supported the theory that effective schools had effective leaders. Williams (2000) found that instructional-improvement and curriculumimprovement scores of principals chosen for the Tennessee National Secondary School Recognition Program (TNSSRP) were significantly higher than scores of principals of randomly selected secondary schools. McLaughlin and Hyle (2001) established that the role of the principal changed from a managerial role to a more relational role, one that increased capacity through communication and respect. Fullan (2002) stressed the role of the principal as a developer of teacher skills and leadership capabilities. Witziers, Bosker, and Kruger (2003) indicated the correlations between leadership and student achievement indicated no more than $1 \%$ of the variation in student achievement was associated with differences in educational leadership. Leithwood and Jantzi (2000) and Demoss (2002) suggested that the ways principals framed how their schools would respond to the testing environment was responsible for schools' test performance. Marks 
and Printy (2003) discovered that when the principal elicited high levels of commitment and professionalism from teachers and worked interactively with teachers in a shared instructional-leadership capacity, schools had the benefit of integrated leadership; they were organizations that learned and performed at high levels. O'Donnell and White (2005) discovered that teacher perceptions of principals' efforts to promote the schoollearning climate had the largest explanatory power for predicting mathematics and reading scores. Kaplan, Owings, and Nunnery (2005) found that principals who rated higher on school-leadership standards had schools with higher student achievement than comparable schools headed by lower-rated principals. Principal quality was linked statistically and practically to student achievement. Nettles and Petscher (2007) identified significant relationships between the implementation practices of Florida Reading First principals and student-reading achievement. Gentilucci and Muto (2007) identified direct and highly influential instructional leadership behaviors as (a) principal approachability, (b) interactive classroom observation and/or visitation, and (c) instructional leadership behaviors that established administrators as the "principal teachers" in their respective schools. Marks and Nance (2007) discovered that principals' influence, in both the supervisory and instructional domains, was strongly related to that of teachers' active participation in decision-making, suggesting the benefits of mutuality in school leadership. Zigarelli (1996) indicated three characteristics that were most important to effective schools: (1) an achievement-oriented school culture; (2) the ability of the principal to hire and fire teachers; and (3) high teacher morale. Hallinger, Bickman, and Davis (1996) supported the belief that a principal can have an indirect effect on school effectiveness through actions that shape the school's learning climate. 
The researchers also found that principal leadership itself is influenced by both personal and contextual variables. The study confirmed the appropriateness of viewing the principal's role in school effectiveness through a conceptual framework that places the principal's leadership behavior in the context of the school organization and its environment and that assesses leadership effects on student achievement through mediating variables.

\section{Teacher's Perception of Leadership Behavior}

Principals directly affect the school climate, which affects teachers' attitudes. In turn, the teachers' perceptions of the principals' leadership behaviors affect the principal's leadership behaviors and decision-making strategies. As principals demonstrate leadership behaviors, they must be aware of the impact their leadership behaviors have on teachers' behaviors and perceptions. Democratic governance is a leadership style that can be very effective for principals. Principals should share leadership by delegating some of their decision-making responsibilities to teachers. This promotes buy-in from teachers and enhances their relationship with the principal. In addition, it produces a trustworthy and collaborative environment (Patton, 2006). Shreeve et al. (1984) declared that when teachers are involved in the process of school decision-making; this process enhances teachers' leadership position, morale, motivation' and job satisfaction in their respective schools. According to Collinson, Cook, and Conley (2005), conditions which harvest organizational learning in schools are encouraging democratic governance and orchestrating the sharing of knowledge. Argyris and Schon (1996) stated that inquiry is necessary for organizational learning. Inquiry, 
accompanied with sharing knowledge, learning, and collaboration, is a part of democratic governance (Rosenholtz, 1999).

According to several researchers, (Cochran-Smith, 2006; Ingersoll, 2003; Russell, 2006; Williams, 2007) teacher-retention rates increase when campus leaders facilitate teacher growth and involve teachers in matters that affect their teaching practices. Sheppard (1996) found positive relationships existed between the instructional leadership behaviors of principals and teachers. These behaviors were directly related to teaching and learning, and professional involvement, and the researcher described them as "the degree to which teachers are concerned about their work, are keen to learn from one another, and are committed to professional development" (p. 335). Sheppard's synthesis of existing studies showed a positive and strong relationship existed between effective instructional-leadership behaviors exhibited by principals and teacher commitment, professional involvement, and innovativeness. Fullan and Stiegelbauer (1991) suggest that attending to teacher interaction and collaboration are essential for learning and change. Rosenholtz's (1989) research on teachers' workplace and teacher quality indicated if teachers felt supported in their own learning, as well as in the classroom, they demonstrated greater efficacy in meeting students' needs. Her research showed that collegiality, networks, and added professional roles increased teacher effectiveness. The importance of social relations in schools has been widely accepted as a critical component to school improvement (Bossert, 1988, Purkey \& Smith, 1983; Rosenholtz, 1989).

Perceptions that a teacher has of the school climate inevitably influences how the teacher views the principal's leadership behaviors. Teachers, through their perceptions of 
school climate, can directly impact the school in terms of the accomplishment of building goals, student achievement and the overall success of the organization. According to Barth (1993), many researchers concluded that teachers' perceptions of climate were closely associated with the principals' leadership style. Lee, Dedrick, and Smith (1991) showed results of perceptions of teachers on the principals' leadership style aligned with Chittom and Sistrunk (1990) who reported a positive association existed between teachers' perceptions of principals' leadership style and teachers' perceptions of school climate. It was noted that if teachers were dissatisfied with the climate of the school, they were also dissatisfied with the principals' leadership style. The school climate, as perceived by teachers, influences the atmosphere for learning within the school. The climate within a school is often an expression of the relationship between the leader and other staff members, because principals are leaders and their behavior influences the way teachers feel about the job, their respective assignments, the students, and their own personal well-being. Teachers develop a subjective perception of how principals influence their own perceptions. According to Jorde-Bloom (1988), perceptions of workers are subjectively formed through personal filters as their role in the organization becomes involved. This may influence teacher attitudes regarding the school climate and the outcome of the school's purpose. Principals influence the conditions in which teachers work; thus, they have an effect on school climate because of their ability to influence teachers' perceptions. Richards (2007) asserted the values and behaviors of principals' influence on how teachers' value principals.

In addition, the researcher conducted a study in which she reported how 150 teachers ranked 22 positive behaviors of principals toward teachers. Seventy five of the 
150 teachers had six to ten years of teaching experience, and 75 had more than ten years of teaching experience. The findings from the study indicated that both groups ranked the following as the top five behaviors that influence teacher moral and stability: (1) respects and values teachers as professionals; (2) supports teachers in matters of student discipline; (3) has an open-door policy; (4) is fair, honest, and trustworthy; and (5) supports teachers with parents. The findings from Richard's study support findings from an earlier study conducted by Harris (2000). Harris conducted a quantitative study to examine teachers' perceptions about the behaviors of principals they valued. Using a survey, data were collected from 123 teachers who were enrolled in a university principal-preparation program. The findings revealed that teachers valued three types of principal behaviors: (1) empowering (23\%); (2) supporting (36\%); and (3) communicating $(41 \%)$. The findings further suggested that praising is less important than treating teachers professionaily, demonstrating support, and having an open-door policy. According to Richards (2007), principals can benefit from knowing which of their behaviors or attitudes are most valued by teachers. According to Hersey, Blanchard, and Johnson (1986), the more leaders can adapt their leadership behaviors to the given situation, the more effective they will be in influencing members of the organization. Combs, Miser, and Whitaker (1999) emphasized that educational leaders must learn empathy in order to understand why people behave as they do. "A Nation at Risk" specifically recommended strong leadership as a means for school improvement. Exploring the teachers' perceptions of their principals' leadership behavior better equips present and future principals with the tools to create a school climate conducive to improving student achievement (Smith, 1996). Lindse, Roberts, and Campbell (2005), 
indicated competent school leaders understand that effective leadership focuses on changing the manner in which school leaders work with others. "Leading effectively in a diverse environment requires that school leaders examine their own values, behaviors, policies and practices of the school in order to facilitate organizational change within the school" (p. 79).

\section{Development of the Audit of Principal Effectiveness}

Valentine and Bowman (1988), through extensive review of the literature and research relative to the role of the principal, initially identified 162 items under 12 constructs that were divided into two instruments. These were mailed to a national sample of 3,660 teachers (proportional over seven regions equally divided into elementary, middle, and high school levels) during the 1983-84 school year. Teachers were asked to rank-order the importance of each item as it related to the effectiveness of principals. The 926 responses were factor-analyzed, identifying 9 factors of 110 items for further study. Teacher perceptions of principal-leadership effectiveness formed the perceptive base for validation of the instrument and the database for item and factor analysis.

To further refine the instrument and provide for construct validity, during the 1984-85 school year a national random sample of 3,300 teachers (proportional over seven regions equally divided into elementary, middle, and high school levels) were sent the refined 110-item survey and asked to rank-order the items as they pertained to principal effectiveness. Factor analysis of the 587 usable returned instruments yielded six factors; however, the first two factors contained 26 and 16 items and lacked the desired clarity of description of the roles of principals. The six factors and related items were combined 
along a conceptual framework into three "domains." These domains were factor-analyzed using varimax orthogonal rotation with iteration and produced nine concise factors describing the roles and necessary skills required of effective principals.

Reliability was indicated by the following: organizational development had a coefficient alpha of .9253; organizational environment had a coefficient alpha of .9443; and educational program had a coefficient alpha of .8894 . Total instrument reliability showed a coefficient alpha of .9698. The three "domains" described above represent the major focus used in the development of the survey instrument. However, each domain can be used as a separate instrument for depicting a major area of responsibility of the principalship (Valentine \& Bowman, 1984).

Subsequent Research Using the Audit of Principal Effectiveness

Valentine and Bowman (1990) used the Audit of Principal Effectiveness as the instrument to compare teacher perceptions of principal-leadership effectiveness between schools selected for the United States Department of Education's School Recognition Program and a random sample of schools across the nation. The research findings were consistent in some areas and contradictory in others. Elementary school principals scored higher as a group than did middle school or high school principals. However, analysis of scores for the nine factors of the "Audit of Principal Effectiveness" showed statistically significant differences between grade levels. Elementary and middle school principals scored higher on organizational direction, organizational linkage, and interactive processes than on organizational procedures, teacher relations, and affective processes. At the high school level, teachers rated principals significantly higher on organizational direction and interactive processes than the other factors. Principals in both the 
recognized schools and the randomly selected schools were rated higher or lower on the same factors with one exception. There was a statistically significant difference in the teacher ratings between the recognized schools and the randomly selected schools on all factors other than student relations. The researchers concluded that the pattern of differences between the teacher perceptions of principal effectiveness supported the belief that more effective schools were administered by more effective principals. A similar study by Williams (2000) provided more data on the "Audit of Principal Effectiveness."

Williams (2000) conducted a study to compare teachers' perceptions of principal effectiveness in secondary schools nominated for the National Secondary School Recognition Program and a randomly selected sample of schools not nominated for the National Secondary School Recognition Program in Tennessee. The following was the central question: Did teachers in schools nominated for the National Secondary School Recognition Program in Tennessee have similar or different perceptions of principal effectiveness, compared to teacher perceptions in schools not nominated for the program? The population $(N=51)$ was comprised of secondary schools with Grades 9 to 12 , an enrollment of 1,000 or more students, and not nominated for the National Secondary School Recognition Program in Tennessee (TNSSRP). Researchers used the TNSSRP record to identify schools $(N=22)$ with an enrollment of 1,000 or more in Grades 9 through 12.

The sample included randomly selected secondary schools $(N=20)$ not chosen for TNSSRP and randomiy selected secondary schools $(N=20)$ that were chosen for the TNSSRP. Listing the schools in alphabetical order and then assigning each school a 
number identified the sample. Numbers were drawn from a table of random numbers that resulted in the school selection. The sample included TNSSRP-nominated secondary schools $(N=14)$ and schools not nominated for the TNSSRP $(N=12)$. The teacher population for the schools not chosen for TNSSRP was 1,288; likewise, the teacher population for TNSSRP-nominated schools was 1,221.

This study was a causal-comparative design with organizational development, organizational environment, and educational program as independent variables and with teacher perspectives of ef ̌̃ective principals as the dependent variable. Data analysis included the distribution of the questionnaire, "Audit of Principal Effectiveness" (APE), which described teacher perceptions of principal effectiveness. The 80 -item questionnaire focused on the role of the principal and included a Likert type scale $(1=$ not effective, $9=$ very effective $)$. The three domains (i.e., organizational development, organizational environment, and educational programs) that evolved from the 80 items had a coefficient alpha reliability rate of $.92, .94$, and .97 , respectively. To test for group differences, the researchers used the $t$-test for independent samples. A high score implied a positive view of principal effectiveness.

The findings revealed that principals in secondary schools chosen for the TNSSRP scored significantly higher in organizational development, organizational directions, and organizational procedure than principals of randomly selected secondary schools not chosen in the area of organizational development. Scores of principals in TNSSRP-nominated secondary schools were significantly higher in student relationships, affective processes, and educational programs than the scores of principals from randomly selected schools. Instructional-improvement and curriculum-improvement 
scores of principals chosen for the TNSSRP were significantly higher than scores of principals of randomly selected secondary schools.

Williams (2000) reported that the goal of the National Secondary School Recognition Program was to recognize exemplary schools. Not surprising was the fact that principals of TNSSRP-nominated schools were perceived as setting lofty goals and holding high expectations. Principals scoring higher in organizational development displayed abilities to work with teachers and to establish relationships that promoted growth.

In summary, the "Audit of Principal Effectiveness" was the instrument used in two large studies investigating teachers' perceptions of principal effectiveness. Valentine and Bowman (1990) used the instrument to compare principal effectiveness between schools designated by the United States Department of Education as having outstanding educational programs and a random sample of schools across the nation used as a control group. A similar study conducted by Williams looked at principal effectiveness between a randomly selected group of secondary schools and a group of schools identified as having outstanding educational programs within the state. Not surprisingly, they found that teachers in the schools recognized as outstanding rated their principals significantly higher on sections of the "Audit of Principal Effectiveness" than teachers in the control groups.

\section{Contribution to Research}

Previous studies have focused on schools identified as having outstanding educational programs. This body of work falls short of determining teacher perceptions of the effectiveness of principals in a school district where diversity is maintained by a 
student-assignment plan primarily based upon the economic status of families in Jefferson County. Previous studies have also neglected to acknowledge that the data were a nested structure (teachers nested within schools), failing to use two-level Hierarchical Linear Modeling (HLM) as a tool to analyze collected data. Previous studies have not included data for first-year teachers and principals. Adding to the body of research, this study will increase the knowledge base of factors predicting perceptions of middle school principal effectiveness in the areas of organizational development, organizational environment, and educational program. 


\section{CHAPTER III}

Method

\section{Participants}

This study examined demographic variables of principals, schools, teachers, student-achievement scores as measured by the Kentucky Core Content Testing, and teachers' perceptions of principal-leadership behavior. Participating middle schools were selected based on their Title I status. The participants in this study included teachers (estimated $N=500$ ) of middle schools that were identified as title I in the Jefferson County Public Schools. The middle schools participating in the study are listed in Table 1. To protect school identity, schools were given letter designations (i.e., School A, School B, etc.). Participation was completely voluntary. Teachers' perceptions of principal-leadership behaviors were collected using the Audit of Principal Effectiveness (APE) at the schools selected for the study. All certified teachers in the selected middle schools were included in the research. 
Table 1

Title I Middle Schools in the Study: Numbers and Percentages of Students in Two Ethnic Categories and in the Category Free/Reduced Price Lunch

Number of Students (\%)

School

Caucasian African-American Free/Reduced-

Price

\begin{tabular}{llll}
\hline School A & $226(47.6)$ & $199(41.9)$ & $289(60.8)$ \\
School B & $553(62.4)$ & $291(32.8)$ & $598(67.5)$ \\
School C & $605(56.6)$ & $392(36.7)$ & $715(66.9)$ \\
School D & $234(35.5)$ & $302(45.8)$ & $575(87.1)$ \\
School E & $239(34.8)$ & $314(45.7)$ & $597(86.9)$ \\
School F & $327(61.1)$ & $179(33.5)$ & $380(71.0)$ \\
School G & $416(60.1)$ & $205(29.6)$ & $558(80.6)$ \\
School H & $340(44.7)$ & $317(41.7)$ & $488(64.1)$ \\
School I & $246(58.3)$ & $164(38.9)$ & $333(78.9)$ \\
School J & $642(61.3)$ & $331(31.6)$ & $771(73.6)$ \\
School K & $350(38.5)$ & $360(39.6)$ & $698(76.7)$ \\
School L & $148(32.2)$ & $258(56.2)$ & $424(92.4)$ \\
School M & $277(40.9)$ & $312(46.1)$ & $446(65.9)$ \\
\hline
\end{tabular}




\section{Instrumentation}

The Audit of Principal Effectiveness was designed to describe teachers'

perceptions of principals' effectiveness. Items for the instrument were generated from an extensive review of literature and research relative to the role of the principal (Valentine \& Bowman, 1986). The three domains and nine factors in Table 2 represent the major areas of focus in the development of the instrument. The factors describe the most significant issues of the instrument. The APE questionnaire, which described teacher perceptions of principal effectiveness, was used to assess nine factors: (1) organizational direction;

(2) organizational linkage; (3) organizational procedures; (4) teacher relations; (5) student relations; (6) interactive processes; (7) affective processes; (8) instructional improvement; and (9) curriculum improvement on middle school student achievement as perceived by teachers. The 80 -item questionnaire focused on the role of the principal and included a Likert-type scale $(1=$ not effective, $9=$ very effective $)$. The three domains (i.e., organizational development, organizational environment, and educational program) that evolved from the 80 items had coefficient alpha reliability coefficients of $.92, .94$, and .97 , respectively (Valentine \& Bowman, 1986).

The Organizational Development domain contained three factors with 27 total items, and it measured teachers' perceptions of organizational direction, organizational linkage, and organizational procedures. The Organizational Environment domain contained four factors with 37 total items, and it measured teacher relations, student relations, interactive processes, and affective processes. The Educational Program 
domain contained two factors with 15 total items, and it measured instructional improvement and curriculum improvement. One item on the survey measured the teachers' perception of the principal's overall effectiveness. Table 2 reports the reliability coefficient estimates for each factor as reported by Valentine and Bowman (1986).

Table 2

Reliability Coefficient Estimates for Each Domain and Factor

$\begin{array}{lll}\text { Factors } & \alpha & \text { Number of items }\end{array}$

Organizational development (coefficient alpha reliability .92)

$\begin{array}{lll}\text { Organizational direction } & .83 & \text { Seven items }\end{array}$

$\begin{array}{lll}\text { Organizational linkage } & .90 & \text { Eleven items }\end{array}$

$\begin{array}{lll}\text { Organizational procedures } & .82 & \text { Nine items }\end{array}$

Organizational environment (coefficient alpha reliability .94)

$\begin{array}{lll}\text { Teacher relations } & .94 & \text { Thirteen items }\end{array}$

$\begin{array}{lll}\text { Student relations } & .90 & \text { Eight items }\end{array}$

$\begin{array}{lll}\text { Interactive processes } & .86 & \text { Nine items }\end{array}$

$\begin{array}{lll}\text { Affective processes } & .79 & \text { Seven items }\end{array}$

Educational program (coefficient alpha reliability .97)

Instructional improvement

$.85 \quad$ Eight items

Curriculum improvement

$.84 \quad$ Seven items

Levels of student achievement on the KCCT are identified by one of four descriptors, Novice, Apprentice, Proficient, or Distinguished, and these results are 
reported annually to school districts in compliance with the federal No Child Left Behind (NCLB) Act. For the purpose of this study, student-achievement scores are represented by the percent of proficient/distinguished students in mathematics and reading as reported by NCLB.

\section{Data Collection}

Teachers' perceptions of principal-leadership behavior were collected using the factors of the APE. Each teacher completed the survey at a regularly scheduled faculty meeting, and the researcher collected the surveys. Due to time constraints, assistant principals in some middle schools distributed and collected the surveys. During faculty meetings, the purpose of the study was described and questionnaire packets were distributed to those teachers who volunteered to participate. Upon completion of the questionnaires, responses were put into an envelope that had an arbitrary code number on it. The same code number was marked on all of the questionnaires from that school. Questionnaires had no information on them that could identify individual teachers. Each principal was contacted for permission to administer the survey during a regularly scheduled faculty meeting, to all teachers. Student-achievement data were collected from the 2008-2009 KCCT as reported by NCLB. A copy of the APE can be found in Appendix A. The researcher estimated that 500 teachers from 13 middle schools would complete the surveys.

\section{Variables}

Outcome variables. The outcome variables are the nine principal-leadership factors being measured and consist of composite ratings of teacher perceptions of principal-leadership behaviors: (a) organizational direction, (b) organizational linkage, 
(c) organizational procedures, (d) teacher relations, (e) student relations, (f) interactive processes, (g) affective processes, (h) instructional improvement, and (i) curriculum improvement as perceivec by teachers.

Predictor Variables. The predictor variables include (a) principal-demographic variables, (b) school-demographic variables, and (c) school-achievement scores. The principal-demographic variables are principal gender, which is measured on nominal scale; principal age, which is measured on interval scale; total years as a classroom teacher, which is measured on interval scale; counselor or other non-administrative position at any level, which is measured on nominal scale; total years as a classroom teacher, which is measured on interval scale; counselor or other non-administrative position at the middle level, which is measured on nominal scale; total years as an assistant principal at any level, which is measured on interval scale; total years of experience as an assistant principal at the middle level, which is measured on interval scale; total years of experience as a principal, which is measured on interval scale: total years of experience as principal at the middle level, which is measured on interval scale; total years of experience as a principal in the current school, which is measured on interval scale; participation in Identifying and Developing Educational Administrators for Schools district program, which is measured on nominal scale; participation in Principals For Tomorrow district program, which is measured on nominal scale; and participation in internship district program, which is measured on nominal scale. This information was obtained from the school principal.

School variables. The school demographic variables (percent free/reduced-price lunch enrollment, which is measured on interval scale; number of Caucasian students, 
which is measured on interval scale; number of African-American students, which is measured on interval scale; number of Exceptional Child Education students, which is measured on interval scale; number of teachers, which is measured on interval scale; number of assistant principals, which is measured on interval scale; number of counselors, which is measured on interval scale; and Title I status, which is measured on nominal scale) were obtained from the Jefferson County Board of Education.

School-achievement scores (reading and mathematics) were measured by overall school student-achievement performance on the KCCT. For the purpose of this study, student-achievemeni scores are represented by the percent of proficient/distinguished students for mathematics and reading as reported by NCLB. These data were measured on interval scale.

Research Design and Data Analysis

The method used for this study was a combination of survey research and correlational/predictive research. The survey method was used to collect data from teachers using the APE questionnaire. Also included with the APE were several demographic items (e.g., teacher gender, teacher age). Data on school principals and schools were obtained from information provided by principals and publically available sources (e.g., school report cards). The questionnaire data and the data form principals and schools provided the basis for the correlational/predictive study. The general plan for the quantitative anaiysis was as foliows. In the first major step, ordinary least squares regression was performed both at the individual teacher level and the school level. These analyses and the accompanying correlation analysis allowed the researcher to explore the data and eliminate predictor variables that had no relationship with the outcome 
variables. Use of Ordinary Least Squares (OLS) regression in this manner is consistent with the advice of Raudenbush and Bryk (2002) on steps to follow in performing HLM. Following the OLS regression, HLM proceeded in three steps. In Step 1, one-way analysis of variance (ANOVA) with random effects was performed. This provided information about how much variation existed within and between schools and the reliability of each school's sample mean as an estimate of its true population mean. The researcher anticipated that there would be statistically significant between-school variance on the outcome variables--APE scores. It was planned that if the random effects ANOVA revealecd significant variance, then the analysis would proceed to Step 2. In Step 2, random coefficient models would be constructed to estimate several statistics. These included the average intercepts and slopes of the regression equations derived from the schools. These anaiyses allowed the researcher to calculate how much the regression equations varied among schools, i.e., the variability of the intercepts and the slopes (i.e., regression coefficients). Step 3 of the HLM will be construction of intercepts-and slopesas-outcomes HLM models. These will allow the researcher to address the main research questions of interest: How much do school-level variables (including both school variables and principal characteristics) affect teacher perceptions of principal effectiveness as measured by the nine APE variables? Data collection and analysis allowed the researchers to address the research questions of the study Research Questions

1. What is the magnitude of linear relationship among the following variables: 
(a) principal-leadership factors as perceived by teachers; (b) school-principal demographic variables; (c) school-demographic variables; and (d) school achievementtest scores?

2. At the individual teacher level, to what degree are perceived school principalleadership behaviors predicted by teacher-demographic variables (e.g., age, level of experience)?

3. At the school ievei, to what degree are perceived school principal-leadership behaviors predicted by teacher-demographic variables (e.g., age, level of experience) and school-level variables: (a) school-principal demographic variables, (b) school demographic variables, and (c) school achievement-test scores?

As described above, in the first step of the HLM analysis random effects, ANOVA was performed. It was planned that if the ANOVA revealed significant between-schools effects, then further HLM analysis would be performed. However, if no significant between-schools effects were found, the research questions of the study would still be addressed. They would be investigated by performing ordinary least squares regression at the individual-teacher level. Power analysis was performed using procedures appropriate for multiple regression. The numbers of teachers employed (500 to 600 ) ensured the ability to detect a moderate effect size with a statistical-significance level of .05 and a power of .80 . 


\section{CHAPTER IV}

Results

The results of the data analysis are presented in this chapter. The first level of analysis was based on the data collected on each participating teacher, and the second level of analysis was based on the data collected on each participating school. The researcher calculated descriptive statistics on both level one and level two variables. The reliability of the instrument and the factor correlations of the nine principal leadership behaviors were also calculated by the researcher. Multiple regression analysis was used with each of the APE factors to determine if the researcher could predict scores on dependent variables based on the descriptive statistics of the teachers. The final set of quantitative analyses consisted of hierarchical linear modeling (HLM) since teachers were clustered within schools (Raudenbush \& Bryk, 2002). The first step of the HLM consisted of a one-way ANOVA, which provided the variance that occurred within and between schools. The intraclass correlation represented the proportion of variance between schools for each dependent variable. In the next step of the HLM, the researcher used a random coefficient model to estimate the average intercept and slopes of the regression equations from the 13 schools. In the final step of the HLM, an intercepts-asoutcomes model was estimated, using level two predictors. 


\section{Participants}

The researcher collected data on the teachers' perception of their principal's leadership behaviors. The study participants were certified teachers $(n=529)$ who were teaching in Title I middle schools $(N=13)$ in Jefferson County Public Schools. The overall percentages (school A 9.5\%, school B 5.7\%, school C 3.4\%, school D 1.9\%, school E 10.4\%, school F 7.8\%, school G 11.7\%, school H 5.1\%, school I 14.6\%, school J 7.9\%, school K 4.9\%, school L 9.5\%, school M 7.8\%) represented the contribution of each school's participating teachers to the study.

Descriptive Statistics on Demographic Variables

Table 3 shows frequency distributions for demographic variables of teachers. Of the respondents, $28.9 \%$ were 21 to 29 years of age; $31.3 \%$ were 30 to 39 years of age; and $39.6 \%$ were above the age of 39 . The majority $(60.2 \%)$ of the respondents were under the age of 40 , which indicated that the participating Title I schools had young teaching staffs. More than $65 \%$ of respondents were female; $76 \%$ were Caucasian; and more than $18 \%$ were Atrican-American. The majority of respondents were Caucasian females under the age of 40 . More than $67 \%$ of the teachers responding had less than nine years of teaching experience; more than $40 \%$ were non-tenured (less than five years of experience); and over $15 \%$ were first-year teachers. More than $79 \%$ of the teachers had worked for their current principal for fewer than five years. The primary subjects taught were distributed fairly evenly. The majority of the teachers $(70 \%)$ obtained a traditional teaching certificate. More than 70\% had a master's degree or higher. 
Table 3

Frequency Distributions for Demographic Variables of Teachers $(N=529)$

\begin{tabular}{|c|c|c|}
\hline Variable & $N$ & $\%$ \\
\hline \multicolumn{3}{|c|}{ Age $(N=454) 75$ missing } \\
\hline Under 21 & 1 & .2 \\
\hline $21-29$ & 131 & 28.9 \\
\hline $30-39$ & 142 & 31.3 \\
\hline $40-49$ & 81 & 17.8 \\
\hline $50-59$ & 80 & 17.6 \\
\hline $60-69$ & 19 & 4.2 \\
\hline \multicolumn{3}{|c|}{ Gender $(N=453) 76$ missing } \\
\hline Female & 306 & 67.5 \\
\hline Male & 147 & 32.5 \\
\hline \multicolumn{3}{|c|}{ Race $(N=445) 84$ missing } \\
\hline African-American & 81 & 18.2 \\
\hline Asian & 6 & 1.3 \\
\hline Caucasian & 338 & 76.0 \\
\hline Hispanic & 5 & 1.1 \\
\hline Other & 15 & 3.4 \\
\hline
\end{tabular}


Table 3 (continued).

\begin{tabular}{|c|c|c|}
\hline Variable & $N$ & $\%$ \\
\hline \multicolumn{3}{|c|}{ Years of experience teaching $(N=415) 114$ missing } \\
\hline 1 year (non-tenured) & 63 & 15.2 \\
\hline 2 - 4 years (non-tenured) & 106 & 25.5 \\
\hline $5-9$ years & 112 & 27 \\
\hline $10-19$ years & 86 & 20.8 \\
\hline $20-29$ years & 41 & 9.9 \\
\hline $30-39$ years & 5 & 1.1 \\
\hline $40-49$ years & 2 & .4 \\
\hline \multicolumn{3}{|c|}{ Years worked for current principal $(N=427)$ missing 102} \\
\hline 1 year & 136 & 31.9 \\
\hline 2 years & 66 & 15.5 \\
\hline 3 years & 88 & 20.6 \\
\hline 4 years & 54 & 12.6 \\
\hline 5 years & 26 & 6.1 \\
\hline 6 years & 15 & 3.5 \\
\hline 7 years & 11 & 2.6 \\
\hline 8 years & 11 & 2.6 \\
\hline $9-18$ years & 20 & 4.6 \\
\hline
\end{tabular}


Table 3 (continued).

Variable

Primary subject taught

Math $(\mathrm{n}=97) 432$ missing

Science $(n=75) 454$ missing

Social studies $(\mathrm{n}=76) 453$ missing

Language arts $(n=91) 438$ missing

Reading $(\mathrm{n}=27) 502$ missing

Other $(n=120) 409$ missing

Certification type $(N=454) 75$ missing

Traditional certification

Alternative certification

Other certification

Highest degree earned $(N=459) 70$ missing

Associate's degree

Bachelor's degree

Master's degree

Doctoral degree

Other degree
$N$

$\%$
97

75

76

91

27

120

317

69.8

122

26.9

15

3.3

2

.4

101

22.0

325

70.8

7

1.5

24

Note. The researcher did not calculate percentages for primary subject taught since some participants recorded multiple primary subjects taught. 
The information in Table 4 shows the descriptive statistics of the level-two respondents, middle-school principals. More than $53 \%$ of the principals were male and $69 \%$ were Caucasian. The principals in this study had an average of 11 years of teaching experience, were assistant principals for an average of 4 years, and have been principals for an average of 6 years.

Table 4

Descriptive Statistics for Principals

\begin{tabular}{lllll}
\hline Variable & $\%$ & $M$ & $S D$ \\
\hline
\end{tabular}

Gender

Female

46.2

Male

53.8

Ethnicity

African-American

30.8

Caucasian

69.2

Yrs. as teacher

11.35

6.12

Yrs. as elementary school teacher

.85

3.05

Yrs. as middle school teacher

4.77

7.04

Yrs. as high school teacher

5.73

4.54

Yrs. as non-administrative position

1.54

2.44 
Table 4 (continued).

Variable

$M$

$S D$

Yrs. as assistant principal at any level

4.19

3.09

Yrs. as assistant principal at K-8 level

.15

.56

Yrs. as assistant principal at middle school level

2.65

2.67

Yrs. as assistant principal at high school level

1.38

3.38

Yrs. as assistant principal in current school

.81

1.38

Yrs. as principal any level

5.96

4.61

Yrs. as principal at $\mathrm{K}-8$ level

.23

.83

Yrs. as principal at middle school level

5.73

4.79

Yrs. as principal in current school

4.89

3.73

Participation in IDEAS program ${ }^{2}$

Participation in PFT program ${ }^{\mathrm{a}}$

.54

.52

Participation in internship program ${ }^{\mathrm{a}}$

.38

.51

${ }^{a}$ The mean for this variable represents the proportion of principals that participated in the program.

\section{Reliability}

Table 5 shows the reliability, mean, and standard deviation of the nine factors. The Cronbach's alpha coefficient for each factor was very high, with the minimum value obtained for the factor student relations $(\alpha=.95)$. Which exceeded the suggested minimum value of 70 (Nunally \& Bernstein, 1994). The factor with the lowest mean 
score was organizational procedures, $M=6.89$, and the factor with the highest mean score was curriculum improvement, $M=7.52$.

Table 5

Factor Reliability, Mean, and Standard Deviation

\begin{tabular}{lcccc}
\hline \multicolumn{1}{c}{ Factor } & $N$ & $\alpha$ & $M$ & $S D$ \\
\hline Organizational direction & 528 & .96 & 7.52 & 1.47 \\
Organizational linkage & 528 & .97 & 7.28 & 1.53 \\
Organizational procedures & 527 & .97 & 6.89 & 1.94 \\
Teacher relations & 527 & .98 & 7.07 & 1.93 \\
Student relations & 526 & .95 & 7.42 & 1.57 \\
Interactive processes & 520 & .97 & 7.18 & 1.75 \\
Affective processes & 518 & .96 & 7.14 & 1.82 \\
Instructional improvement & 522 & .96 & 7.35 & 1.66 \\
Curriculum improvement & 511 & .97 & 7.52 & 1.56 \\
Overall & 509 & & 7.33 & 1.81 \\
\hline
\end{tabular}

Table 6 shows that all nine factors are highly correlated with each other. This was expected since ali nine factors related to each other. Results revealed significant positive correlations among all nine factors of principal leadership. Organizational procedures had the highest correlation $(\mathrm{p}<.01, \mathrm{r}=.923)$ with teacher relationships. The weakest correlation $(\mathrm{p}<.01, \mathrm{r}=.709)$ was between organizational direction and student relations. 
Table 6

Factor Correlation: Principal Leadership Factors

\begin{tabular}{|c|c|c|c|c|c|c|c|c|c|}
\hline Factor & OD & OL & OP & TR & SR & IP & $\mathrm{AP}$ & II & $\mathrm{CI}$ \\
\hline Org. direction & & $.899^{\prime}$ & $.824 * *$ & $.778^{* *}$ & $.709 * *$ & $.862 * *$ & $.826^{* *}$ & $.851 * *$ & $.848 * *$ \\
\hline Org. linkage & & - & $.851 * *$ & $.796^{* *}$ & $.744^{* *}$ & $.891 * *$ & $.855 * *$ & $.864 * *$ & $.838 * *$ \\
\hline Org. procedures & & & - & $.923^{* *}$ & $.755^{* *}$ & $.857 * *$ & $.898 * *$ & $.840^{* *}$ & $.793 * *$ \\
\hline Teacher relations & & & & - & $.794^{* *}$ & $.829 * *$ & $.897 * *$ & $.833 * *$ & $.757 * *$ \\
\hline Student relations & & & & & - & $.783 * *$ & $.763^{* *}$ & $.758^{* *}$ & $.728^{* *}$ \\
\hline Interac. processes & & & & & & - & $.898 * *$ & $.900 * *$ & $.876^{* *}$ \\
\hline Affec. processes & & & & & & & - & $.899 * *$ & $.833^{* *}$ \\
\hline Instr. improvement & & & & & & & & - & $.893 * *$ \\
\hline Curr. improvement & & & & & & & & & - \\
\hline
\end{tabular}

Note. $\mathrm{OD}=$ organizational direction; $\mathrm{OL}=$ organizational linkage; $\mathrm{OP}=$ organizational procedures; $\mathrm{TR}=$ teacher relations; $\mathrm{SR}=$ student relations; $\mathrm{IP}=$ interactive processes; $\mathrm{AP}=$ affective processes; $\mathrm{II}=$ instructional improvement; $\mathrm{CI}=$ curriculum improvement. $* * p<.01$

\section{Multiple Regression}

Multiple regression analyses were performed with each of the APE factors and the overall score used as a separate dependent variable. The same procedure was used for each regression. The forward method of entry was used, which produced a regression equation that contained all predictor variables that significantly predicted $($ at $p<.05)$ the dependent variable. Potential predictor variables were the following: (a) age, 
(b) number of years of teaching experience, (c) number of years worked for principal, (d) gender, (e) race, (f) type of certification, and (g) type of degree. The variable gender was coded female $=1$ and male $=0$. Race was coded white $=1$ and other $=0$. Type of certification was coded $1=$ traditional teacher certification and $0=$ alternative certification or other. Type of degree was coded $1=$ graduate degree and $0=$ bachelor's degree.

Table 7 shows the standardized regression coefficients (B) and unstandardized regression coefficients $(\beta)$ for variables that were statistically significant for each dependent variable. The same three variables entered one or more of the regression equations. These were teacher age, number of years the teacher worked for the principal, and teacher gender. Teacher age had uniformly positive coefficients. This meant that the older the teacher, the higher the rating of the principal. Number of years the teacher worked for the principal had negative coefficients, meaning that the fewer the years the person worked for the principal, the higher the rating. Finally, gender had negative coefficients. Since gender was coded female $=1$ and male $=0$, a negative coefficient meant the male teachers rated principals higher than the female teachers did. Each of the relationships involved controliing for all of the other variables in the regression equation. 
Table 7

Teacher Level Regression: Statistics for Significant Predictors of Dependent Variables

Significant predictor variables

Dependent

Teacher

Years working

Teacher

variable

$\frac{\text { age }}{\text { B } \beta}$

for principal

gender

Org. direction

Org. linkage

$.140 .121^{*}$

$-.086-.152 * *$

Org. procedures

$.179 .120^{*}$

$-.153-.211^{* *}$

$-.438-.115^{*}$

Teacher relations

$.168 .117^{*}$

$-.107-.152 * *$

$-.472-.129 *$

Student relations

Interac. processes

$$
.164 .119^{*}
$$

$-.096-.145^{* *}$

$-.500-.143 * *$

Affec. processes

$.140 .101^{*}$

$-.105-.157^{* *}$

$-.470-.134 * *$

Instr. improvement

$.165 .129^{*}$

$-.116-.186 * *$

$-.370-.113^{*}$

Curr. improvement

$.163 .135^{* *}$

$-.089-.146^{* *}$

Overall

$-.104-.151 * *$

$* \mathrm{p}<.05, * * \mathrm{p}<.01$

Table 8 shows the proportion of variance accounted for by each predictor. As can be seen in the table, two variables had no significant predictors. These were Organizational Direction and Student Relations. Using adjusted $R$ squared values, the percentages of variance in the dependent variables accounted for by the predictors ranged 
from $2 \%$ to $5.8 \%$. With organizational linkage as the dependent variable, $2.4 \%$ of the variance was accounted for by teacher age $(\mathrm{p}<.05, \mathrm{r}=.121)$ and years the teacher worked for the principal $(\mathrm{p}<.01, \mathrm{r}=-.152)$. Accordingly, teacher age $(\mathrm{p}<.05, \mathrm{r}=.120)$; number of years the teacher worked for principal $(\mathrm{p}<.01, \mathrm{r}=-.211)$; and teacher gender $(\mathrm{p}<.05, \mathrm{r}=-.115)$ explained $5.8 \%$ of the variance in organizational procedures. Teacher relations as the dependent variable, $4.2 \%$ of the variance was accounted for by teacher age $(\mathrm{p}<.05, \mathrm{r}=.117)$; number of years the teacher worked for principal $(\mathrm{p}<.01, \mathrm{r}=$ $.152)$; and teacher gender $(p<.05, r=-.129)$. With interactive processes, $4.4 \%$ of the variance was accounted for by teacher age $(p<.05, r=.119)$; number of years the teacher worked for principal $(\mathrm{p}<.01, \mathrm{r}=-.145)$; and teacher gender $(\mathrm{p}<.01, \mathrm{r}=-.143)$. For affective processes, $4.2 \%$ of the variance was accounted for by teacher age $(\mathrm{p}<.05, \mathrm{r}=$ $.101)$; number of years the teacher worked for principal $(\mathrm{p}<.01, \mathrm{r}=-.157)$; and teacher gender $(\mathrm{p}<.01, \mathrm{r}=-.134)$. With instructional improvement as the dependent variable, $4.9 \%$ of the variance was accounted for by teacher age $(p<.05, r=.129)$; number of years the teacher worked for principal $(\mathrm{p}<.01, \mathrm{r}=-.186)$; and teacher gender $(\mathrm{p}<.05, \mathrm{r}$ $=-.113$ ). For curriculum improvement, $2.5 \%$ of the variance was accounted for by teacher age $(\mathrm{p}<.01, \mathrm{r}=.135)$ and number of years the teacher worked for principal $(\mathrm{p}<$ $.01, \mathrm{r}=-.146)$. With overall score as the dependent variable, $2 \%$ of the variance was accounted for by the number of years the teacher worked for principal $(\mathrm{p}<.01, \mathrm{r}=-.151)$. 
Table 8

Teacher Level Regression: F Statistics and Adjusted $R^{2}$

$\begin{array}{llllll}\text { Dependent variable } & F & p & R^{2} & \text { Adjusted } R^{2}\end{array}$

Org. direction

Org. linkage

$$
F(2,392)=5.79
$$

.003

.029

.024

Org. procedures

$F(3,391)=9.06 \quad<.001 \quad .065$

.058

Teacher relations

$F(3,391)=6.74 \quad<.001 \quad .049$

.042

Student relations

Interac. processes

$F(3,389)=7.02 \quad<.001 \quad 051$

.044

Affec. processes

$F(3,389)=6.76 \quad<.001 \quad .050$

.042

Instr. improvement

$F(3,391)=7.83 \quad<.001 \quad 057$

.049

Curr. improvement

$F(2,388)=6.01 \quad .003 \quad .030$

.025

Overall

$F(1,387)=9.08 \quad .003 \quad .023$

.020

Hierarchical Linear Modeling

The final set of quantitative analyses consisted of Hierarchical Linear Modeling (HLM), an analytic method described by Raudenbush and Bryk (2002). In this study, teachers (level one) were clustered within schools (level two). HLM controls for clustering of observations and heteroscedasticity (Goldberger, 1991). In the multi-level model, the researcher used a one-way ANOVA with random effects to determine the variation between schools, a random coefficient model to estimate the regression equations from the 13 schools, and an intercepts-as-outcomes model was estimated, using 
level-two predictors that were statistically significant in the OLS analysis of school means.

One-Way ANOVA with Random Effects

The one-way ANOVA provided information about how much variation lay within and between schools. The model for one-way ANOVA was represented by the following equations reported in Raudenbush and Bryk (2002).
Level-one equation (teacher level):
$\mathrm{Y}_{\mathrm{ij}}=\boldsymbol{\beta}_{0 \mathrm{j}}+\mathrm{r}_{\mathrm{ij}}$
Level-two equation (school level):
$\beta_{0 \mathrm{j}}=\gamma_{00}+\mathrm{u}_{0 \mathrm{j}}$

HLM analysis has the most value when there is sufficient variance at the school level that it can be modeled with additional variables. Ma (2001) stated that HLM is beneficial when $10 \%$ or more of the variance in the dependent variable is associated with a level-two variable. Table 9 and Table 10 show the results for one-way ANOVA of the ten dependent variables. Each was a score on the survey instrument.

Table 9 shows the average school means and standard errors for each dependent variable. A test of whether there is significant variation among school means is shown as a random effect. As can be seen by the significant obtained chi-square statistics in Table 10 , there was significant variation among school means for each variable. A measure of effect size in random effects ANOVA is the intraclass correlation, which in this study represents the proportion of variance between schools (Raudenbush \& Bryk, 2002). 


$$
\hat{\rho}=\frac{\hat{\tau}_{00}}{\left(\hat{\tau}_{00}+\hat{\sigma}^{2}\right)}
$$

Table 9

Random ANOVA Models Fixed Effects: Average School Means and Standard Errors

\begin{tabular}{lll}
\hline Dependent variable & $M$ & $S E$ \\
\hline Org. direction & 7.310 & .250 \\
Org. linkage & 7.064 & .274 \\
Org. procedures & 6.721 & .305 \\
Teacher relations & 6.878 & .323 \\
Student relations & 7.273 & .191 \\
Interac. processes & 6.948 & .312 \\
Affec. processes & 6.917 & .310 \\
Instr. improvement & 7.166 & .278 \\
Curr. improvement & 7.307 & .281 \\
Overall & 7.088 & .326 \\
\end{tabular}

As can be seen in the last column of Table 10, there was a range of values, mostly about .25. The proportion of variance between schools ranged from .17 for Interactive Processes to .36 for Organizational Procedures. Since the intraclass correlations were well above the .10 threshold, it was reasonable to engage in modeling to determine what 
level-two variables might be associated with the school means for the ten survey outcomes.

Table 10

Random ANOVA Models Random Effects: Variance Components and Intraclass Correlations

Dep. variable

School mean, $\mathrm{u}_{0}$

Level-one effect, $r_{i j} \quad$ Intra

Var. comp. df

$\chi^{2}$

Var. comp.

\begin{tabular}{lccccc}
\hline Org. direction & 0.826 & 12 & $158.418^{* *}$ & 1.730 & .23 \\
Org. linkage & 0.997 & 12 & $185.672^{* *}$ & 1.794 & .32 \\
Org. procedures & 1.215 & 12 & $149.014^{* *}$ & 3.000 & .36 \\
Teacher relations & 1.374 & 12 & $156.184^{* *}$ & 2.962 & .29 \\
Student relations & 0.445 & 12 & $88.076^{* *}$ & 2.165 & .32 \\
Interac. processes & 1.295 & 12 & $178.613^{* *}$ & 2.369 & .17 \\
Affec. processes & 1.271 & 12 & $162.619^{* *}$ & 2.609 & .35 \\
Instr. improvement & 1.020 & 12 & $177.111^{* *}$ & 2.120 & .33 \\
Curr. improvement & 0.963 & 12 & $166.804^{* *}$ & 1.897 & .32 \\
Overall & 1.301 & 12 & $171.930^{* *}$ & 2.528 & .34
\end{tabular}

Note . Var. Comp. $=$ Variance Component and Intra $=$ Intraclass correlation.

$* * \mathrm{p}<.01$. 


\section{Random Coefficient Model}

A random coefficient model was constructed to estimate the average intercept and slopes of the regression equations derived from 13 schools. The HLM procedure also allowed the researcher to calculate how much the intercepts and slopes varied among schools. Slopes are the regression coefficients in the regression equations at level one (with individual teachers as the unit of analysis).

Level-one regression equations were constructed with two individual-level predictors that had been shown to be significant in the OLS individual-level analyses. These were the variables teacher gender and teacher age. The researcher decided to use these variables since both were basic demographic variables that would likely be available in other analyses that could be performed with these data and comparable data sets. These variables were group-centered. The HLM random coefficient models are summarized in Tables 11 through 13. As can be seen in Table 11, one of the two fixed effects had large $t$ values associated with it: gender was significantly related to each dependent variable, with the exception of Curriculum Improvement. This confirms the results of the individual levei OLS regression analysis. 
Table 11

Random Coefficient Models Fixed Effects: Average School Means and Standard Errors

\begin{tabular}{|c|c|c|c|c|c|c|c|c|}
\hline \multirow{3}{*}{$\begin{array}{c}\text { Dependent } \\
\text { variable }\end{array}$} & \multirow{2}{*}{\multicolumn{2}{|c|}{$\begin{array}{l}\text { Avg. school } \\
\text { mean, } u_{0 j}\end{array}$}} & \multirow{2}{*}{\multicolumn{3}{|c|}{$\begin{array}{c}\text { Teacher gender } \\
\text { slope, } \gamma_{10}\end{array}$}} & \multirow{2}{*}{\multicolumn{3}{|c|}{$\begin{array}{l}\text { Teacher age } \\
\text { slope, } \gamma_{20}\end{array}$}} \\
\hline & & & & & & & & \\
\hline & Coeff. & SE & Coeff. & SE & $\mathrm{t}$ & Coeff. & SE & $\mathrm{t}$ \\
\hline O. direction & 7.410 & .272 & -.419 & .182 & $-2.302^{*}$ & .0540 & .0490 & 1.113 \\
\hline O. linkage & 7.148 & .298 & -.523 & .202 & $-2.590^{*}$ & .0490 & .0500 & .967 \\
\hline O. procedures & 6.843 & .325 & -.798 & .259 & $-3.080^{*}$ & .0003 & .0700 & .004 \\
\hline T. relations & 7.012 & .347 & -.852 & .321 & $-2.654^{*}$ & .0042 & .0731 & .057 \\
\hline S. relations & 7.391 & .224 & -.515 & .214 & $-2.410^{*}$ & .0402 & .0517 & .779 \\
\hline I. processes & 7.064 & .342 & -.764 & .258 & $-2.965^{*}$ & .0512 & .0582 & .880 \\
\hline A. processes & 7.035 & .333 & -.766 & .277 & $-2.767^{*}$ & -.0239 & .0740 & -.323 \\
\hline I. improvement & 7.274 & .303 & -.596 & .229 & $-2.601^{*}$ & .0733 & .0533 & 1.373 \\
\hline C. improvement & 7.414 & .287 & -.430 & .218 & -1.974 & .0896 & .0503 & 1.784 \\
\hline Overall & 7.205 & .333 & -.628 & .264 & $-2.381^{*}$ & -.0361 & .0694 & -.519 \\
\hline
\end{tabular}

Note. Coeff. $=$ Coefficient. For all significance tests, degrees of freedom were 12.

$* p<.05$.

As shown in Table 12, the random effects of the random-coefficient models are addressed by three hypotheses. First, the school means, controlling for gender and age, were shown to have significant differences among one another. This implies that there was significant variance that could be modeled, with variables measured at the school 
level. The slopes of the predictors' gender and age did not have significant chi-square values associated with them. This meant they did not significantly vary. Two exceptions were for the gender slopes for Teacher Relations and Interactive Processes

Table 12

Random Coefficient Models Random Effects: Variance Components

\begin{tabular}{|c|c|c|c|c|c|c|}
\hline \multirow[t]{2}{*}{$\begin{array}{c}\text { Dependent } \\
\text { variable }\end{array}$} & \multicolumn{2}{|c|}{$\begin{array}{l}\text { Avg. school } \\
\text { mean, } u_{0 j}\end{array}$} & \multicolumn{2}{|c|}{$\begin{array}{l}\text { Teacher gender } \\
\text { slope, } u_{1 j}\end{array}$} & \multicolumn{2}{|l|}{$\begin{array}{c}\text { Teacher age } \\
\text { slope, } \mathrm{u}_{2 \mathrm{j}}\end{array}$} \\
\hline & Var. comp. & $\chi^{2}$ & Var. comp. & $\chi^{2}$ & Var. comp. & $\chi^{2}$ \\
\hline O. direction & 0.907 & $174.032 * *$ & * $\quad 0.241$ & 12.987 & .00084 & 4.748 \\
\hline O. linkage & 1.107 & $222.467^{* *}$ & * $\quad 0.342$ & 16.474 & .00346 & 7.490 \\
\hline O. procedures & 1.283 & $148.634^{* *}$ & 0.532 & 14.740 & .00986 & 7.019 \\
\hline T. relations & 1.484 & $168.740^{* *}$ & 1.011 & $24.145^{*}$ & .01699 & 9.819 \\
\hline S. relations & 0.596 & $115.511^{* *}$ & 0.369 & 15.722 & .00005 & 5.134 \\
\hline I. processes & 1.453 & $206.651^{* *}$ & 0.604 & $22.867^{*}$ & .00338 & 3.147 \\
\hline A. processes & 1.370 & $178.127^{* *}$ & 0.707 & 18.283 & .02577 & 10.252 \\
\hline I. improvement & 1.128 & $198.788^{* *}$ & 0.451 & 17.421 & .00070 & 8.194 \\
\hline C. improvement & 1.018 & $184.573^{* *}$ & 0.409 & 19.916 & .00036 & 3.959 \\
\hline Overall & 1.368 & $180.770^{* *}$ & 0.614 & 18.359 & .01705 & 8.365 \\
\hline
\end{tabular}

Note. Var. Comp. $=$ Variance Component. For all significance tests, degrees of freedom were 12 .

${ }^{*} p<.05,{ }^{* *} p<.01$. 
The researcher estimated the amount of variance in the dependent variables that were predicted by teacher gender and age. This involved using data from the one-way random-effects ANOVA and the random-coefficient model, as described in the formula below.

$\left[\left(\hat{\sigma}^{2}\right.\right.$ random ANOVA $)-\left(\hat{\sigma}^{2}\right.$ random coefficient model $\left.)\right] /\left(\hat{\sigma}^{2}\right.$ random ANOVA $)$

The last column of Table 13 shows the results. Adding the predictors' gender and age reduced the within-school variance by .18 to .26 . In other words, $18 \%$ to $26 \%$ of the variances in scale scores were accounted for by individual teacher scores on the variables teacher gender and teacher age. However, the more important of the two predictors was gender. As shown in Table 11 in column two, the gender slope effect was significant for 9 out of 10 comparisons. As a consequence of the random-coefficient modeling, the researcher decided to further explore the data, using intercept and slopes-as-outcomes models. In the latter, the level-one predictor in each regression was teacher gender. 
Table 13

Random Coefficient Models Random Effect: Level-One Variance Component and Proportion of Variance in Variable Accounted for by Predictors

\begin{tabular}{lcc}
\hline \multicolumn{1}{c}{$\begin{array}{l}\text { Dependent } \\
\text { variable }\end{array}$} & $\begin{array}{c}\text { Level one effect, } \mathrm{r}_{\mathrm{ij}} \\
\text { variance component }\end{array}$ & $\begin{array}{c}\text { Proportion of variance } \\
\text { accounted for by predictors }\end{array}$ \\
\hline Org. direction & 1.372 & .21 \\
Org. linkage & 1.350 & .25 \\
Org. procedures & 2.455 & .18 \\
Teacher relations & 2.300 & .22 \\
Student relations & 1.594 & .26 \\
Interac. processes & 1.846 & .22 \\
Affec. processes & 2.029 & .22 \\
Instr. improvement & 1.670 & .21 \\
Curr. improvement & 1.476 & .22 \\
Overall & 2.029 & .20 \\
\hline
\end{tabular}

Intercepts-as-Outcomes Model

The random-coefficient model revealed that mean scores on the dependent variables significantly varied among schools. For two outcome variables, Teacher Relations and Interactive Processes, the slopes of the predictor variable teacher gender also significantly varied. In the last step of multi-level modeling, an intercepts-asoutcomes HLM model was estimated, using level-two predictors that were found to be statistically significant in the OLS analysis of school means. For most models, these were 
the following: (a) the gender of the principal and (b) the principal's average years of teaching experience. For two models, a level-two predictor variable was the school's percentage of low-income students who were proficient in mathematics. Low-income was defined as "students receiving free or reduced-price lunch." Mathematics achievement pertained to the average score of the Kentucky Core Content Test (KCCT) in mathematics. The level-two predictors were grand-mean centered. Level-one regression equations had the variable, teacher gender, as a predictor that was groupcentered.

Table 14 and Table 15 show summaries of the results. As shown in the last two columns of Table 14, there was a significant level-two predictor of every dependent variable except Interactive Processes. For five variables, principal gender was a significant predictor. In each case, higher mean scores on the dependent variables were associated with female principals. For eight variables, the principal's average teaching experience was a significant predictor. In each case, higher mean scores were associated with higher principal's average teaching experience. For one variable, Instructional Improvement, higher mean scores on the variable were associated with a higher score average for percentage of free and reduced-price lunch students who were proficient on the KCCT in mathematics. 
Table 14

Fixed Effects for Intercept and Slopes-as-Outcomes Models: Coefficients and Standard Errors for Intercepts

\begin{tabular}{|c|c|c|c|c|c|c|c|c|}
\hline \multirow[t]{2}{*}{$\begin{array}{l}\text { Dependent } \\
\text { variable }\end{array}$} & \multicolumn{2}{|c|}{$\begin{array}{l}\text { Avg. school } \\
\text { mean, } \gamma_{00}\end{array}$} & \multicolumn{3}{|c|}{$\begin{array}{l}\text { Principal gender } \\
\text { slope, } \gamma_{10}\end{array}$} & \multicolumn{3}{|c|}{$\begin{array}{l}\text { Principal's avg. years } \\
\text { teaching slope, } \gamma_{20}\end{array}$} \\
\hline & Coeff. & $\mathrm{SE}$ & Coeff. & $\mathrm{SE}$ & $\mathrm{t}$ & Coeff. & $\mathrm{SE}$ & $\mathrm{t}$ \\
\hline O. direction & 7.413 & .187 & .849 & .384 & 2.213 & .203 & .084 & $2.411^{*}$ \\
\hline O. linkage & 7.163 & .204 & .934 & .419 & 2.227 & .230 & .091 & $2.519^{*}$ \\
\hline O. procedures & 6.864 & .186 & 1.242 & .381 & $3.259 * *$ & .244 & .086 & $2.855^{*}$ \\
\hline $\mathrm{T}$. relations & 7.027 & .230 & .590 & .286 & 2.062 & .211 & .071 & $2.963^{*}$ \\
\hline S. relations & 7.387 & .168 & & & & .227 & .075 & $3.037^{*}$ \\
\hline I. processes $^{\mathrm{a}}$ & 7.072 & .249 & .657 & .344 & 1.909 & & & \\
\hline A. processes & 7.063 & .195 & 1.166 & .401 & $2.905^{*}$ & .266 & .089 & $2.988^{*}$ \\
\hline I. improvement ${ }^{\mathrm{b}}$ & 7.284 & .183 & 1.291 & .370 & $3.485^{* *}$ & & & \\
\hline C. improvement & 7.414 & .196 & .914 & .402 & $2.270^{*}$ & .221 & .088 & $2.505^{*}$ \\
\hline Overall & 7.219 & .204 & 1.104 & .418 & $2.639 *$ & .272 & .092 & $2.946^{*}$ \\
\hline
\end{tabular}

Note Coeff. $=$ Coefficient. For all significance tests, degrees of freedom were 10, except for Student Relations, where the teacher age slope had 11 degrees of freedom.

${ }^{\text {a }}$ For the slope of the level-two predictor Low-income proficient in Math: Coefficient = $0.048, \mathrm{SE}=0.025, t=1.932, p>.05$ 
${ }^{\mathrm{b}}$ For the slope of the level-two predictor Low-income proficient in Math: Coefficient $=$ $0.062, \mathrm{SE}=0.025, t=2.44, p<.05$.

${ }^{*} p<.05,{ }^{* *} \mathrm{p}<.01$

As can be seen by the significant chi-square statistics in Table 15, significant variation existed among school means for each variable. In the last column of Table 15, there was a range of values, mostly about .60 . The proportion of variance between schools accounted for by predictors ranged from .48 for student relations to .72 for organizational procedures. For the variable student relations, $48 \%$ of the variance was accounted for by the predictor variables. With organizational procedures, $72 \%$ of the variance was accounted for by the predictor variables. 
Table 15

Intercept-as-Outcomes Models Random Effect: Level-One Variance Component and Proportion of Variance in Variable Accounted for by Predictors

\begin{tabular}{|c|c|c|c|c|c|}
\hline \multirow[t]{2}{*}{ Dep. variable } & \multicolumn{3}{|c|}{ School mean, $\mathrm{u}_{0 \mathrm{j}}$} & \multirow{2}{*}{$\begin{array}{l}\text { Level one effect, } \mathbf{r}_{\mathrm{ij}} \\
\text { Var. comp. }\end{array}$} & \multirow[t]{2}{*}{ Variance } \\
\hline & Var. comp. & $\mathrm{df}$ & $\chi^{2}$ & & \\
\hline Org. direction & .401 & 10 & $110.606^{* *}$ & 1.180 & .56 \\
\hline Org. linkage & .488 & 10 & $136.229 * *$ & 1.409 & .56 \\
\hline Org. procedures & .359 & 10 & $58.903^{* *}$ & 2.526 & .72 \\
\hline Teacher relations $^{\mathrm{a}}$ & .604 & 10 & $77.229 * *$ & 2.297 & .59 \\
\hline Student relations & .307 & 11 & $84.507^{* *}$ & 1.630 & .48 \\
\hline Interac. processes ${ }^{b}$ & .739 & 10 & $124.214^{* *}$ & 1.857 & .49 \\
\hline Affec. processes & .419 & 10 & $75.650^{* *}$ & 2.111 & .69 \\
\hline Instr. improvement & .372 & 10 & $97.639^{* *}$ & 1.721 & .67 \\
\hline Curr. improvement & .441 & 10 & $114.832 * *$ & 1.529 & .57 \\
\hline Overall & .462 & 10 & $87.579^{* *}$ & 2.083 & .66 \\
\hline
\end{tabular}

${ }^{\mathrm{a}}$ For teacher gender slope; $\mathrm{SD}=0.85117 ;$ Var. Component $=0.72449 ; \mathrm{df}=12 ; \chi^{2}=$ $27.74256, p=0.006$.

${ }^{\mathrm{b}}$ For teacher gender slope; $\mathrm{SD}=0.60535 ;$ Var. Component $=0.36645 ; \mathrm{df}=12 ; \chi^{2}=$ $37.449, p=0.010$.

$* * \mathrm{p}<.01$ 
Overall Summary of Data Analysis

Table 16 provides a summary of the study for both the teacher-level analyses and the HLM analyses. At the individual-teacher level, the variables teacher age, number of years working for a principal, and teacher gender were important predictors. At the school level, principal's average teacher experience and principal gender were the most important predictors. There were no significant teacher-level predictors in the areas of organizational direction and student relations. Also, there were no significant schoollevel predictors in the area of interactive processes.

Table 16

Significant Predictors of Leadership Factors at the Teacher and School Level

\begin{tabular}{lll}
$\begin{array}{l}\text { Dependent } \\
\text { variable }\end{array}$ & $\begin{array}{c}\text { Significant teacher- } \\
\text { level predictors }\end{array}$ & $\begin{array}{c}\text { Significant school- } \\
\text { level predictors }\end{array}$ \\
\hline $\begin{array}{l}\text { O. direction } \\
\text { O. linkage }\end{array}$ & Teacher age & P-teaching experience \\
& Yrs. teacher worked for principal & \\
& Teacher age & \\
O. procedures & Yrs. teacher worked for principal ${ }^{\mathrm{a}}$ & P-teaching experience \\
& Teacher gender & \\
T. relations & Teacher age & P-teaching experience
\end{tabular}


Table 16 (continued).

$\begin{array}{ccc}\text { Dependent } & \text { Significant teacher- } & \text { Significant school- } \\ \text { variable } & \text { level predictors } & \text { level predictors }\end{array}$

Yrs. teacher worked for principal ${ }^{\mathrm{a}}$

Teacher gender

S. relations

P-teaching experience

I. processes Teacher age

Yrs. teacher worked for principal ${ }^{\mathrm{a}}$

Teacher gender

$\begin{array}{lll}\text { A. processes } & \text { Teacher age } & \text { P-teaching experience }\end{array}$

Yrs. teacher worked for principal ${ }^{\mathrm{a}} \quad$ Principal gender $^{2}$

Teacher gender

I. improvement Teacher age Principal gender

Yrs. teacher worked for principal ${ }^{\mathrm{a}} \quad \%$ students $\mathrm{PM}^{\mathrm{b}}$

Teacher gender

$\begin{array}{lll}\text { C. improvement Teacher age } & \text { P-teaching experience }\end{array}$

Yrs. teacher worked for principal ${ }^{\mathrm{a}} \quad$ Principal gender

Overall Yrs. teacher worked for principal $^{\mathrm{a}} \quad$ P-teaching experience

Principal gender

Note: For the variable principal gender, female principals received higher ratings than male principals, controlling for other predictors in the model. For the variable teacher 
gender, male teachers scored their principal higher than female teachers. P-Teaching Experience $=$ the principal's average number of years as a teacher.

${ }^{\text {a }}$ Inverse relation

${ }^{b}$ Percentage of Low-Income Students scoring Proficient in Mathematics.

The following summarizes Table 16: (a) the older the teacher, the higher the rating of the principal; (b) the fewer years the teacher worked for the principal, the higher the rating; (c) the male teachers rated principals higher than female teachers; (d) female principals were associated with higher mean scores on the dependent variables; (e) more teaching experience of the principal related to higher mean scores on the dependent variables; and (f) higher mean scores on instructional improvement were associated with a higher average score for percentage of free and reduced-price lunch students who were proficient on the KCCT in mathematics. 


\section{CHAPTER V}

\section{Discussion of Findings}

The more we understand how the principal's leadership behavior is perceived by teachers, school districts and university personnel will be better equipped to prepare future principals for successful leadership. This chapter includes a summary of this study and the conclusions from the data presented in Chapter IV. The five sections in this chapter include a summary of the study; presentation of findings based on the data collected from teachers and principals; implications; recommendations for future research; and a conclusion.

\section{Summary of Study}

The study was an exploratory correlational study, using the questionnaire method of collecting data. The study addressed the need for a greater understanding of how teachers perceive the leadership behaviors of school principals. The purpose of this study was to determine the magnitude of the relationship among (a) principal-leadership factors as perceived by teachers, (b) school-principal demographic variables, (c) schooldemographic variables, and (d) school achievement-test scores. The researcher determined, at the teacher level and the school level, what extent of perceived principal leadership-behaviors as measured by the "Audit of Principal Effectiveness" (APE), (Valentine \& Bowman, 1984) were predicted by teacher- and school-demographic variables. Descriptive statistics, one-way ANOVA, random-coefficient models, as well as 
intercepts-as-outcomes models were used to analyze the data. This data were collected from 529 certified teachers in 13 Title I middle schools located in Louisville, Kentucky.

Presentation of Findings

Research Questions

What is the magnitude of linear relationship among the following variables:

(a) principal leadership factors as perceived by teachers; (b) school-principal demographic variables; (c) school-demographic variables; and (d) school-achievement test scores? The exploratory correlational study revealed significant correlations between principal leadership factors, school-principal demographic variables, and school achievement-test scores. Level-one and level-two variables were significant predictors for seven of the ten leadership factors. Although there were variables that significantly predicted organizational direction and student relations, there were no level-one variables that were significant predictors for these variables. Likewise, interactive processes had variables that were significant predictors although there were no level-two variables that were significant predictors.

At the individual-teacher level, to what degree are perceived school-principal leadership behaviors predicted by teacher demographic variables (e.g., age, level of experience)? Teacher-level variables that significantly predicted the teacher's perception of the principal's leadership behaviors were teacher age, years the teacher worked for current principal, and teacher gender. Teacher age had a positive correlation for the seven variables it predicted. This meant the older the teacher, the higher the rating of the principal. The number of years the teacher worked for the principal had a negative correlation for the eight variables it predicted. This indicated the fewer years the teacher 
worked for the principal, the higher the rating on perceived leadership behaviors. Teacher gender also had a negative correlation for the five variables it predicted due to the method gender was coded. Male teachers rated principals higher than female teachers on all five variables that teacher-gender predicted.

At the school level, to what degree are perceived school-principal leadership behaviors predicted by teacher demographic variables (e.g., age, level of experience) and school-level variables: (a) school-principal demographic variables, (c) school demographic variables, and (d) school-achievement test scores? School-level variables that significantly predicted the teacher's perception of the principal's leadership behaviors were principal's gender; principal's teaching experience, and the percentage of low-income students scoring proficient in mathematics. Principal's gender had a positive correlation for the five variables it predicted due to the method gender was coded. This meant female principals were associated with higher mean scores on the dependent variables than male principals. The principal's teaching experience had a positive correlation for the eight variables it predicted. The more teaching experience of the principal related to higher mean scores on the dependent variables. The percentage of low-income students scoring proficient in mathematics had a positive correlation for the one variable it predicted. This indicated the higher mean scores on instructional improvement were associated with a higher percentage of free and reduced-price students who were proficient on the Kentucky Core Content Test (KCCT) in mathematics. Teacher-Level Variables

Teacher age. The teacher's age significantly influenced the teacher's perception of the principal's leadership behaviors. As teacher age increased, the teacher scored the 
principal higher on the principal's perceived leadership behaviors in the following areas:

(a) organizational linkage; (b) organizational procedures; (c) teacher relations;

(d) interactive processes; (e) affective processes; (f) instructional improvement; and

(g) curriculum improvement. These results indicated that younger teachers may need to be more involved with school leadership such as team leaders or department leaders. Principals should be actively involved with making sure that younger teachers are receiving the amount of support needed in the classroom and making sure they are receiving appropriate professional development to be more successful in the classroom. Johnson (1981) reported that teachers between 26 and 30 years of age perceived lack of administrative support as extremely stressful regardless of experience. According to Witt (1993), job involvement can be seen as a reflection of work experiences. The more positive these experiences, the higher the job involvement, which will lead to a positive attitude toward the organization. Teachers who become involved and are in leadership positions in the school experience satisfaction. Keedy (1995) assessed the extent to which teacher practical knowledge was practiced schoolwide. Johnson (1981), Witt (1983), and Keedy (1995) addressed teacher issues involved in restructuring schools.

Teacher gender. The teacher's gender significantly influenced the teacher's perception of the principal's leadership behaviors. Male teachers scored their principal higher than female teachers on their perceived leadership behaviors in the following areas: (a) organizational procedures; (b) teacher relations; (c) interactive processes; (d) affective processes; and (e) instructional improvement. In this study, males represented $32.5 \%$ and females represented $67.5 \%$ of participating teachers. Male teachers continue to be underrepresented in the teaching profession. Principals should 
make an effort to better understand their relationship with gender differences in the workplace. School districts should make attempts to recruit more male teachers for the classroom; although the most important factor to keep in mind when hiring teachers is the quality of the applicants and not just the gender (Driessen, 2007).

Years teacher worked for principal. The number of years a teacher worked for his/her current principal significantly influenced the teacher's perception of the principal's leadership behaviors. The longer a teacher worked for a principal, the lower the teacher scored the principal in the following areas: (a) organizational linkage; (b) organizational procedures; (c) teacher relations; (d) interactive processes; (e) affective processes; (f) instructional improvement; (g) curriculum improvement; and (h) overall score. Principals must make sure that tenured teachers are considered part of the decision-making process in the school. When teachers feel they are a part of the decision-making process, they feel they are a valued part of the organization. School-Level Variables

Principal's gender. The principal's gender significantly influenced the teachers' perception of their principal's leadership behaviors. Female principals received higher scores than male principals on their perceived leadership behaviors in the following areas: (a) organizational procedures; (b) affective processes; (c) instructional improvement; (d) curriculum improvement; and (e) overall score. According to a research study conducted by Eagley et al. (1992), female principals tended to invite the participation of others in the decision-making process. Men adopted a less collaborative style and are relatively more direct and assertive. Some researchers assert that women typically bring to administrative positions an approach to leadership that is consistent 
with developmental, collaborative, and relationship-oriented behaviors (Wallin \& Crippen, 2007). These behaviors are seen as more compatible than traditional male leadership behaviors. In a research study conducted by Bulach et al. (1999), gender did not play a role in the supervisory climate, and it seemed that behaviors that promoted a good supervisory climate affected both genders the same. Female principals tend to have a more democratic leadership style and include stakeholders in the decision-making process. This makes teachers feel they are a valued part of the organization. Gender trends have been recognized over the past decades with respect to women and leadership. School personnel who are responsible for preparing and selecting school principals should use this information when deciding on an appropriate candidate.

Principal's teaching experience. The principal's teaching experience significantly influenced the teachers' perception of their principal's leadership behaviors. Principals with more teaching experience received higher scores than principals with less teaching experience on their perceived leadership behaviors in the following areas:

(a) organizational direction; (b) organizational linkage; (c) organizational procedures; (d) teacher relations; (e) student relations; (f) affective processes; (g) curriculum improvement; and (h) overall score. This perceived respect of the principal's teaching experience gives the principal credibility with the teacher. It is difficult for teachers, especially tenured teachers, to accept leadership and professional development from a principal who has less classroom experience than the teachers. Principals who have little classroom experience are expected to evaluate teachers' classroom performance and provide professional development for teacher growth. This problem is magnified when interacting with tenured teachers. According to Shakeshaft (1987), women often spent 
more years in the classroom due to their roles as mothers. Females having spent more time in the classroom before entering administration may be another indication of why female principals received higher scores on their perceived leadership behaviors. Although in this study, the seven male principals' combined teaching experience was 85 years, for an average of 12 years of teaching experience. The six female principals' combined teaching experience was 63 years, for an average of 11 years of teaching experience.

Percentage of low-income students scoring proficient in mathematics. The percentage of low-income students scoring proficient in mathematics significantly influenced the teachers' perception of only one of their principals' leadership behaviors. In schools with larger percentages of low-income students scoring proficient in mathematics, teachers scored principals higher on perceived leadership behavior in the area of instructional improvement. When a school has a large portion of low-income students scoring proficient in mathematics, the accountability scores increase, resulting in less pressure on teachers and a more favorable view of administration.

\section{Implications}

This study has implications for personnel involved in conducting principalleadership programs at the university level; school district personnel responsible for principal-preparation programs; current school principals; and school committees responsible for hiring principals. For example, university personnel must incorporate the findings of this study into the curriculum for those seeking to obtain principal certification. These findings require potential principal-certification students to observe current school principals and have in-depth discussions with school principals regarding 
their experiences with gender in the workplace and how to work with tenured teachers who may have much more teaching experience than the principal. School districts should provide professional-development opportunities for school principals to learn and practice effective leadership behaviors according to the findings of this study. Preparing the potential principals with effective leadership behaviors enhances the successful performance of the principal. School districts also should mandate ongoing, continuous evaluations on the teacher's perception of the principal's leadership behaviors to help ensure principals understand how their leadership behaviors are perceived. School districts also should consider increasing the teaching experience required to become a school principal. Having more experience in the classroom will only enhance the principal's leadership performance in the school.

This study also has implications for school principals. Often, school principals are introduced to theories in leadership, but there is little information provided to the principals on their perceived leadership behaviors. School principals who continue to explore methods to improve their own perceived leadership behaviors will benefit students and teachers, which, in turn, may improve the academic performance of the school. School principals must cultivate a climate where the teacher's feedback on the perception of the principal's leadership behaviors is welcomed and encouraged. The results of this research also have implications for school committees responsible for hiring principals. If effective leadership behaviors, as perceived by teachers, can be determined, the selection of effective principals with these desirable characteristics would possibly increase teachers' performance. This would require hiring committees to screen potential candidates for these desirable leadership characteristics. This study will 
increase the knowledge base of factors predicting perceptions of principal effectiveness in the areas of educational program, organizational development, and organizational environment. As more knowledge is developed, it can be used in areas such as principal certification, ongoing professional development, and principal-selection process. This study contributed to the existing body of knowledge on teachers' perception of their principal's leadership behaviors, specifically in Title I middle schools.

\section{Recommendations for Future Studies}

Further research will need to be conducted to determine if the results of this study can be replicated with a larger number of participants. Studies should be extended to teachers from urban and rural school districts across the United States to compare the findings with the current study. Similar studies conducted in different demographic areas may provide results representative of the diverse experiences teachers have with their perception of the principal's leadership behaviors. It is recommended that studies extend to $\mathrm{K}-12$ since the middle school climate is unique compared to high school and elementary school. In order to advance our understanding of perceived principalleadership behaviors, future research must continue to explore the concept of genderbased leadership. Males and females offer strengths in different areas of perceived leadership behaviors. The research must investigate why teachers' perception of the female principal's leadership behaviors is higher than their perception of the male principal's leadership behaviors. The influence of the principal's teaching experience also should be investigated further. Additional research would benefit from a longitudinal, mixed-methodology approach where qualitative data would provide a more 
detailed understanding of how principals perceived leadership behaviors over an extended period of time.

\section{Limitations of the Study}

There were several limitations to the study. They included the following. First, the study included first-year teachers. Thus, some respondents in some schools had limited experience with the school principal they were rating. Second, the APE instrument involved self-reports of perceptions. As with any attitudinal instrument, halo effects may have occurred, in which the overall perception of the principal might have influenced the respondent to rate the principal in a certain way. For example, if the teacher had an overall positive impression of the principal, this might have influenced the teacher to rate the teacher as positive on many if not all of the items. Finally, as previously stated, this was a study of perceptions of principal-effectiveness. This is not the only way effectiveness can be defined. Another definition of effectiveness might be principal influence on student academic performance (e.g., percentage of students proficient in reading and mathematics).

\section{Conclusion}

Since teachers work more closely with the principal on a day-to-day basis than any other person, it is critical that future school leaders strive to understand how they are perceived by teachers, and, thus, adapt their leadership behaviors in order to be more successful in their leadership position. Principals should have a strong understanding of the dynamics of teacher and principal gender; teacher age; teaching experience of the principal; and the number of years a teacher works for the current principal, and how this may affect the principal's perceived leadership behaviors. It is crucial that school 
districts and universities implement the findings of this study regarding the teacher's perception of the principal's leadership behaviors and apply this knowledge to principalpreparation programs for future school leaders. 


\section{REFERENCES}

Achilles, C. M. (1987). A vision of better school. In W. Greenfield (Ed.), Instructional leadership: Concepts, issues, and controversies (pp. 17-37). Newton, MA: Allyn and Bacon.

Andrews, R. L., \& Soder, R. (1987). Principal leadership and student achievement. Educational Leadership, 4, 9-11.

Argyris, C., \& Schon, D. (1996). Organizational learning II: Theory, method, and practice. Reading, MA: Addison-Wesley.

Austin, G. (1979). Exemplary schools and the search for effectiveness. Educational Leadership, 37, 10-14.

Bamburg, J. D., \& Andrews, R.L. (1991). School goals, principals, and achievement. School Effectiveness and School Improvement, 2, 176-191.

Barth, R. (1993). Reflection on conversations. Journal of Personal Evaluation, 7, 217 221.

Bass, B. M. (1985). Leadership and performance beyond expectations. New York, NY: The Free Press, Macmillan, Inc.

Blase, J. J. (1987). Dimensions of effective school leadership: The teacher's perspective. American Educational Research Journal, 24, 589-610.

Blumberg, A., \& Greenfield, W. (1980). The effective principal: Perspectives on school leadership. Boston: Allyn and Bacon. 
Blumberg, A., \& Greenfield, W. (1986). The effective principal: Perspectives on school leadership $\left(2^{\text {nd }}\right.$ ed.). Boston, MA: Allyn and Bacon.

Bolman, L. G., \& Deal, T. E., (1997). Reframing organizations: Artistry, choice, and Leadership ( $2^{\text {nd }}$ ed.). San Francisco, CA: Jossey-Bass.

Boocock, S. S. (1972). An introduction to the sociology of learning. Boston: HoughtonMufflin.

Bossert, S. T., (1988). School effects. In N. J. Boyan (Ed.), Handbook of research on educational administration (pp. 341-352). New York: Longman.

Bossert, S. T., Dwyer, D. C., Rowan, B., Lee, G. V. (1982). The instructional management role of the principal. Educational Administration Quarterly, 18, 3464.

Brandt, R. (1982). The new catechism for school effectiveness. Educational Leadership, $66,68-75$.

Branscum, J. D. (1983). Competencies of rural Oklahoma school principals. High School Journal, 66, 141-148.

Brookover, W. B., \& Lezotte, L. W. (1979). Changes in school characteristics coincident with changes in student achievement: Executive summary. East Lansing, MI: Institute for Research on Teaching.

Bulach, C, Boothe, D., \& Michael, P. (1999). Supervisory behaviors that affect school climate. Paper presented at the annual meeting of the American Educational Research Association, Montreal, Canada. (ERIC Document Reproduction Service No. ED 430282).

Bulach, C., \& Lunenberg, F. (1995). The influence of the principal's leadership style on 
school climate and student achievement. People and Education, 3, 333-351.

Carnegie Forum's Task Force on Teaching as a Profession. (1986, May 21). A nation prepared: Teachers for the $21^{\text {st }}$ century. Chronicle of Higher Education, (pp. 43$54)$.

Cheng, Y. C. (1994). Principal's leadership as a critical factor for school performance: Evidence from multi-levels of primary schools. School Effectiveness and School Improvement, 5, 299-317.

Chittom, S.A., \& Sistrunk, W.E. (1990). The relationship between secondary teachers' job satisfaction and their perceptions. East Lansing, MI: National Center for Research on Teacher Learning. (ERIC Document Reproduction Service No. Ed 326567)

Clark, D. L., Lotto, L. S., \& McCarthy, M. M. (1980). Factors associated with success in urban elementary schools. Phi Delta Kappan, 66, 467-470.

Clift, R., Johnson, M., Holland, P., \& Veal, M.L. (1992). Developing the potential for collaborative school leadership. American Educational Research Journal, 29, $877-908$.

Cochran-Smith, M. (2006). Stayers, leavers, lovers and dreamers: Why people teach and why they stay. Bank Street College of Education, 1-23.

Cohen, E. G., \& Miller, R. H. (1980). Coordination and control of instruction in schools. Pacific Sociological Review, 23, 446-472.

Coleman, J. S., Campbell, E. Q., Hobson, C. J., McPartland, J., Mood, A. M., Weinfeld, F. D., and York, R. L. (1966). Equality of educational opportunity. Washington, DC: U.s. Office of Education National Center for Education Statistics. 
Collinson, V., Cook, T., \& Conley, S. (2005). Organizational learning in schools and school systems: Improving learning, teaching, and leading. Theory into Practice, $45,107-116$.

Combs, A. W., Miser, A. B., \& Whitaker, K.S. (1999). On becoming a school leader. Association for Supervision and Curriculum Development. Alexandria, Va.

Cotton, K., \& Savard, W. (1980). Time factors in learning. Paper prepared for Alaska State Department of Education by the Northwest Regional Laboratory, Portland, OR.

Council of Chief State School Officers. (2003). State education accountability reports and indicator reports: Status of reports across the states-2003. Washington, DC: Author.

Cuban, L. (1984). Transforming the frog into a prince: effective schools research, policy, and practice at the district level. Harvard Educational Review, 54, 129151.

David, J. (2000). Educators and parents as partners in school governance. In R. Pankratz \& J. Petrosko (Eds.). (2000). All children can learn. San Francisco: Jossey-Bass.

Dawson, J. (1984). The principals role in facilitating teacher participation mediating the influence of school contact. (ERIC Document Reproduction Service No. ED 244346)

Deal, T. E., \& Celotti, L. S. (1980). How much influence do (and can) educational administrators have on classrooms? Phi Delta Kappan, 61, 471-473.

DeMoss, K. (2002). Leadership styles and high-stakes testing: Principals make a difference. Education and Urban Society, 35, 111-132. 
Driessen, G. (2007). The feminization of primary education: effects of teachers' sex on pupil achievement, attitudes and behavior. Review of Education, 53, 183-203.

Eagley, A., Karau, S., \& Johnson, B. (1992). Gender and leadership style among school principals: A meta-analysis. Educational Administration Quarterly, 28, 76102.

Edmonds, R. R. (1979). Effective schools for the urban poor. Educational leadership, $37,15-24$.

Fordham, S., \& Ogbu, J. U. (1986). Black students' school success: “Coping with the burden of acting white." The Urban Review, 18, 176-206

Fuhr, M. (1970). Leadership role of principal related to innovative practices in selected schools in Ohio. Unpublished doctoral dissertation, Wayne State University, Detroit.

Fullan, M. (2002). The change leader. Educational Leadership, 59, 16-20.

Fullan, M., \& Stiegelbauer, S. (1991). The new meaning of educational change $\left(2^{\text {nd }}\right.$ ed.). New York, NY: Teachers College Press.

Gentilucci, J.L., \& Muto, C.C. (2007). Principals' influence on academic achievement: The student perspective. National Association of Secondary School Principals, 91, 219-236.

Glasman, N. (1984). Student achievement and the school principal. Educational Evaluation and Policy Analysis, 6, 283-296.

Goldberger, A. S. (1991). A Course in Econometrics. Cambridge, MA: Harvard University Press. 
Goldhammer, R. (1969). Clinical Supervision. New York: Holt, Rinehart and Winston.

Greenfield, W. (1987). Moral imagination and interpersonal competence: Antecedents to instructional leadership. In W. Greenfield (Ed.) Instructional leadership: Concepts, issues, and controversies. (pp. 56-76). Newton, MA: Allyn \& Bacon. Gronn, P. C. (1982). Neo-Taylorism in educational administration? Educational Administration Quarterly, 18, 17-35.

Hallinger, P., Bickman, L., \& Davis, K. (1996). School context, principal leadership, and student reading achievement. The Elementary School Journal, 96, 527-549.

Hallinger, P., \& Heck, R. (1996). Reassessing the principal's role in school effectiveness: A review of empirical research, 1980-1995. Educational Administration Quarterly, 32, 5-44.

Hannaway, J., \& Sproull, L. S. (1979). Who's running the show? Coordination and control in educational organizations. Administrators Notebook, 27, 1-4.

Harris, S. (2000). Behave yourself. Principal Leadership, 1, 36-39.

Heck, R. H. (1992) Principal's instructional leadership and school performance: Implications for policy development, Educational Evaluation and Policy Analysis, 14, 21-34.

Heck, R., Larsen, R., \& Marcoulides, G. (1990). Instructional leadership and school achievement: Validation of a causal model. Educational Administration Quarterly, 26, 94-125.

Hersey, P., Blanchard, K., \& Johnson, D.E., (1996). Management of organizational behavior: Utilizing human resources ( $7^{\text {th }}$ ed.). Englewood, NJ: Prentice-Hall, Inc. 
Ingersoll, R. (2003). Is there are shortage among math and science teachers? Science Educator, 12, 1-9.

Johnson, A.B. (1981). Special Education Burnout: A three part investigation. Paper presented at the annual convention of the council for exceptional children. New York, NY.

Johnson, J., Livingston, M., Schwartz, R., \& Slate, J. (2000). What makes a good elementary school? A critical examination. Journal of Educational Research, 93,339-348.

Jorde-Bloom, P. (1988). Closing the gap: An analysis of teacher and administrator perceptions of organizational climate in the early childhood setting. Teaching and Teacher Education, 4, 111-120.

Kaerney, J. (1977). The principal. Teacher of teachers. NASSP Bulletin, 61, 1-6.

Kaplan, L.S., Owings, W.A., \& Nunnery, J. (2005). Principal quality: A virginia study connecting interstate school leaders licensure consortium standards with student achievement. National Association of Secondary School Principals, 89, 28-44.

Keedy, J. L. (1995). Teacher personal practical knowledge on classroom restructuring. Journal of Educational Research, 89, 76-89.

Keedy, J. L., \& Achilles, C. M. (1982). Principal norm setting as a component of effective schools. In Phi Delta Kappa The Role of the Principal, Hot Topics Series (pp. 35-45). Bloomington, IN: Phi Delta Kappa Center on Evaluation, Development, and Research.

Kentucky Department of Education. (2002). DAC implementation guide. Frankfort, KY: Author. 
Kentucky Education Reform Act of 1990, Kentucky Revised Statute 160.435.

Kotter, J. P. (1990). A force for change: How leadership differs from management. New York: Free Press.

Lee, V. E., Dedrick, R.G., \& Smith, J.B. (1991). The effect of the social organization of the schools on teachers' efficacy and satisfaction. Sociology of Education, 64, 190-208.

Leithwood, K., \& Jantzi, D. (1990). Transformational leadership: How principals can help reform school cultures. School Effectiveness and School Improvement, 1,249-280.

Leithwood, K., \& Jantzi, D. (2000). The effects of transformation leadership on student engagement with school. Journal of Educational Administration, 38, 112-129.

Leithwood, K., \& Montgomery, D. (1982). The role of the elementary school principal in program improvement. Review of Educational Research, 52, 309-339.

Levine, D. U., \& Stark, J. (1982). Instructional and organizational arrangements that improve achievement in inner-city schools. Educational Leadership, 40, 41-46.

Lindle, J. (2000). School-based decision-making. In J. Petrosko \& J. Lindle (Eds.), 2000 Review of Research on the Kentucky Education Reform Act (p. 279). Lexington, KY: The Kentucky Institute for Education Research.

Lindsey, R. B., Roberts, L. M., \& Campbell Jones, F. (2005). The culturally proficient school: An implementation guide for school leaders. Thousand Oaks, CA: Corwin Press.

Lipham, J. M., \& Hoeh, J. A. (1974). The principalship: Foundation and functions. New York: Harper and Row. 
Little, J. W. (1982). Norms of collegiality and experimentation: Workplace conditions of school success. American Educational Research Journal, 19, 325-340.

Lyons, J. E., (1981). Competencies needed by beginning secondary school principals. NASSP Bulletin, 59-66.

Ma, X. (2001). Stability of school academic performance across subject areas. Journal of Educational Measurement, 38, 1-18.

Marks, H. M., \& Nance, J.P. (2007). Contexts of accountability under systemic reform: Implications for principal influence on instruction and supervision. Educational Administration Quarterly, 43, 3-37.

Marks, H. M., \& Printy, S.M. (2003). Principal leadership and school performance: An integration of transformational and instructional approaches. Educational Administration Quarterly, 39, 370-397.

Martin, W. J., \& Willower, D. J., (1981). The managerial behavior of high school principals. Educational Administrative Quarterly, 17, 69-90.

McLaughlin, L., \& Hyle, A. (2001). The school principal as change agent: An explanatory case study. Paper presented at the Association Annual Meeting of the American Educational Research, Session.

Meyer, J. W., \& Rowan, B. (1978). The structure of educational organizations. San Francisco: Jossy Bass.

Nakornsri, T. (1977). Principal's role behavior and administrative performance as perceived by selected teachers. Dissertation Abstracts International, 38, 7062A.

National Commission on Excellence in Education. (1983). A nation at risk: the imperative of educational reform. Washington, DC: U.S. Department of 


\section{Education.}

Neagley, R. L., \& Evans, D. N. (1964). Handbook for effective supervision of instruction. Englewood Cliffs. New Jersey: Prentice-Hall.

Nettles, S., \& Petscher, Y. (2007). Development and validation of a principal implementation practices measure: The principal implementation questionnaire. Journal of Personnel Evaluation in Education, 20, 247-259.

No Child Left Behind Act, Pub. L. No. 107-110, 115 Stat. 1425 (2002).

Nunnally, J. C., \& Bernstein, I.H. (1994). Psychometric Theory ( $3^{\text {rd }}$ ed.). New York: McGraw-Hill.

O’Donnell, R.J., \& White, G.P. (2005). Within the accountability era: Principals' instructional leadership behaviors and student achievement. National Association of Secondary School Principals, 89, 56-71.

Okpala, C. O., Smith, F., \& Ellis, R. (2000). A clear link between school and teacher characteristics, student demographics, and student achievement. Education, 120, 487-494.

Pankratz, R., \& Petrosko, J. (Eds.). (2000). All children can learn. San Francisco: Jossey-Bass.

Patton, M. (2006). The law of increasing returns: A Process for retaining teachersNational recommendations. National Journal for Publishing and Mentoring doctoral Student Research, 3, 1-9.

Peterson, K. D. (1978). The principal's tasks. Administrator's Notebook, 26, 1-14.

Pipho, C. (1990). Reforming education in Kentucky. Phi Delta Kappan, 71, 662-664. Pitner, N. J. (1988). The study of administrator effects and effectiveness. In N. Boyan 
(Ed.), Handbook of research in educational administration (pp. 99-122). New York: Longman.

Pollard, D. S. (1989). Against the odds: A profile of academic achievers from the urban underclass. Journal of Negro Education, 58, 297-308.

Pounder, D. G., Ogawa, R. T., \& Adams, E. A. (1995). Leadership as an organizationwide phenomena: Its impact on school performance. Educational Administration Quarterly, 31, 540-563.

Purkey, S., \& Smith, M. (1983). Effective schools: A review. Elementary School Journal, $83,427-452$.

Raudenbush, S.W., \& Bryk, A.S. (2002). Hierarchical linear models: Applications and data analysis methods $\left(2^{\text {nd }}\right.$ ed.). Thousand Oaks, CA: Sage.

Rayder, N., Abrams, A., \& Larson, J. (1978). Effect of socio-contextual variables on child achievement. Journal of Teacher Education, 29, 58-63.

Reavis, C., Vinson, D., \& Fox, R. (1999). Importing a culture of success via a strong principal. Clearing House, 72, 199-203.

Richards, J. (2007). How effective principals encourage their teachers. Principal, 86, 4850.

Rosenholtz, S. (1989). Teacher's workplace: The social organization of schools. New York: Longman.

Russell, A. (2006). The facts and fictions about teacher shortages. American Association Of State Colleges and Universities, 2, 2-5.

Rutter, M., Maughan, B., Mortimore, P., Houston, J., \& Smith, A. (1979). Fifteen thousand hours: Secondary schools and their effects on children. Cambridge, 
MA: Harvard University Press.

Sergiovanni, T. J. (1984). Leadership and excellence in schooling. Educational Leadership, 5, 4-13.

Shakeshaft, C. (1987). Women in education administration. Newberry Park, CA: Sage.

Sheppard, B. (1996). Exploring the transformational nature of instructional leadership. Alberta Journal of Educational Research, 42, 325-344.

Shreeve, W., Goetter, W. G., Norby, J. R., Waunch, S. A., Stueckle, A.F., De Michele, B., \& et al. (1984). Job satisfaction: A responsibility of leadership: A report. (ERIC Document Reproduction Service No. Ed 275638)

Smith, P. A. (1996). A study of the relationship between teachers' perceptions of the leadership behavior of principals and the organizational climate in secondary schools of Alabama. (Doctoral dissertation, University of Alabama, 1996). Dissertation Abstract International, 59A 46 (UMI No. 99973931)

Stringfield, S., \& Teddlie, C. (1988). A time to summarize: The Louisiana school effectiveness study. Educational Leadership, 46, 43-49.

Stringfield, S., \& Teddlie, C. (1991). Observers as predictions of schools' multiyear outlier status on achievement tests. Elementary School Journal, 91, 357-376.

United States Department of Education. (2003). No child left behind: A toolkit for teachers. Washington, DC: Author.

Valentine, J.W., \& Bowman, M.L. (1984). Audit of principal effectiveness. MLLC. Retrieved July 8, 2004, from http://mllc.org/surveys/APEInstrumentwithwatermark.pdf

Valentine, J.W., \& Bowman, M.L. (1988). Audit of Principal Effectiveness: A method 
for self-improvement, NASSP Bulletin, 72, 18-26.

Valentine, J.W., \& Bowman, M.L. (1990). Principal effectiveness in national recognized and randomly selected schools. Educational Administration and Supervision, 11, 81-87.

Valentine, J.W., Bowman, M. L., \& Michael, L. (1987). The audit of principals effectiveness. Columbia Missouri, University of Missouri.

Van de Grift, W., \& Houtveen, A.A.M. (1999). Educational leadership and pupil achievement in primary education. School Effectiveness and School Improvement, 10, 373-389.

Wallin, D., \& Crippen, C. (2007). Superintendent leadership style: A gendered discourse analysis. Journal of Women in Educational Leadership, 5, 21-39.

Weber, G. (1971). Inner-city children can be taught to read: Four successful schools. Washington, DC: Council for Basic Education.

Wellisch, J., MacQueen, Q., Carriere, R., \& Duck, G. (1978). School organization and management in successful schools. Sociology of Education 51, 211-226.

Williams, H. (2000). Teacher perceptions of principal effectiveness in selected secondary schools in Tennessee. Education, 121, 264-276.

Williams, L. (2007). Leaders we have a problem! It is teacher retention. . What can we do about it? The Lamar University Electronic Journal of Student Research, 1-8.

Willis, Q. (1980). The work activity of school principals. An observational study. The Journal of Educational Administration, 18, 27-54.

Witt, L. (1993). Reaction to work assignments as predictors of organizational commitment: The moderating effect of occupational identification. Journal of 
Business Research, 26, 17-30.

Witziers, B., Bosker, R.J., \& Kruger, M.L. (2003). Educational leadership and student achievement: The elusive search for an association. Educational Administration Quarterly, 39, 398-425.

Zigarelli, M. (1996). An empirical test of conclusions from effective schools research. Journal of Educational Research, 90, 102-110. 


\section{APPENDIX A}

\section{AUDIT of PRINCIPAL EFFECTIVENESS \\ Teacher Form 1-88}

Directions: There are 80 statements in this instrument. The statements describe specific principalship skills. Because teachers work more closely with principals than any other professional group, teachers' perceptions are particularly important. Please take a few minutes to read each statement and select the response that most appropriately describes your assessment of your principal's ability for each item. DO NOT record your name. All responses will be reported as a group, not individual data. Please be honest and candid with your responses.

For each item, select the response that describes HOW EFFECTIVELY YOUR PRINCIPAL PERFORMS EACH SKILL. Please use the following nine-point scale as the measure of effectiveness.

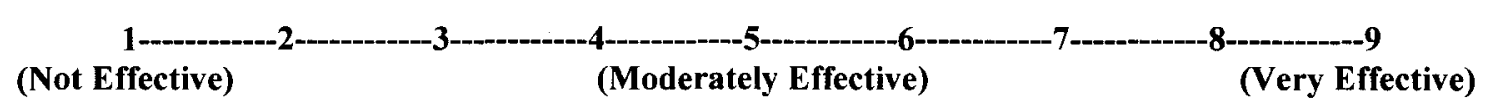

1. The principal assists the faculty in developing an understanding of, and support for, the beliefs and attitudes that form the basis of the educational value system of the school.

2. The principal provides for the identification of, and the reaching of consensus on, the educational goals of the school.

3. The principal has high, professional expectations and standards for self, faculty, and school.

4. The principal helps the faculty develop high, professional expectations and standards for themselves and the school.

5. The principal envisions future goals and directions for the school.

6. The principal encourages changes in school programs that lead to a better school for the students.

7. The principal communicates to teachers the directions the school's programs need to take for growth.

8. The principal develops plans for the cooperation and involvement of the community, individuals, and agencies of the school.

9. The principal utilizes resources from outside the school to assist in the study, development, implementation, and/or evaluation of the school.

10. The principal provides for the gathering of information and feedback from individuals and agencies in the community.

11. The principal provides for the dissemination of information to individuals and agencies in the community.

12. The principal is supportive of, and operates within, the policies of the district.

13. The principal maintains good rapport and a good working relationship with other administrators of the district.

14. The principal invests time with the district office and other external agencies to obtain support and resources from the agencies.

15. The principal strives to achieve autonomy for the school.

16. The principal develops and implements school practices and policies that synthesize educational mandates, requirements and theories, e.g. legal requirements, social expectations, theoretical premises.

17. The principal understands and analyzes the political aspects of education and effectively interacts with various communities, e.g. local, state, national, and/or various subcultures within the local community.

18. The principal informs the staff of new developments and ideas in education.

19. During the identification of needed change, the principal's style is more supportive and participative than directive and authoritative.

20. During evaluation of change, the principal's style is more supportive and participative than directive and authoritative. 
21. The principal anticipates the effects of decisions.

22. The principal fairly and effectively evaluates school personnel.

23. The principal employs new staff who enhance the overall effectiveness of the school and complement the existing staff.

24. Through discussion with teachers about concerns and problems that affect the school, the principal involves teachers in the decision-making process.

25. The principal discusses school-related problems with teachers, seeking their opinions and feelings about the problem.

26. The principal utilizes a systematic process for change that is known and understood by the faculty.

27. The principal has the patience to wait to resolve a problem if the best solution to that problem is not yet readily evident.

28. The principal is willing to admit to making an incorrect decision and corrects the decision if feasible.

29. The principal is perceptive of teacher needs.

30. The principal gives teachers the support they need to be effective.

31. The principal diagnoses the causes of conflict and successfully mediates or arbitrates conflict situations.

32. Teachers feel at ease in the presence of the principal.

33. When deserving, teachers are complimented by the principal in a sincere and honest manner.

34. The principal is receptive to suggestions.

35. The principal is accessible when needed.

36. The principal takes time to listen.

37. Teachers feel free to share ideas and concerns about school with the principal.

38. When teachers discuss a problem with the principal, the principal demonstrates an understanding and appreciation of how teachers feel about the problem.

39. When talking to the principal, teachers have the feeling the principal is sincerely interested in what they are saying.

40. Through effective management of the day-by-day operation of the school, the principal promotes among staff, parents, and community a feeling of confidence in the school.

41. The principal finds the time to interact with students.

42. Students feel free to initiate communication with the principal.

43. Students in the school view the principal as a leader of school spirit.

44. The principal encourages student leadership.

45. The principal helps develop student responsibility.

46. The principal is highly visible to the student body.

47. The principal positively reinforces students.

48. The principal enjoys working with students.

49. The principal keeps teachers informed about those aspects of the school program of which they should be aware.

50. When the principal provides teachers with the information about school operations, the information is clear and easily understood.

51. When teachers are informed of administrative decisions, they are aware of what the principal expects of them as it relates to the decision.

52. The principal is able to organize activities, tasks, and people.

53. The principal develops appropriate rules and procedures.

54. The principal uses systematic procedures for staff appraisal, e.g. retention, dismissal, promotion procedures.

55. The principal establishes the overall tone for discipline in the school.

56. The principal establishes a process by which students are made aware of school rules and policies.

57. The principal communicates to teachers the reasons for administrative practices used in the school.

58. The principal works with other leaders of the school in the implementation of a team approach to managing the school.

59. The principal encourages faculty to be sensitive to the needs and values of other faculty in the school.

60. The principal helps teachers clarify or explain their thoughts by discussing those thoughts with them. 
61. During meetings, the principal involves persons in the discussion who might otherwise not participate.

62. The principal shares personal feelings and opinions about school issues with teachers.

63. Humor used by the principal helps to improve the school environment by creating a more congenial working climate.

64. Personal thoughts shared by the principal about school help teachers develop a sense of pride and loyalty as members of the school.

65. The principal is knowledgeable of the general goals and objectives of the curricular areas.

66. The principal is knowledgeable of the varied teaching strategies teachers might appropriately utilize during instruction.

67. The principal possesses instructional observation skills that provide the basis for accurate assessment of the teaching process in the classroom.

68. The principal actively and regularly participates in the observations and assessment of classroom instruction, including teaching strategies and student learning.

69. The principal has effective techniques for helping ineffective teachers.

70. The principal maintains an awareness and knowledge of recent research about the learning process.

71. When criticizing poor practices, the principal provides suggestions for improvement.

72. The principal is committed to instructional improvement.

73. The principal promotes the development of educational goals and objectives that reflect societal needs and trends.

74. The principal promotes the diagnosis of individual and group learning needs of student and application of appropriate instruction to meet those needs.

75. The principal administers a school-wide curricular program based upon identification of content goals and objectives and the monitoring of student achievement toward those goals and objectives.

76. The principal participates in instructional improvement activities such as program and curriculum planning and monitoring of student learning outcomes.

77. The principal uses objective data such as test scores to make changes in curriculum and staffing.

78. The principal has a systematic process for program review and change.

79. The principal encourages articulation of the curricular program.

80. Using the nine-point scale, give your rating of your principal's overall effectiveness. 
APPENDIX B

\title{
AUDIT of PRINCIPAL EFFECTIVENESS
}

\section{DOMAIN AND FACTOR DESCRIPTORS}

\author{
Domain: Organizational Development
}

The Domain of Organizational Development provides insight about the ability of the principal to work with personnel inside and outside the school setting to establish processes and relationships that effectively promote growth and change of the organization as a whole. The specific statistical factors for Organizational Development are defined below. (27 items)

Factor: Organizational Direction. The principal provides direction for the school through work with faculty to develop goals, establish expectations, and promote appropriate change. ( 7 items)

Factor: Organizational Linkage. The principal promotes positive working relationships between the school, the community the school serves, and other educators and agencies that work with the school. (11 items)

Factor: Organizational Procedures. The principal utilizes effective procedures for problem-solving, decision-making, and change. (9 items)

\section{Domain: Organizational Environment}

The Domain of Organizational Environment provides insight about the ability of the principal to nurture the on-going climate of the school through development of positive interpersonal relationships among members of the organization and effective day-by-day operational procedures for the school. The specific statistical factors for Organizational Environment are defined below. (37 items)

Factor: Teacher Relations. The principal develops effective working relationships with staff through appropriate communication skills, sensitivity to needs, appropriate support, and reinforcement. (13 items)

Factor: Student Relations. The principal develops effective working relationships with students through appropriate communication skills, encouragement, support, and high visibility. (8 items)

Factor: Interactive Processes. The principal organizes tasks and personnel for the effective day-by-day management of the school, including providing appropriate information to staff and students, developing appropriate rules and procedures, and setting the overall tone for discipline in the school. ( 9 items) 
Factor: Affective Processes. The principal encourages the expression of feelings, opinions, pride, and loyalty through team management, sensitivity, humor, and personal example. ( 7 items)

\section{Domain: Educational Program}

The Domain of Educational Program provides insight about the ability of the principal to serve as the educational leader of the school through active involvement in instructional leadership and curriculum development. The specific statistical factors for Educational Program are defined below. (15 items)

Factor: Instructional Improvement. The principal influences positively the instructional skills present in the school through clinical supervision, knowledge of effective schooling, and commitment to quality instruction. (8 items)

Factor: Curriculum Improvement. The principal promotes an articulated, outcomebased curriculum through diagnosis of student needs and systematic program review and change. ( 7 items) 


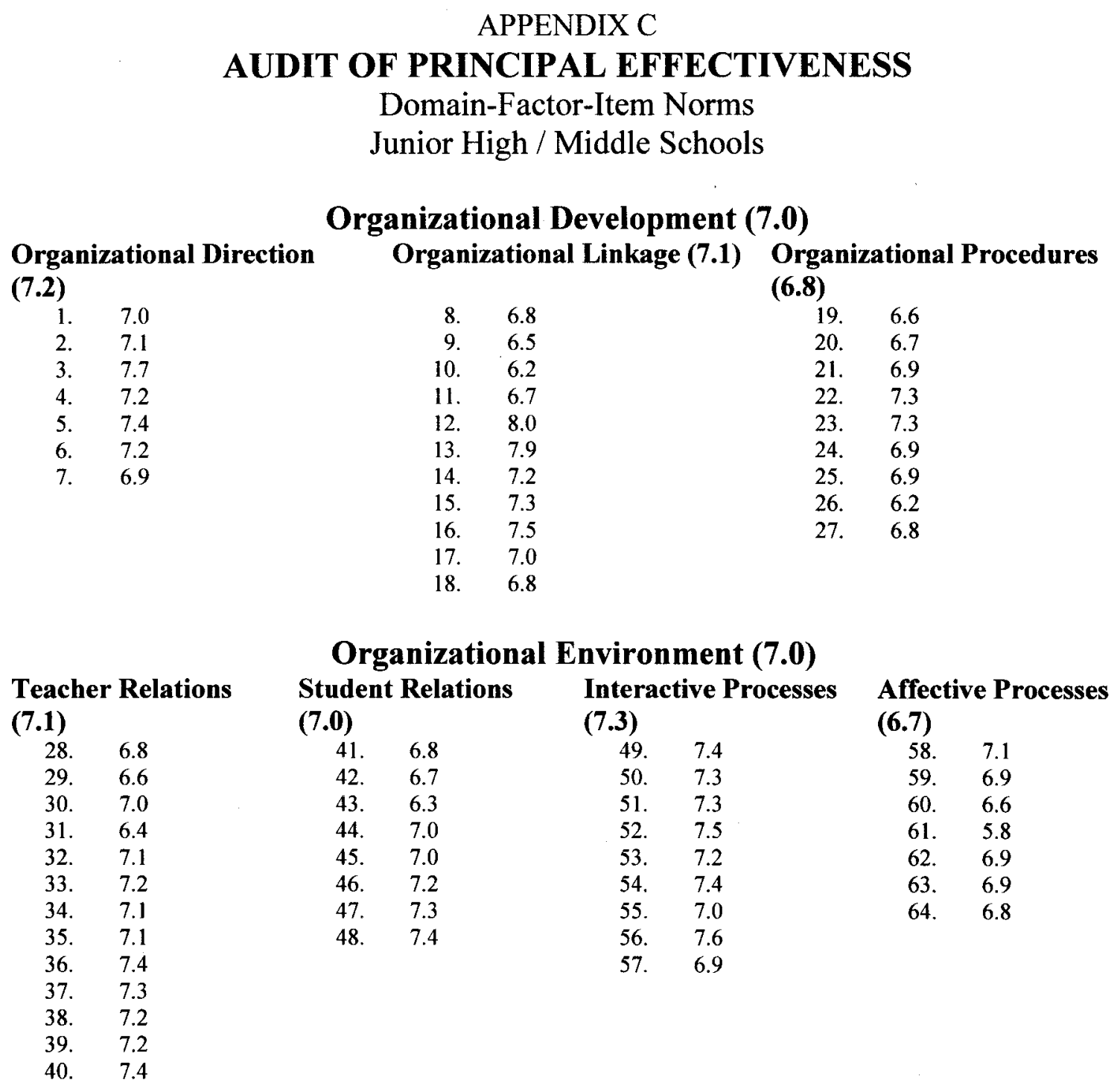

\section{Educational Program (7.0)}

Instructional Improvement $\quad$ Curriculum Improvement (6.9) (7.1)

$\begin{array}{llll}65 . & 7.3 & 73 . & 7.3 \\ 66 . & 7.2 & 74 . & 7.0 \\ 67 . & 7.2 & 75 . & 7.1 \\ 68 . & 6.8 & 76 . & 6.8 \\ 69 . & 6.3 & 77 . & 6.9 \\ 70 . & 7.1 & 78 . & 6.6 \\ 71 . & 7.2 & 79 . & 6.9 \\ 72 . & 7.7 & & \end{array}$

Overall Effectiveness - Item $80 \quad 7.3$

Random Schools: Identified by random sampling of US Schools in 1987-88. 


\section{APPENDIX D}
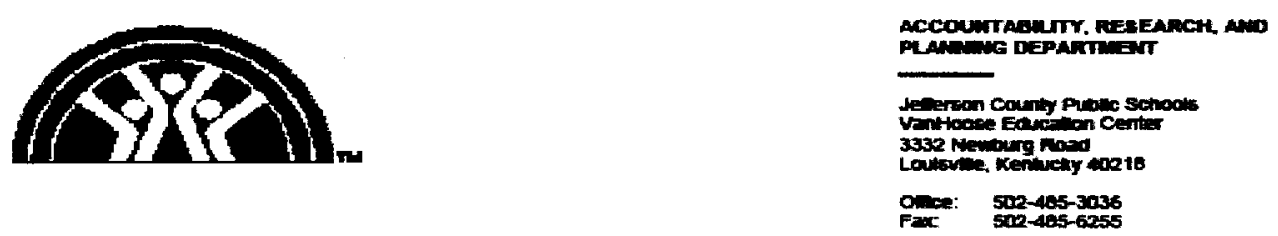

RESEARCH PERMISSION

October 25, 2010

Joseph Petrosko, Ph.D.

Professor

University of Louisville

College of Education and Human Development

Study Title: Teacher Perceptions of Middle School Principal Leadership Behaviors

Dear Dr. Petrosko,

The Jeflerson County Public Schools Internal Review Board (IRB) has received your research study request for initial approval. Thanks for providing the IRB approval from the University of Louisville (Tracking \#: 10.0251). Your request to conduct your study is aporoved under Expedited Review procedures, according to 45 CFR 46.110

(b) , since this study fals under Expedited Category ( 7$)$ Research on individual or group characteristics or behavior (including, but not limited to, research on perception, cognition, motivation, identity, language, communication, cultural beliefs or practices, and social behavior) or research employing survey, interview, oral history, focus group, program evaluation, human factors evaluation, or quality assurance methodologies.

Approval does not guarantee participation of a particuar school in the research study. If the research study interferes with the educational process in a school, the principal may request that his/her school be exchuded from the study. A copy of the final report must be sent to the Accountability, Research, and Planning Department when the study has been completed.

If you have any questions or concems, please feel free to contact our ofice at (502) 485-3036. Thank you for your interest in conducting research associated with our schools.

Sincerely,

\section{Marco Muñoz}

Marco A. Muñoz, Ed.D

Evaluation Specialist

Internal Review Board 


\section{APPENDIX E}

\section{INSTITUTIONAL REVIEW BOARDS}

University of Louisville

MedCenter One, Suite 200

501 E. Broadway

Louisville, Kentucky 40202-1798

Office: $502-852-5188$

Fax: 502-852-2164

To: Petrosko, Joseph

From: The University of Louisville Institutional Review Board (IRB)

Date: Wednesday, May 19, 2010

Subject: Approval Letter

Tracking \#: 10.0251

Title: Teacher Perceptions of Middle School Principal Leadership Behaviors

Approval 5/17/2010 12:00:00 AM

Date:

Expiration 5/16/2011 12:00:00 AM

Date:

This study was reviewed on by the chair/vice chair of the Institutional Review Board and approved through the Expedited Review Procedure, according to 45 CFR 46.110 (b), since this study falls under Expedited Category (7) Research on individual or group characteristics or behavior (including, but not limited to, research on perception, cognition, motivation, identity, language, communication, cultural beliefs or practices, and social behavior) or research employing survey, interview, oral history, focus group, program evaluation, human factors evaluation, or quality assurance methodologies.

This study was also approved through 45 CFR 46.117(c), which means that an IRB may waive the requirement for the investigator to obtain a signed informed consent form for some or all subjects if it finds either:

o That the only record linking the subject and the research would be the consent document and the principal risk would be potential harm resulting from a breach of confidentiality. Each subject will be asked whether the subject wants documentation linking the subject with the research, and the subject's wishes will govern; or

- That the research presents no more than minimal risk of harm to subjects and involves no procedures for which written consent is normally required outside of the research context. The following items have been approved: 
- Informed Consent Preamble, May 2010

- Principal Leadership Questions, revised 1986

- Principal Leadership Questions, revised 1986

- Demographic Questions, not dated

- E-mail to school principals, not dated

- Research Protocol, not dated

This study now has final IRB approval from 05/17/2010 through 05/16/2011. You should complete and return the Progress Report/Continuation Request Form EIGHT weeks prior to this date in order to ensure that no lapse in approval occurs. The committee will be advised of this action at their next full board meeting.

Site Approval

If this study will take place at an affiliated research institution, such as Jewish Hospital/St Marys Hospital, Norton Healthcare, or University of Louisville Hospital, permission to use the site of the affiliated institution may be necessary before the research may begin. If this study will take place outside of the University of Louisville Campuses, permission from the organization should be obtained before the research may begin. Failure to obtain this permission may result in a delay in the start of your research.

Privacy \& Encryption Statement

The University of Louisville's Privacy and Encryption Policy requires such information as identifiable medical and health records: credit card, bank account and other personal financial information; social security numbers; proprietary research data; dates of birth (when combined with name, address and/or phone numbers) to be encrypted. For additional information: http://security.louisville.edu/PolStds/ISO/PS018.htm.

1099 Information (If Applicable)

As a reminder, in compliance with University policies and Internal Revenue Service code, all payments (including checks, gift cards, and gift certificates) to research subjects must be reported to the University Controller's Office. Petty Cash payments must also be monitored by the issuing department and reported to the Controller's Office. Before issuing compensation, each research subject must complete a $\mathrm{W}-9$ form. For additional information, please contact the Controller's Office at 852-8237 or contro

11@louisville.edu.

The following is a link to an Instruction Sheet for BRAAN2 "How to Locate Stamped/Approved Documents in BRAAN2"

https://louisville.edu/research/braan2/help/Docs.pdf

Please begin using your newly approved (stamped) consent(s) at this time. The previous versions are no longer valid. If you need assistance in accessing any of the study documents, please feel free to contact our office at (502) 852-5188. You may 
also email our service account at hsppofc@louisville.edu for assistance.

Best wishes for a successful study. If you have any questions please contact the HSPPO at (502) 852-5188 or hsppofc@louisville.edu.

Thank you.

Board Designee: Quesada, Peter

Once you begin your human subject research the following regulations apply:

1. Unanticipated problems or serious adverse events encountered in this research study must be reported to the IRB within five (5) work days.

2 . Any modifications to the study protocol or informed consent form must be reviewed and approved by the IRB prior to implementation.

3. You may not use a modified informed consent form until it has been approved and validated by the IRB.

4. Please note that the IRB operates in accordance with laws and regulations of the United States and guidance provided by the Office of Human Research Protection (OHRP), the Food and Drug Administration (FDA), the Office of Civil Rights (OCR) and other Federal and State Agencies when applicable.

5. You should complete and SUBMIT the Continuation Request Form eight weeks prior to this date in order to ensure that no lapse in approval occurs.

Letter Sent By: Block, Sherry, 5/19/2010 2:59 PM

Full Accreditation since June 2005 by the Association for the Accreditation of Human Research Protection Programs, Inc. 


\section{APPENDIX F}

Page 1 of 1

\section{Johnson, Anthony A}

From: caod49 [caod49 mail mizzou.edu)

Sent: Monday, October 19, 2009 12:04 PM

To: Johnson. Anthony A

Cc: $\quad \operatorname{caod49}$

Subject: Audit of Principal Effectiveness and the Principal Leadership Questionnaire- PLQ

Dear Anthony.

My name is Catherine O'Brien and I am one of the graduate research assistants here at the Middle Level Leadership Center (MLLC). Dr. Valentine has asked me to respond to your request for permission to use the Principal Leadership Questionnaire- PLQ. This instrument was not developed and published by Dr. Valentine at MLLC. Therefore, MLLCC cannot grant permission for its usage, or provide copies of the instrument or its scoring and interpretation guides. Please use the information below to make the contact required for permission to use this instrument.

Principal Leadership Questionnaire (PLQ)

Contact: Dr. Kenneth Arthur Leithwood

-Address: 252 Bloor Street West, Ontario Institute for Studies in Education of the University of Toronto. Toronto. Ontario M5S 1 V6

-Email: kleithwood@oise.utoronto.ca

I have attached the documents you need to use the Audit of Principal Effectiveness per Dr. Valentine's approval. If you have any questions regarding our instrument as you are conducting your research, please do not hesitate to give us a call.

Best wishes,

CAO

Catherne A. O'Brien

Doctorial Candidate: Educational Leadership and Policy Analysis

Graduate Research Assistant: Middle Level Leadership Center

University of Missouri-Columbia

Hill Hall. Romm 21 !

573.882 .044 ?

caod49@i mail.missouriedu 


\section{CURRICULUM VITAE}

NAME: $\quad$ R. Anthony Johnson

ADDRESS: 350 Ariana Drive

Fisherville, Kentucky 40023

DOB: $\quad$ Cincinnati, Ohio - February 21, 1970

EDUCATION

\& TRAINING: $\quad$ A.S., Criminal Justice

Chaminade University

$1993-1995$

B.A., Mathematics

University of Louisville

$1997-1999$

M.A.T., Teaching

University of Louisville

$1999-2000$

S.Ed., Educational Leadership

University of Louisville

$2004-2008$

Ph.D., Educational Leadership

University of Louisville

$2007-2011$

AWARDS: Golden Key International Honour Society, Inducted 2008

Scottish Right Fellowship Scholarship, Received 2006 and 2007

Japan Fulbright Memorial fund, Received 2005

Honorable Discharge, United States Army, Received 1997

Meritorious Service Medal, United States Army, Received 1997

Kentucky Colonel, Commissioned by Governor Paul Patton 1997

Noble Patron of Armor, United States Armor Assoc., Commissioned 1997

GTE Math/Science Scholarship, Received 1999 
PROFESSIONAL SOCIETIES: Jefferson County Assistant Principal's Association National Middle School Association

Honorable Order of Kentucky Colonels

United States Armor Association 